\title{
WestVirginiaUniversity
}

THE RESEARCH REPOSITORY @ WVU

Graduate Theses, Dissertations, and Problem Reports

2007

\section{Epithelial mechanisms in airway responses induced by hyperosmolarity}

\author{
Yi Jing \\ West Virginia University
}

Follow this and additional works at: https://researchrepository.wvu.edu/etd

\section{Recommended Citation}

Jing, Yi, "Epithelial mechanisms in airway responses induced by hyperosmolarity" (2007). Graduate Theses, Dissertations, and Problem Reports. 2602.

https://researchrepository.wvu.edu/etd/2602

This Dissertation is protected by copyright and/or related rights. It has been brought to you by the The Research Repository @ WVU with permission from the rights-holder(s). You are free to use this Dissertation in any way that is permitted by the copyright and related rights legislation that applies to your use. For other uses you must obtain permission from the rights-holder(s) directly, unless additional rights are indicated by a Creative Commons license in the record and/ or on the work itself. This Dissertation has been accepted for inclusion in WVU Graduate Theses, Dissertations, and Problem Reports collection by an authorized administrator of The Research Repository @ WVU.

For more information, please contact researchrepository@mail.wvu.edu. 


\title{
Epithelial Mechanisms in Airway Responses Induced by Hyperosmolarity
}

\author{
Yi Jing \\ Dissertation submitted to the School of Medicine \\ at West Virginia University \\ in partial fulfillment of the requirements \\ for the Degree of \\ Doctor of Philosophy \\ in Pharmacology and Toxicology \\ Jeffrey S. Fedan, Ph.D., Chair \\ David J. Smith, Ph.D. \\ Daniel C. Flynn, Ph.D. \\ Michael R. Miller, Ph.D. \\ William F. Wonderlin, Ph.D. \\ Department of Pharmacology and Toxicology \\ Morgantown, West Virginia \\ 2007
}

Keywords: airway epithelium, airway smooth muscle, cell volume, epithelium-derived relaxing factor, exercise-induced asthma, guinea-pig trachea, hyperosmolarity, ion transport, kinase inhibitor, phosphorylation 


\section{Abstract \\ Epithelial Mechanisms in Airway Responses Induced by Hyperosmolarity}

Yi Jing

There is airway dilation in normal people but obstruction in asthmatic patients during exercise; this has been thought to be initiated by hyperventilation causing evaporative water loss and hyperosmolarity of the airway surface liquid (ASL). In animal experiments the epithelium can detect osmolarity increases in the ASL and mediate relaxation of airway smooth muscle by releasing epithelium-derived relaxing factor (EpDRF), while in asthmatic patients this local regulatory function could be altered because of damage to epithelium. Challenged by hyperosmolarity, epithelial cells undergo shrinkage, volume-related ion transport, and release regulatory mediators, such as EpDRF. The changes in epithelial ion transport and EpDRF-mediated airway relaxation in response to hyperosmolarity have been found to be functionally linked in the guinea-pig isolated, perfused trachea. The two responses could be regulated through common stress-sensitive signaling pathways, and the epithelial shrinkage could be involved in the detecting hyperosmolar stress, leading to EpDRF release. We hypothesize that hyperosmolar challenge activates stress-sensitive protein kinases (PK)s, e.g. MAP kinases, in epithelium, and that the activity of PK(s) regulates epithelial bioelectric events and EpDRF release. The guinea-pig isolated, perfused trachea apparatus was used to investigate the effects of kinase and ion transport inhibitors on airway epithelial bioelectric and smooth muscle relaxation responses induced by hyperosmolarity. Western blots were used to examine the phosphorylation of p38 and JNK signaling proteins. Epithelial cell volume responses to hyperosmolarity were investigated. The results indicate that a physiologically-relevant increase in osmolarity elicits concentration-dependent epithelial hyperpolarization and smooth muscle relaxation, as well as epithelial shrinkage. The rapid and prolonged shrinkage is similar to the quick and long-lasting hyperpolarization and relaxation responses, suggesting a possible link between the epithelial shrinkage and EpDRF release. However, a common signaling pathway regulating both of the bioelectric and relaxation responses was not identified. Therefore, in terms of kinase signaling, there may not be a cause-effect relationship between the two responses. Inhibition of p38 potentiated the airway relaxation elicited by hyperosmolarity, suggesting that p38 inhibitors have the potential for the treatment of bronchoconstriction induced by exercise through the potentiation of EpDRF release. 


\section{Dedication}

To my family,

My wife Lian Chang and son Ray Jing

(By giving me love and a warm family,

You made it more meaningful for me to pursue my dreams.)

My parents, Yuexian Jing, Mushao Yin and sister, Song Jing (Your unconditional support means more to me than you will ever know.) 


\section{Acknowledgements}

As my graduate study concludes, I would like to take this opportunity to thank every one of you who have ever helped me over the years.

First, I want to thank my advisor, Dr. Jeffrey Fedan. More than five years ago your working spirit and enthusiasm to your research attracted me to this pulmonary physiology field which was completely new to me. From the moment I became your student, you never forget to shape me as a conscientious and tough scientific researcher. You challenged me with novel techniques and tough questions, and we experienced both the frustrations and joys of my every effort together. You trusted me and taught me patiently through the entire intense training. You are not only my scientific advisor but also my English language mentor. I will always be grateful for your guidance and unwavering support; and yes, of course, remember the joyful moments brought about by your great sense of humor.

I sincerely appreciate the support of my committee members, Dr. David Smith, Dr. Daniel Flynn, Dr. Michael Miller and Dr. William Wonderlin. Some of you taught me repeatedly in my major classes, Biochemistry, Medical Pharmacology and Molecular Pharmacology. I also gained a lot knowledge from going through the processes of my qualify exams. You helped me to improve my research project, solve the problems that appeared in my experiments and better organize the data in my dissertation. Your professional consultation and guidance ensured the quality of my graduate training.

I would like to thank Dr. Michael Van Scott for your important input in the modification of the trachea perfusion apparatus. Although you are away at East Carolina University, I could always get your technical support over long distance phone calls. Now, the novel apparatus patent application has been filed and is pending approval. In my published posters, your sharp critiques and suggestions have made my presentations more professional.

My study in $\mathrm{NIOSH}$ was greatly supported by outstanding lab manager Janet Dowdy. You managed general supplies for the whole lab and many of my special orders. When I was having technique difficulties you always tried to help me, without your support my study could have been much more difficult. You were also my patient English tutor. I have learned so much English from you that I even picked up some New York accent. To Dr. David Wu, Dr. Burcin Ismailoglu and fellow student Michael Dodrill, I appreciate all of your help, our friendship and pleasant talks have made my long hours in the lab enjoyable.

My graduate study was partially supported by the Mylan Laboratories Chair of Pharmacology Fund; and some tuition fees were from the Dan Watts Fund. I would like to thank the leader of the WVU Pharmacology Program, Dr. William Fleming. Although you have retired and the department has merged to Biochemistry and Physiology, Pharmacology still exists in my mind as a family. I will always cherish my training experience in such an outstanding program, and be proud to say that I was once a member of this family. To Dr. Charles Craig and 
Dr. Robert Stitzel, I would like to thank you for your teaching in the Medical pharmacology and leadership in the Pharmacology Program, Medical School and University. Your "Modern Pharmacology with Clinical Applications", as the "Bible" of pharmacology, gave me great help during my study. I also want to thank Dr. Stephen Graber who recruited me to the Pharmacology Program through a highly competitive process. Your admission notice brought me the opportunity to become a pharmacologist. Dr. Mark Reasor, I want to thank you not only for your teaching in the Medical Pharmacology, but also for your prayers in my wedding ceremony. That day was so special to me that I also was baptized as a Christian. From then on I have been blessed by God.

To the Biochemistry Department, I would like to thank all faculty members, graduate students and administrative secretaries, especially Dr. Diana Beattie and Dr. Lisa Salati. Your outstanding leadership makes Biochemistry a highly professional training program. Although I am on the pharmacology track, I was actually under Biochemistry requirements most of the time. Therefore, I am a lucky receiver of your high standard training.

I would like to thank Dr. Vincent Castranova, the leader of the Pathology and Physiology Research Branch at NIOSH, and secretarial staff Joyce Blosser, Irene Fominko, Kathy Kelley and Freshcorn Cara, for supporting me and my project. Your help made my study in $\mathrm{NIOSH}$ possible and easier in many different ways. Dr. David Frazer, thank you for teaching me in the Pulmonary Physiology and supporting my fellowship application to the American Heart Association. Dr. Lyndell Millecchia, thank you for helping me take photos and movies of epithelial cells under the microscope. Dr. Min Ding and Dr. Fei Chen, thank you for providing information and technical advice for my western blots. I would like to thank Kathy Fedan for answering my statistic questions and Winnie Moyers for taking care of my animal orders. Yongju Lu, Chris Felton, Victor Robinson, Terry Meighan, and Mark Barger, thank you for the help during the development of new methods in our lab; and Ali Afshari, thank you for the ride when I was injured during the volley ball game.

Dr. Taocong Jin, Xuedong Zheng, Dr. Yuan Wang, Yan Liu, and Dr. Gang Li, Jing Liu, we have been good friends for years, thank you for providing your support and helpful information. Dr. Long Yin, Shuo Zhang and Dr. Zhongsheng Tong, Jianling Hang, best friends in my hometown, thank you for taking care of my parents and Ray. Our friendship is a great gift, I will cherish it always.

This acknowledgment section would not be complete without thanking the support of my family. At this moment, I would like to thank my son Ray Jing for bringing extraordinary joys to my life; my wife Lian Chang for giving me great love and understanding; my parents professor Yuexian Jing, Mushao Yin and parents-in-law professor Chongbin Chang, Yuru Zhang, and other relatives for your unconditional help by taking care of Ray; my sister Song Jing, brother-in-law Dr. Tianshou Zhao and your daughter Jing Zhao for your consistent support. My graduate study would not be possible without your support. Thank you for your contributions, I love you all so much. 


\section{Table of Contents}

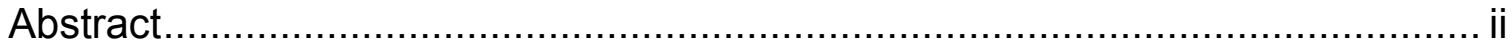

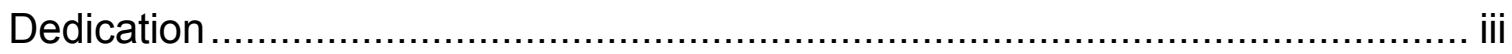

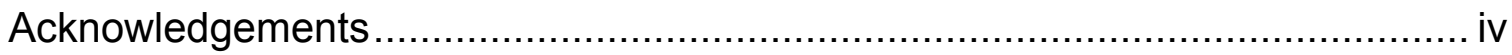

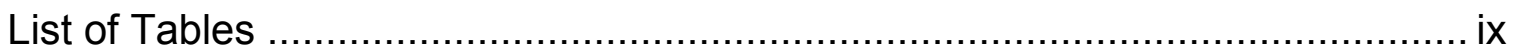

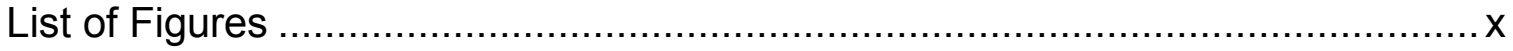

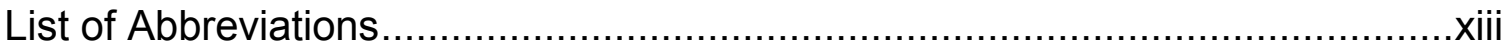

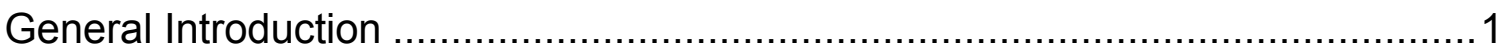

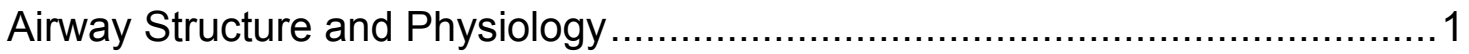

Airway Surface Liquid and Epithelial Ion Transport ..................................... 3

Airway Epithelium: A Multifunctional Protective Barrier ............................... 4

EpDRF and the Perfused Trachea Apparatus .......................................... 6

Exercise-induced Asthma (EIA): Two Theories ......................................... 8

Epithelium-mediated Airway Responses to Hyperosmolarity ........................ 10

\section{Chapter I}

Epithelial Kinase Signaling in Airway Bioelectric and Mechanical Responses

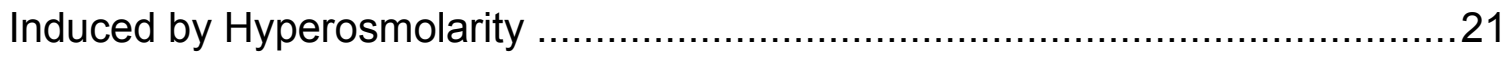

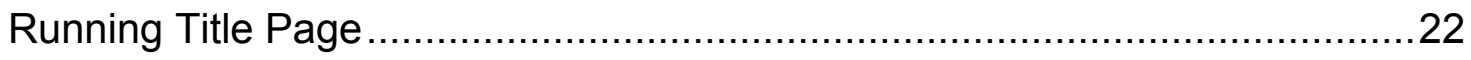

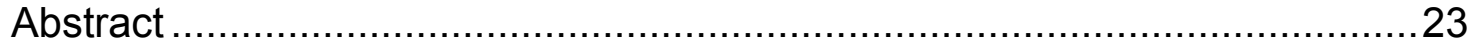

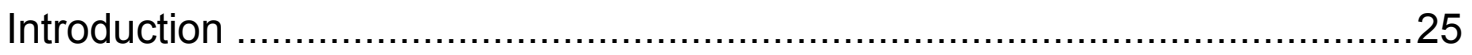

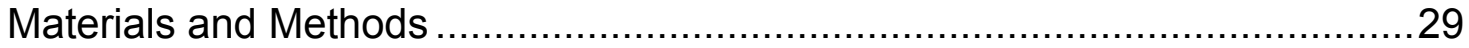

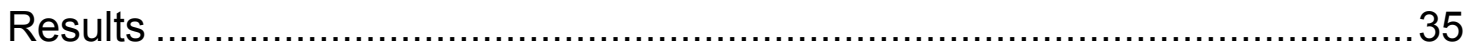




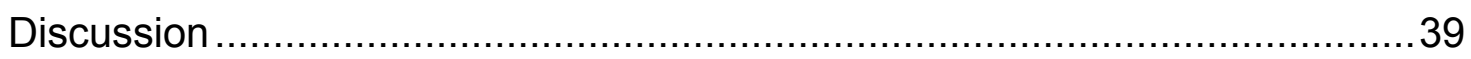

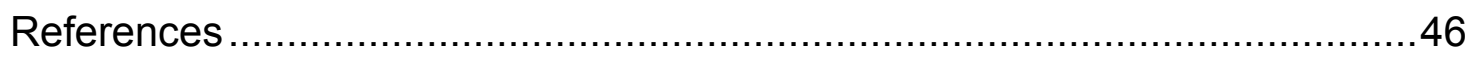

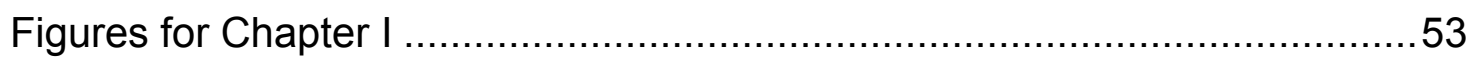

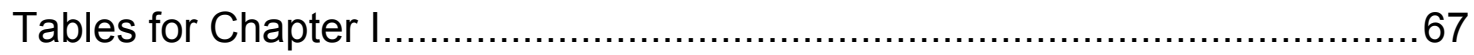

\section{Chapter II}

Epithelial Mechanisms in Airway Bioelectric and Mechanical Responses Induced by Hyperosmolarity: Studies on a Novel Tracheal Perfusion Apparatus .............68

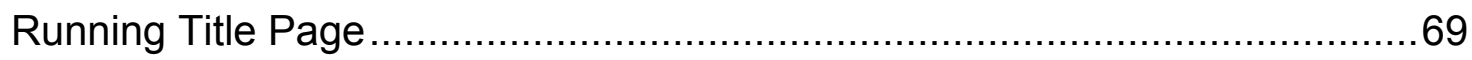

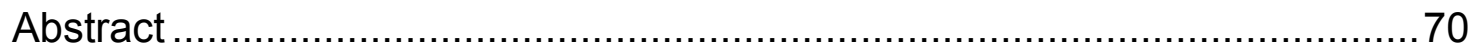

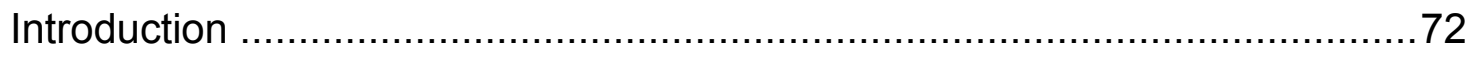

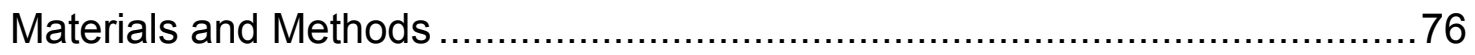

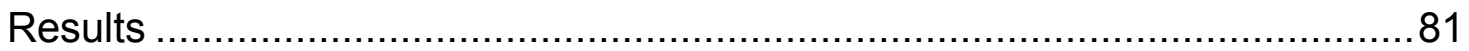

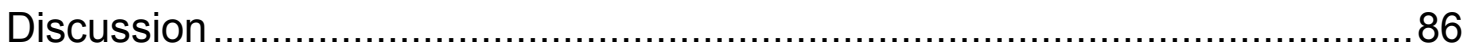

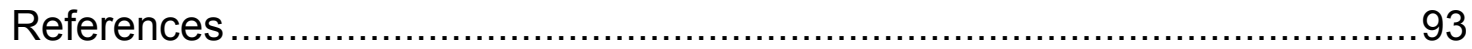

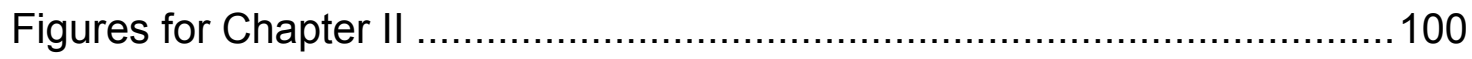

\section{Chapter III}

Volume Change in Guinea-pig Airway Epithelial Cells Induced by Methacholine

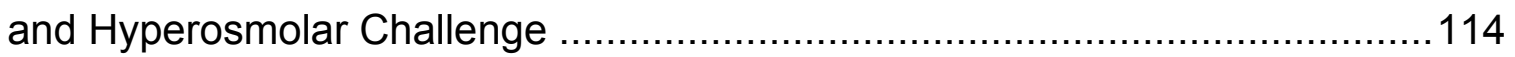

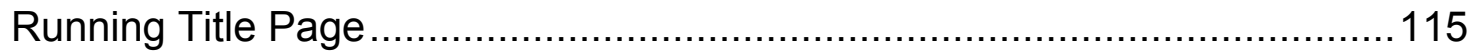

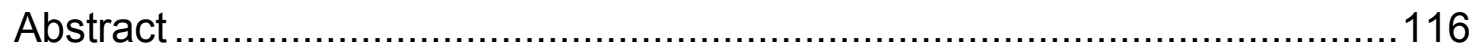

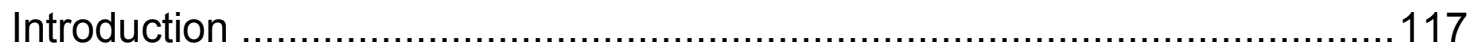

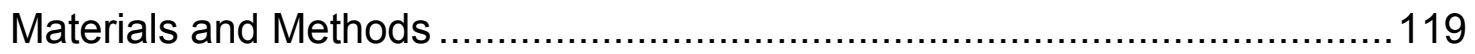




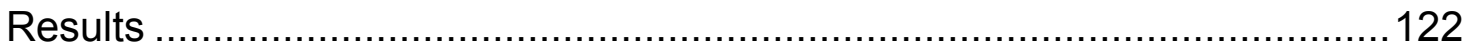

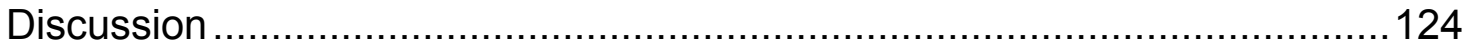

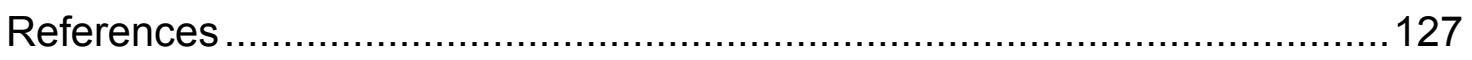

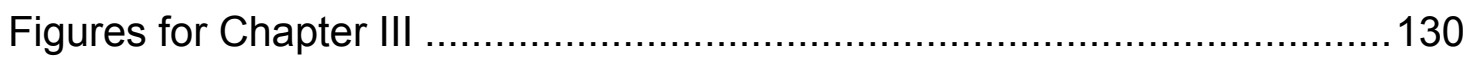

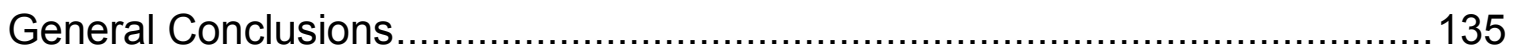

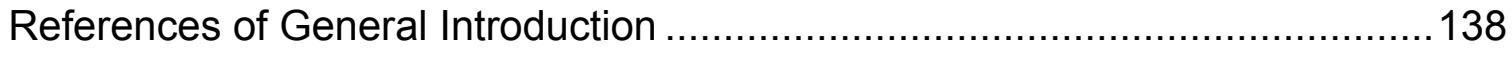

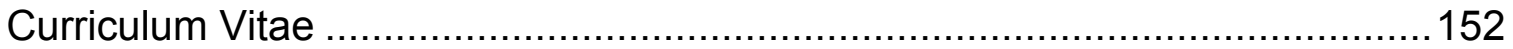




\section{List of Tables}

\section{General Introduction}

GI-1. Properties of the kinase and phosphatase inhibitors and the stress inducer, $\mathrm{NaAsO}_{2}$

\section{Chapter I}

Cl-1. Effects of MAP kinase inhibitors on basal $V_{t}(m V)$ and $\triangle P\left(\mathrm{~cm} \mathrm{H}_{2} \mathrm{O}\right) \ldots \ldots .67$

$\mathrm{Cl}$-2. Effects of other kinase inhibitors, $\mathrm{NaAsO}_{2}$ and $\mathrm{Na}_{3} \mathrm{VO}_{4}$ on basal $\mathrm{V}_{\mathrm{t}}(\mathrm{mV})$ and $\triangle \mathrm{P}\left(\mathrm{cm} \mathrm{H}_{2} \mathrm{O}\right)$ 67 


\section{List of Figures}

\section{General Introduction}

GI-1. Anatomy of human tracheobronchial tree and pulmonary subsegments ..13

GI-2. Airway branching in the human lung with approximate dimensions 14

GI-3. Change of airway wall structure at the three principal levels 15

GI-4. Ultrastructure of tracheal, bronchial and bronchiolar epithelium 16

GI-5. Cilia of airway epithelial cells 17

GI-6. Illustration of airway epithelial ion transport 18

GI-7. MAP kinase signaling pathways and the examined inhibitors 19

\section{Chapter I}

$\mathrm{Cl}$-1. Concentration-response relationship for D-M-induced bioelectric and mechanical responses 53

$\mathrm{Cl}-2$. Effects of the kinase inhibitors on MCh-induced contraction 54

Cl-3. Effects of $\mathrm{NaAsO}_{2}$ and $\mathrm{Na}_{3} \mathrm{VO}_{4}$ on $\mathrm{MCh}$-induced contraction 55

Cl-4. Effects of the MAP kinase inhibitors on MCh-induced hyperpolarization ..56

$\mathrm{Cl}-5$. Effects of the kinase inhibitors on MCh-induced hyperpolarization 57

Cl-6. Effects of the MAP kinase inhibitors on D-M-induced hyperpolarization ...58

Cl-7. Effects of the kinase inhibitors on D-M-induced hyperpolarization ............59

Cl-8. Effects of $\mathrm{NaAsO}_{2}$ and $\mathrm{Na}_{3} \mathrm{VO}_{4}$ on D-M-induced hyperpolarization ..........60

Cl-9. Effects of the MAP kinase inhibitors on D-M-induced airway relaxation ...61

$\mathrm{Cl}-10$. Effects of the kinase inhibitors on D-M-induced airway relaxation 62

$\mathrm{Cl}$-11. Phosphorylation of $\mathrm{p} 38$ induced by hyperosmolar D-M 63 
Cl-12. Phosphorylation of JNK induced by hyperosmolar D-M

\section{Chapter II}

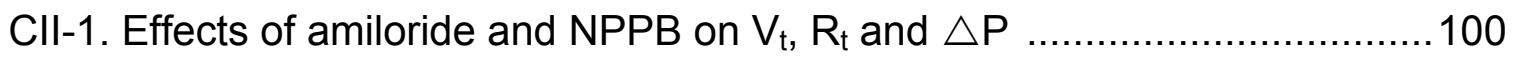

CII-2. Effects of ouabain and bumetanide on $V_{t}, R_{t}$ and $\triangle P \ldots \ldots \ldots \ldots \ldots \ldots \ldots . . . .102$

Cll-3. Effects of histamine and terbutaline on $V_{t}, R_{t}$ and $\triangle P$.....................104

CII-4. Effects of hyperosmolar $\mathrm{NaCl}$ and $\mathrm{D}-\mathrm{M}$ on $\mathrm{V}_{\mathrm{t}}, \mathrm{R}_{\mathrm{t}}$ and $\triangle \mathrm{P} \ldots \ldots \ldots \ldots \ldots \ldots \ldots$

CII-5. Effects of DMSO on MCh- and D-M-induced $V_{t}$ and $R_{t}$ responses f......108

CII-6. Effects of SP 600125 on MCh- and D-M-induced $V_{t}$ and $R_{t}$ responses .109

CII-7. Effects of dicumarol on MCh- and D-M-induced $V_{t}$ and $R_{t}$ responses ....110

CII-8. Effects of chelerythrine on MCh- and D-M-induced $V_{t}$ and $R_{t}$ responses 111

CII-9. Effects of $\mathrm{NaAsO}_{2}$ on MCh- and D-M-induced $V_{t}$ and $\mathrm{R}_{t}$ responses $\ldots . . .112$

Cll-10. Effects of $\mathrm{Na}_{3} \mathrm{VO}_{4}$ on MCh- and D-M-induced $V_{t}$ and $\mathrm{R}_{t}$ responses .....113

\section{Chapter III}

CIII-1. Clump of epithelial cells after protease digestion ...............................130

CIII-2. Isolated epithelial cells in MKH solution .........................................131

CIII-3. Time-dependent effects of D-M on the volume of airway epithelial cells 132

CIII-4. Concentration-dependent effects of D-M on the volume of airway epithelial cells

CIII-5. Epithelial cell volume changes induced by MCh and D-M 134

\section{General Conclutions}

GC-1. Proposed model of epithelial ion transport and EpDRF release induced by hyperosmolarity 
GC-2. Effects of p38 inhibitors on hyperosmolarity-induced airway smooth muscle response 138 


\section{List of Abbreviations}

$\begin{array}{ll}\text { ACh } & \text { Acetylcholine } \\ \text { ASL } & \text { Airway surface liquid } \\ \text { CaM-K-II } & \text { Calmodulin kinase-II } \\ \text { D-M } & \text { D-mannitol } \\ \text { DMSO } & \text { Dimethyl sulphoxide } \\ \text { EC } 50 & \text { Concentration producing } 50 \% \text { of the maximal effect } \\ \text { ECL } & \text { Enhanced chemiluminescence } \\ \text { EIA } & \text { Exercise-induced asthma } \\ \text { EL } & \text { Extraluminal } \\ \text { EMEM } & \text { Minimum essential medium eagle } \\ \text { EpDRF } & \text { Epithelium-derived relaxing factor } \\ \text { ERK } & \text { Extracellular-regulated kinase } \\ \text { FBS } & \text { Fetal bovine serum } \\ \text { IL } & \text { Intraluminal } \\ \text { IL-8 } & \text { Interleukin-8 } \\ \text { Isc } & \text { Transepithelial short-circuit current } \\ \text { JNK } & \text { c-Jun N-terminal kinase } \\ \text { MAP kinase } & \text { Mitogen-activated protein kinase } \\ \text { MCh } & \text { Acetyl- } \beta \text {-methylcholine chloride (methacholine) } \\ \text { MKH } & \text { Modified Krebs-Henseleit } \\ \text { MLCK } & \text { Myosin light chain kinase } \\ & \\ \text { ER } & \end{array}$




$\begin{array}{ll}\text { mosM } & \text { Milliosmolar } \\ \text { PI-3-K } & \text { Phosphatidylinositol 3-kinase } \\ \text { PKC } & \text { Protein kinase } C \\ \text { RANTES } & \text { Regulated on Activation, Normal T-cell Expressed and Secreted } \\ \mathrm{R}_{t} & \text { Transepithelial resistance } \\ \mathrm{SE} & \text { Standard error } \\ \mathrm{V}_{t} & \text { Transepithelial potential } \\ \triangle P & \text { Inlet minus outlet perfusion pressure difference }\end{array}$




\section{General Introduction}

Oxygen $\left(\mathrm{O}_{2}\right)$ is needed for metabolism in the body to produce energy, so a continuous supply of $\mathrm{O}_{2}$ must be available for their cell functioning. Carbon dioxide $\left(\mathrm{CO}_{2}\right)$, as a by-product of this aerobic metabolism, must be removed from the vicinity of the metabolizing cells (Levitzky, 2003). The human respiratory system is developed to perform this gas exchange, and is composed of the thoracic wall, airways, lung and its blood circulation system. The primary function of the airways is to deliver $\mathrm{O}_{2}$ to the lung gas-exchanging surfaces and exhaust $\mathrm{CO}_{2}$. Under normal circumstances the distribution of air and blood to the gas-exchanging surfaces is nicely matched, although they are regulated separately (Weibel, 1980). Any pathological condition, such as asthma, which causes narrowing or obstruction of the major airways will increase their resistance. Asthma is a respiratory disorder that is associated with reversible airway obstruction, inflammation, airway hyperresponsiveness and remodeling (McFadden, 1999). Over the past 20 years asthma has been diagnosed with increasing frequency and is now recognized as a major medical problem in the United States (Slavin and Reisman, 2002). It has been estimated that asthma

costs at least 6 billion dollars per year for physician visits, medication and laboratory evaluation, and over 10.7 billion dollars of costs in days missed from work (Weiss et al., 2000).

\section{Airway Structure and Physiology}

The human airway is a tracheobronchial tree branching system (Fig. Gl-1). Air 
is inspired from nostrils, and sometimes from mouth when needed, passing through the pharynx, larynx, trachea, bronchi, bronchioles, and eventually reaches the gas-exchanging zone alveoli. From the trachea to the alveolar sacs human airway branches into 23 generations (Fig. GI-2). The first 16 generations are purely conductive; transitional airways lead into the respiratory zone made of alveoli (Weibel, 1963). Along with the diameter decrease from bronchus to alveolus the structure of airway wall is also shifted from thicker to thinner in three major patterns (Fig. GI-3); and the epithelial cells gradually reduce their thickness from pseudostratified to cuboidal and eventually to squamous at the gas-exchanging area. The airway wall contains cartilage only in bronchi and gradually becomes thinner as the alveolus is approached. The airways in the conducting zone have many elements, but basically there are three important structures: the epithelium, basement membrane and smooth muscle. The smooth-muscle layer disappears in the alveoli (Weibel and Burri, 1973).

In the conducting airways epithelia are composed primarily of two cell types, ciliated cells and goblet cells (Fig. GI-4), as well as some other types of cells interspersed in the epithelium, including undifferentiated or basal cells, brush cells, Clara cells, Kulchitsky cells and serous cells (Kuhn, 1976; Nadel, 1980; Weibel, 1980). Each type of cell has some specific functions, e.g., undifferentiated or basal cells serve as stem cells for the replacement of other types of cells; brush cells may have sensory function; and Clara cells are rich in cytochrome P-450 and many other metabolic enzymes (Kuhn, 1976; Weibel, 1980; Goldie and Hay, 
1997). The ciliated cells line most of the surface of the airways; their chief characteristic is the presence of a rich tuft of cilia (Fig. GI-5). The synchronized beating of cilia propels the overlying mucous blanket towards the larynx and pharynx. The goblet cells are the secretory cells that together with the submucous glands synthesize polysaccharide-rich mucus in their Golgi apparatus and secrete it onto the epithelial surface (Kuhn, 1976).

\section{Airway Surface Liquid (ASL) and Epithelial Ion Transport}

ASL is the protective fluid on the apical side of airway epithelium. The ASL is elaborated in two layers; a high viscosity gel layer (mucus) lies on the top of a low viscosity solution (sol) hypophase in which an aqueous electrolyte solution is maintained (Weibel, 1980). The depth and molecular composition of the ASL is tightly regulated by epithelial ion transport (Widdicombe et al., 1997; Tarran, 2004). The osmolarity of the ASL is carefully maintained at an isotonic level or slightly higher than that of the interstitium, 285 mosM (Boucher, 1999). The average thickness of the sol hypophase is about 5-7 $\mu \mathrm{m}$ in depth, which is approximately the same length of the cilia extending. The gel layer is a discontinuous mucus blanket (Clarke and Boucher, 1993; Widdicombe and Widdicombe, 1995; Boucher, 1999). Epithelial cilia beat within the flexible hypophase with low viscous resistance while the sticky surface layer traps foreign microorganisms and particles. The movement of the hypophase can flow up the airways as a coherent sheet, which allows for the effective clearance of the foreign particles out of the airway system (Weibel, 1980). 
The model of airway epithelial ion transport has been described (Boucher, 1994a, b). For most of the mammalian species, epithelial cells in the conducting airways actively extrude $\mathrm{Na}^{+}$through the $\mathrm{Na}^{+}-\mathrm{K}^{+}$-pump located at the basolateral membrane, which creates the drive for the entry of $\mathrm{Na}^{+}$into the epithelium through $\mathrm{Na}^{+}$channels on the apical membrane (Boucher, 1999). The $\mathrm{Na}^{+}$extrusion makes intracellular environment more negative, which favors $\mathrm{Cl}^{-}$to be secreted down its electric gradient to the apical surface through $\mathrm{Cl}^{-}$channels. $\mathrm{Cl}^{-}$secretion could also be caused secondarily by the activity of $\mathrm{Na}^{+}-\mathrm{K}^{+}-2 \mathrm{Cl}^{-}$cotransporter located at the basolateral membrane (Willumsen et al., 1989). Because the tight junction structure in the paracellular pathway limits the free movement of ions by providing a transepithelial resistance $\left(R_{t}\right)$, a transepithelial potential $\left(V_{t}\right)$ could be maintained (Fig. GI-6).

\section{Airway Epithelium: A Multifunctional Protective Barrier}

The airway epithelium plays multifunctional roles in maintaining the stability of internal and external milieu of the airways (Munakata et al., 1989; Hamilton et al., 2001). Together with the intercellular tight junctions it forms a barrier to the entry of inhaled substance, microorganisms and particles (Gumbiner, 1987; Schneeberger and Lynch, 1992; Godfrey, 1997b). In addition to this primary function, airway epithelium is much more than a passive diffusion barrier (Folkerts and Nijkamp, 1998; Hamilton et al., 2001). It is a metabolic site processing both endogenous and exogenous substances (Goldie and Hay, 1997); it recognizes foreign particles (antigens) and secretes inflammatory mediators including 
RANTES, IL-8, -16, prostaglandins and nitric oxide (Slavin and Reisman, 2002); it actively transports ions and fluid to maintain the ASL (Boucher, 1999; Widdicombe, 2002); and it serves as a sensor and transducer that detects osmolarity increases in the ASL and regulates underlying smooth muscle tone by releasing epithelium-derived relaxing factor (EpDRF) (Dortch-Carnes et al., 1999; Fedan et al., 1999).

The idea that respiratory epithelium could modulate the airway smooth muscle tone was rendered for the first time in 1985. Flavahan et al. (1985) reported that mechanical removal of the epithelium from canine bronchial rings increased the sensitivity of its underlying smooth muscle to airway contractile agonists and transmural nerve stimulation. In epithelium-intact preparations, the peak airway contraction elicited by a particular electrical frequency was followed by a decrease in tone as the stimulation continued; but with epithelium-denuded preparations the decrease in muscle tone was abolished. In epithelium-denuded preparations precontracted with acetylcholine (ACh) isoproterenol-induced relaxations were attenuated (Flavahan et al., 1985). Later, the increased smooth muscle sensitivity to airway contractile agonists, ACh, histamine, and 5-hydroxytryptamine on epithelium-removed bovine tracheal strips was observed (Barnes et al., 1985). In the following months and years, the fact that airway epithelium modulates the tone of its underlying smooth muscle was confirmed on preparations made from guinea-pig (Farmer et al., 1986; Hay et al., 1986; Murlas, 1986), human and rabbit (Raeburn et al., 1986a, b) airways. All these results 
suggested the possibility that the increased sensitivity of airway smooth muscle to contractile agonists after removal of the epithelium was due to the loss of an epithelium-derived inhibitory factor, or EpDRF, which normally inhibits smooth muscle reactivity to contractile stimulation (Hay et al., 1987a, b).

\section{EpDRF and the Perfused Trachea Apparatus}

The first convincing evidence supporting the EpDRF hypothesis came with the development of the coaxial bioassay technique. In this system, a rat endothelium-denuded aorta strip (recipient tissue) was positioned coaxially within the lumen of an epithelium-intact guinea-pig trachea acting as a donor of EpDRF or a denuded trachea. The aorta strip was attached to a force transducer so that the tension of this tissue could be measured. The aorta strip was precontracted with an $\alpha_{1}$-adrenoceptor agonist, phenylephrine, then treated with ACh, which subsequently relaxed the aorta strip. The relaxation of the aorta strip was abolished when the assay was performed with preparations in which the epithelium was removed (Ilhan and Sahin, 1986). In the following studies similar results were reported when the guinea-pig tracheal smooth muscle and rat anococcygeal muscle were used as the recipient tissues (Güc et al., 1988a, b), and when the human bronchus was used as a donor tissue (Fernandes et al., 1990a). Further pharmacological characterization of EpDRF demonstrated that EpDRF was neither a product of nitric oxide synthase, cyclooxygenase, lipoxygenase and cytochrome P450; nor related to free radical production, soluble

guanylate cyclase, $\beta$-adrenoceptors, platelet-activating factor and metabolites of 
arachidonic acid (Barnes et al., 1985; Munakata et al., 1988, 1990; Goldie et al., 1990; Fernandes and Goldie, 1990b). Although great efforts have been made to understand the mechanism of EpDRF, the identity of EpDRF remains elusive. Because hemoglobin attenuates airway smooth muscle relaxation induced by hyperosmolarity through tightly binding with carbon monoxide (CO), CO may have a potential role in this epithelium-mediated airway relaxation (Fedan et al., 2004b).

In the late 1980s, the guinea-pig isolated, perfused trachea apparatus was developed. The advantage of this preparation is that the intraluminal (IL) and extraluminal (EL) sides of the trachea are completely separated. The contractile agonists can be applied to the EL side to get a direct access to the airway smooth muscle, while pharmacological agents added to the IL must diffuse across the epithelium before interacting with the underlying smooth muscle. Because the epithelial tight junction barrier is rather impermeable to many molecules (Fedan and Frazer, 1992), any responses observed of the smooth muscle will be affected by the epithelium. This development provided a useful apparatus for the studies of epithelium-mediated airway responses (Munakata et al., 1988). Studies performed on this preparation demonstrated that hyperosmolarity of the IL perfusing solution was a major stimulus for the release of EpDRF. Application of hyperosmolar solutions made with $\mathrm{NaCl}, \mathrm{KCl}$, urea, D-mannitol (D-M) and other solutes to the IL side of carbachol-contracted trachea elicited the smooth muscle relaxation; the relaxation response was attenuated if the epithelium was removed. 
These results indicate that the relaxation induced by hyperosmolar solutions was epithelium-dependent (Munakata et al., 1988).

\section{Exercise-induced Asthma (EIA): Two Theories}

Exercise-induced asthma attacks have intrigued scientists for a long period of time. Over the last 20 years there have been considerable debates about the mechanism of exercise-induced airway narrowing in asthmatic patients (Anderson and Daviskas, 2000). The two major theories are the thermal hypothesis and the osmotic hypothesis. EIA was originally thought to be related to the consequences of heating and humidifying large volume of inspired air during exercise. The thermal hypothesis developed from the earlier airway cooling theory put forward in 1979 (Deal et al., 1979), and revised to the thermal theory in 1986 (McFadden et al., 1986). It was concluded that "the magnitude of EIA is directly proportional to the thermal load placed on the airways-respiratory heat exchange." There is some evidence to support this hypothesis (McFadden, 1990, 1999). The thermal hypothesis proposes that the narrowing of the airways is a direct consequence of microvascular events; and does not embrace a role of airway epithelium and smooth muscle.

The osmotic hypothesis was developed and has been sustained since 1984 (Anderson, 1984) with airway epithelium involvement being added in 1989 (Anderson et al., 1989) and the submucosal involvement in signaling bronchial blood flow in 1992 (Anderson and Daviskas, 1992). It has been calculated that the volume of ASL is less than $1 \mathrm{ml}$ in the first 10 generations of airways (Anderson, 
1984). Mathematic models developed to estimate the water loss from airways suggest that only the first 12 generations of airways are needed to humidify the inspired air (Daviskas et al., 1990, 1991); about $7.39 \mathrm{mg} / \mathrm{L}$ water is calculated to be the net loss from airways during exercise under the author's experimental conditions. Although this value seems small, it is relatively large compared to the volume of fluid available in the first 12 generations. Therefore, the rate of water loss is great enough to cause a rapid osmolarity increase in ASL (Anderson et al., 1989, 1997b). Measuring the osmolarity of ASL in a canine model, Freed and Davis (1999) found a 130 mosM increase during hyperventilation of dry air, and a 40 mosM increase 4-6 min after the hyperventilation.

Asthma is a chronic inflammatory disorder of the airways. The pathogenesis of airway inflammation is characterized by inflammatory cell infiltration, airway smooth muscle proliferation and epithelial damage (Elias et al., 2003; Pelaia et al., 2005). As mentioned above, exercise-induced airway obstruction in the asthmatic patients is thought to be triggered by hyperventilation and increased osmolarity of the ASL (Hallstrand et al., 2005a; Anderson, 2006). Inhalation of hypertonic saline or D-M powder to elevate the osmolarity of the ASL in asthmatic patients activates mast cells and triggers the release of histamine and leukotriene (Taube et al., 2001; Brannan et al., 2003), leading to obstruction of the airways. Based on the osmotic theory, a method has been developed to diagnose the potential asthmatic individuals through the bronchoconstriction that results after the inhalation of D-M dry powder (Anderson et al., 1997a; Brannan et al., 1998). 


\section{Epithelium-mediated Airway Responses to Hyperosmolarity}

Although the osmotic theory has been developed for years, the epithelial mechanism in the response of airway smooth muscle to hyperosmolarity is still poorly understood. Studies performed on the guinea-pig perfused trachea have demonstrated that airway epithelium can perceive an osmolarity increase in the ASL and elicit underlying smooth muscle relaxation by releasing EpDRF (Munakata et al., 1988; Fedan et al., 1990). The fact that the epithelium behaves as an osmometer and signaling transducer was also observed in human airways (Willumsen et al., 1994; Matsui et al., 2000). A more recent study presented evidence that the epithelium appears to detect the change in osmolarity rather than the osmolar concentration per se (Fedan et al., 2004a). The details about how the epithelium senses changes in osmolarity and initiates regulatory signaling are not clear. Previous studies in other cells suggested that cell volume change in response to hyperosmolarity could activate stress sensitive mitogenactivated protein (MAP) kinases (Roger et al., 1999; Duzgun et al., 2000; Zhang and Bourque, 2003).

Challenged by hyperosmolarity, airway epithelium reacts by releasing regulatory mediators. Studies in vivo demonstrated that hyperosmolar solution applied directly to the airway surface induced mucosal vasodilation mediated by epithelium-derived nitric oxide (Smith et al., 1993; Prazma et al., 1994). Experiments in vitro with guinea-pig isolated, perfused trachea demonstrated that hyperosmolar challenge elicited transepithelial depolarization; the $V_{t}$ change was 
followed by EpDRF-mediated airway relaxation (Dortch-Carnes et al., 1999). The epithelial bioelectric and smooth muscle mechanical responses to hyperosmolar challenge are thought to be functionally linked, because blockade of epithelial ion transport with $\mathrm{Na}^{+}$and $\mathrm{Cl}^{-}$channel blockers attenuated the epithelium-mediated airway relaxation (Fedan et al., 1999). Their findings suggest that the bioelectric and mechanical responses are both epithelium-dependent, and the bioelectric response may be involved in the process of EpDRF release.

Hyperosmolar challenge causes cell shrinkage and volume-related ion transport (Lang et al., 1998). Studies with many types of cells demonstrated that hyperosmolarity or cell shrinkage activates MAP kinases (Shrode et al., 1998; Roger et al., 1999; Duzgun et al., 2000; Sheikh-Hamad and Gustin, 2004). The volume-related ion transport is regulated directly or indirectly by protein phosphorylation (Klein et al., 1993, 1999; Davis et al., 2001; Heinzinger et al., 2001; Liedtke and Cole, 2002a). The release of regulatory mediators in response to hyperosmolarity could be modulated by protein kinases (Hashimoto et al., 1999; Furuichi et al., 2002). Therefore, the hypothesis of the present study was hyperosmolar challenge activates protein kinases in epithelium, and the activity of protein kinases regulates epithelial bioelectric events and EpDRF release.

To test this hypothesis, specific kinase inhibitors were used to investigate possibly involved kinase pathways in epithelial signaling. Because the stress-sensitive MAP kinases play an important role in airway inflammation, and the MAP kinase inhibitors are being tested in the clinic for their therapeutic effects 
to asthma (Pelaia et al., 2005), the involvement of the three MAP kinases, p38, c-Jun N-terminal kinase (JNK) and extracellular-regulated kinase (ERK), was examined using two structurally different inhibitors in each case (Fig. GI-7, Table $\mathrm{Gl}-1$ ). Moreover, the involvement of four other kinases, protein kinase $\mathrm{C}(\mathrm{PKC})$, phosphatidylinositol 3-kinase (PI-3-K), calmodulin kinase II (CaM-K-II) and myosin light chain kinase (MLCK) (Table Gl-1), were examined, because they have been reported to be involved in the regulation of epithelial ion transport (Shrode et al., 1998). To get a better understanding for the role of these kinases, the phosphatase inhibitor, $\mathrm{Na}_{3} \mathrm{VO}_{4}$, and the stress inducer, $\mathrm{NaAsO}_{2}$, were also examined (Table GI-1). 


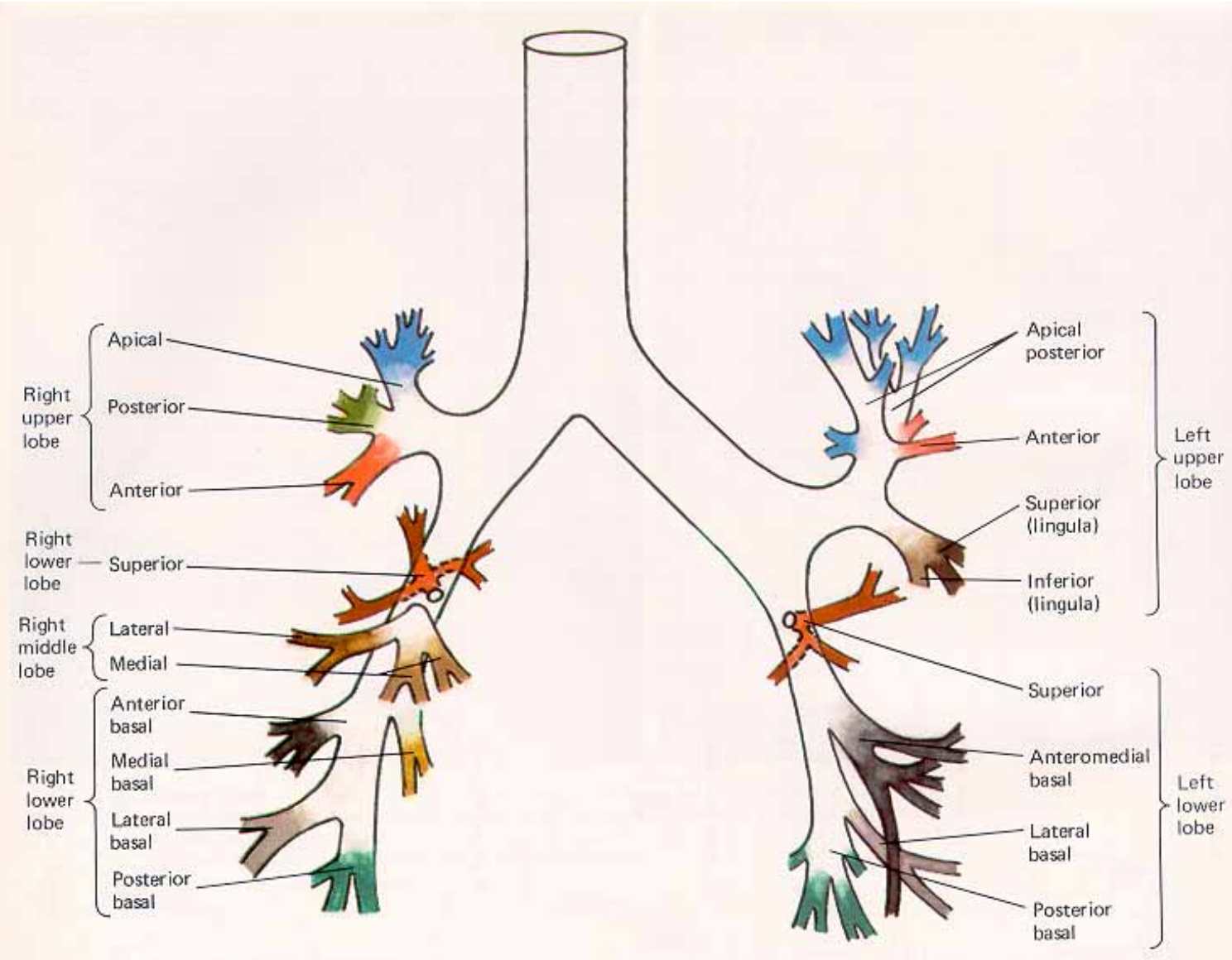

Fig. GI-1. Anatomy of human tracheobronchial tree and pulmonary subsegments. Trachea branches into bronchi and smaller airways of left and right lung lobes. Reproduced with permission from McGraw-Hill, Inc.; Pulmonary Diseases and Disorders by Alfred P. Fishman, Copyright 1980. 


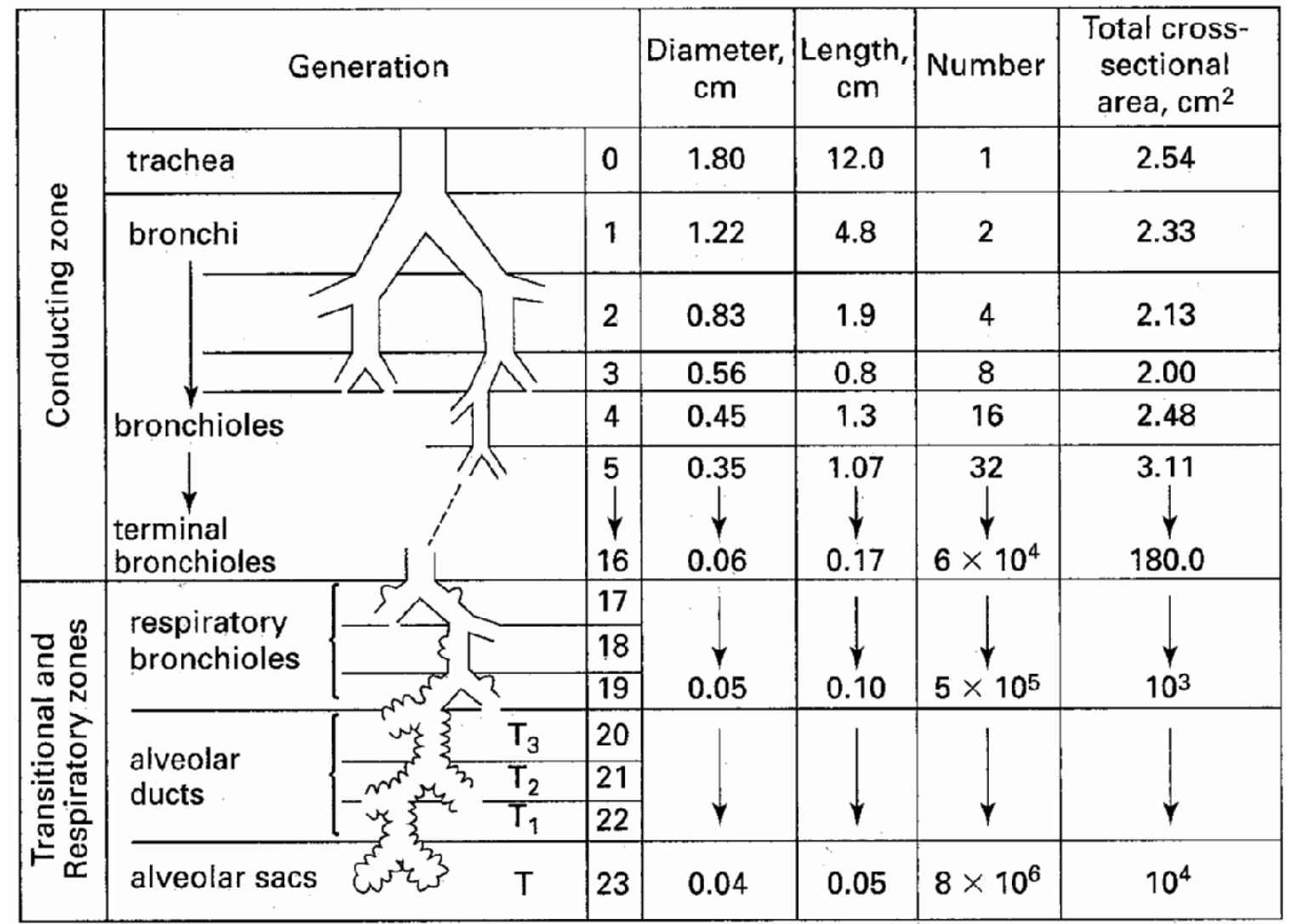

Fig. GI-2. Schematic representation of airway branching in the human lung with approximate dimensions. The first 16 generations are purely conducting; transitional airways lead into the respiratory zone made of alveoli. (Figure after Weibel, 1963. Data from Bouhuys, 1977). Reproduced with permission from McGraw-Hill, Inc.; Pulmonary Physiology, Sixth Edition, by Michael G. Levitzky, Copyright 2003. 


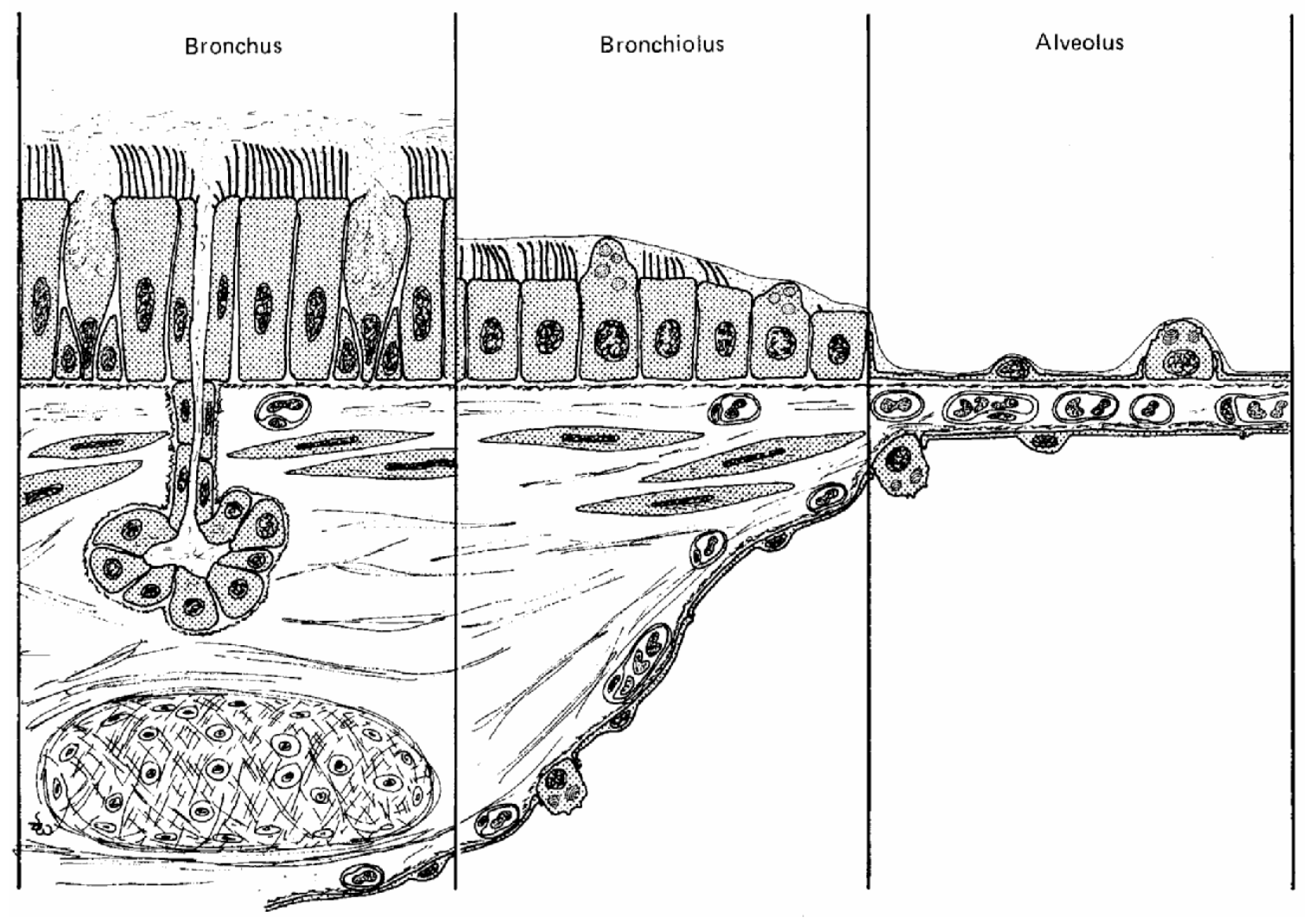

Fig. GI-3. Change of airway wall structure at the three principal levels. The epithelial layer gradually becomes reduced from pseudostratified to cuboidal and then to squamous, but retains its lining structure. The smooth-muscle layer disappears in the alveoli. The airway wall contains cartilage only in bronchi and gradually becomes thinner as the alveolus is approached. (Figure originally from Weibel and Burri, 1973). Reproduced with permission from McGraw-Hill, Inc.; Pulmonary Diseases and Disorders by Alfred P. Fishman, Copyright 1980. 


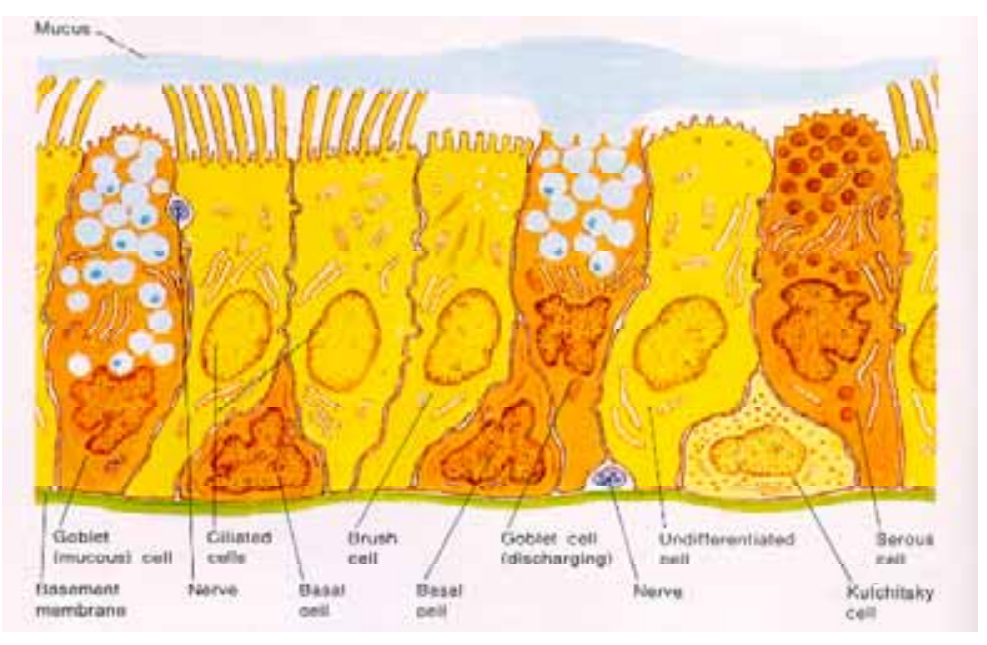

A

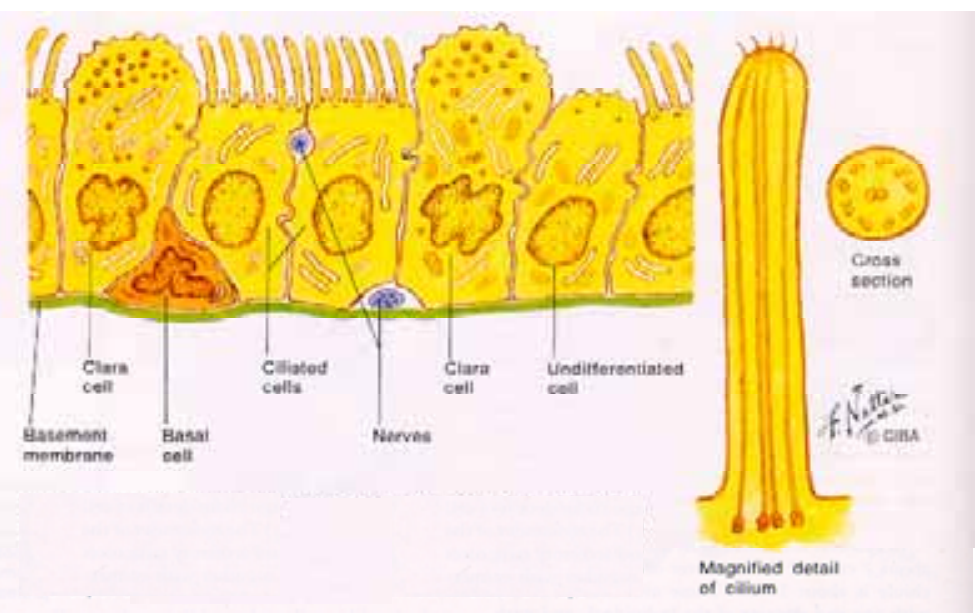

B

Fig. GI-4. Ultrastructure of tracheal, bronchial and bronchiolar epithelium. (A) Trachea and large bronchi. (B) Bronchioles. There are distinct differences in epithelial morphology along proximal and distal airways. Reproduced with permission from Novartis Medical Education; The CIBA Collection of Medical Illustrations, Respiratory System, Volume 7, Illustrated by Frank H. Netter, Copyright 1997. 


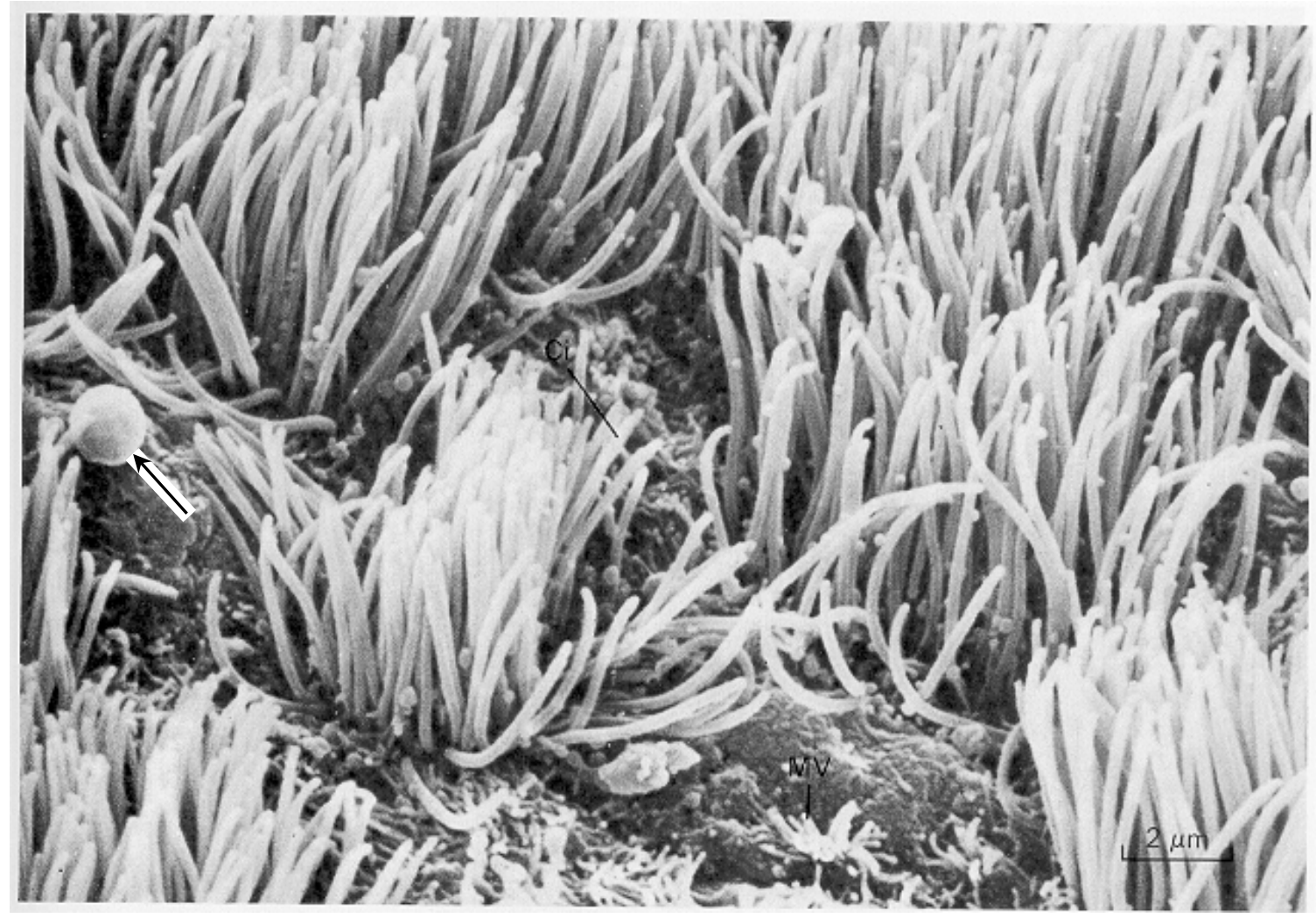

Fig. GI-5. Cilia of airway epithelial cells. Surface view of bronchiolar epithelium shows tufts of cilia forming on individual ciliated cells and microvilli on other cells. Note secretion droplet (arrow). Reproduced with permission from McGraw-Hill, Inc.; Pulmonary Diseases and Disorders by Alfred P. Fishman, Copyright 1980. 


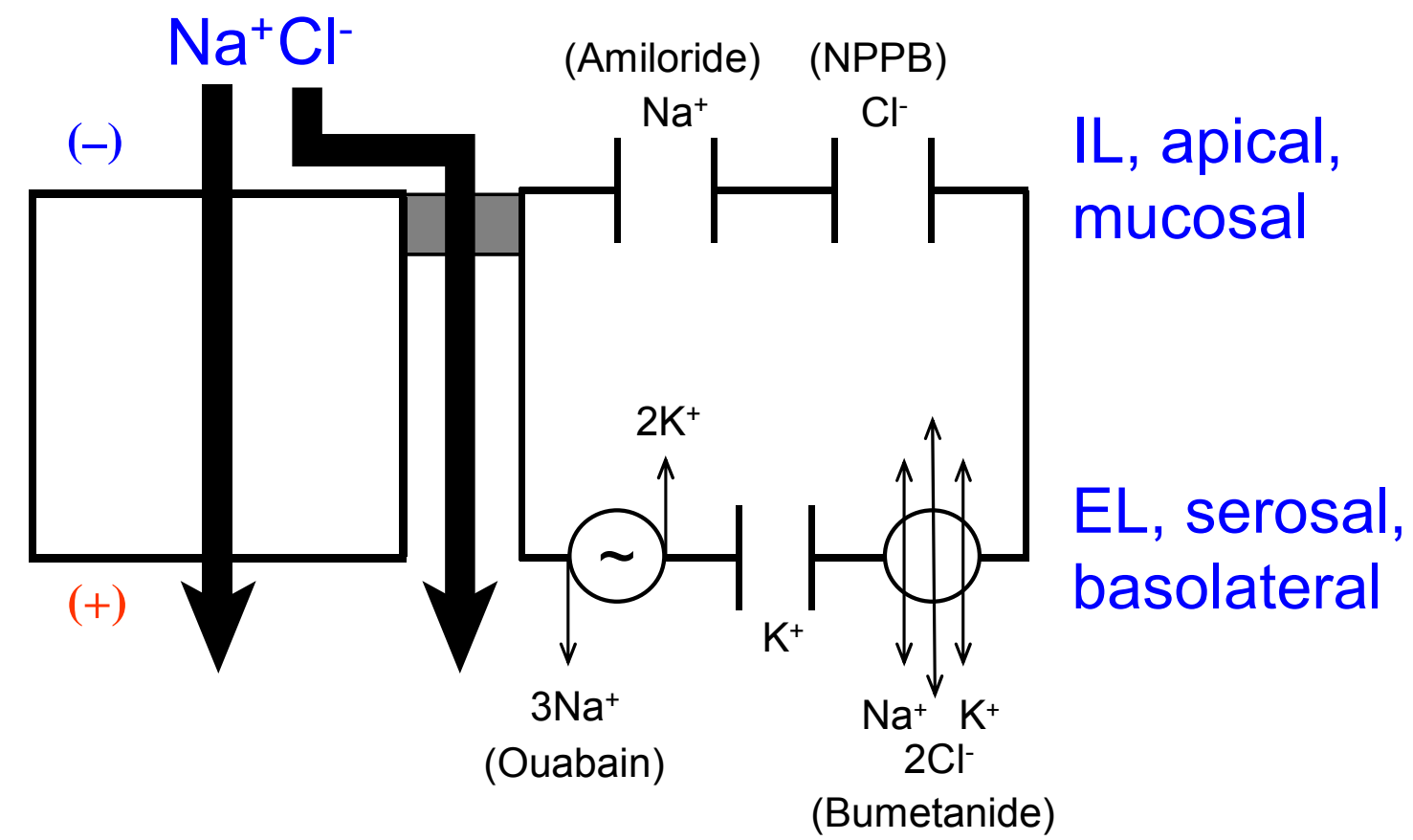

Fig. GI-6. Illustration of airway epithelial ion transport. The ion channels and transporters are asymmetrically distributed at the apical and basolateral surfaces. The specific inhibitors of ion channels and transporters are shown in parenthesis. The tight junction structures between epithelial cells form a resistant barrier to the movement of ions and help to maintain a transepithelial potential. The big arrows indicate general transcellular movement of $\mathrm{Na}^{+}$and the passive paracellular movement of $\mathrm{Cl}^{-}$. Figure is illustrated by and provided as a courtesy of Jeffrey $\mathrm{S}$. Fedan, Ph.D. 


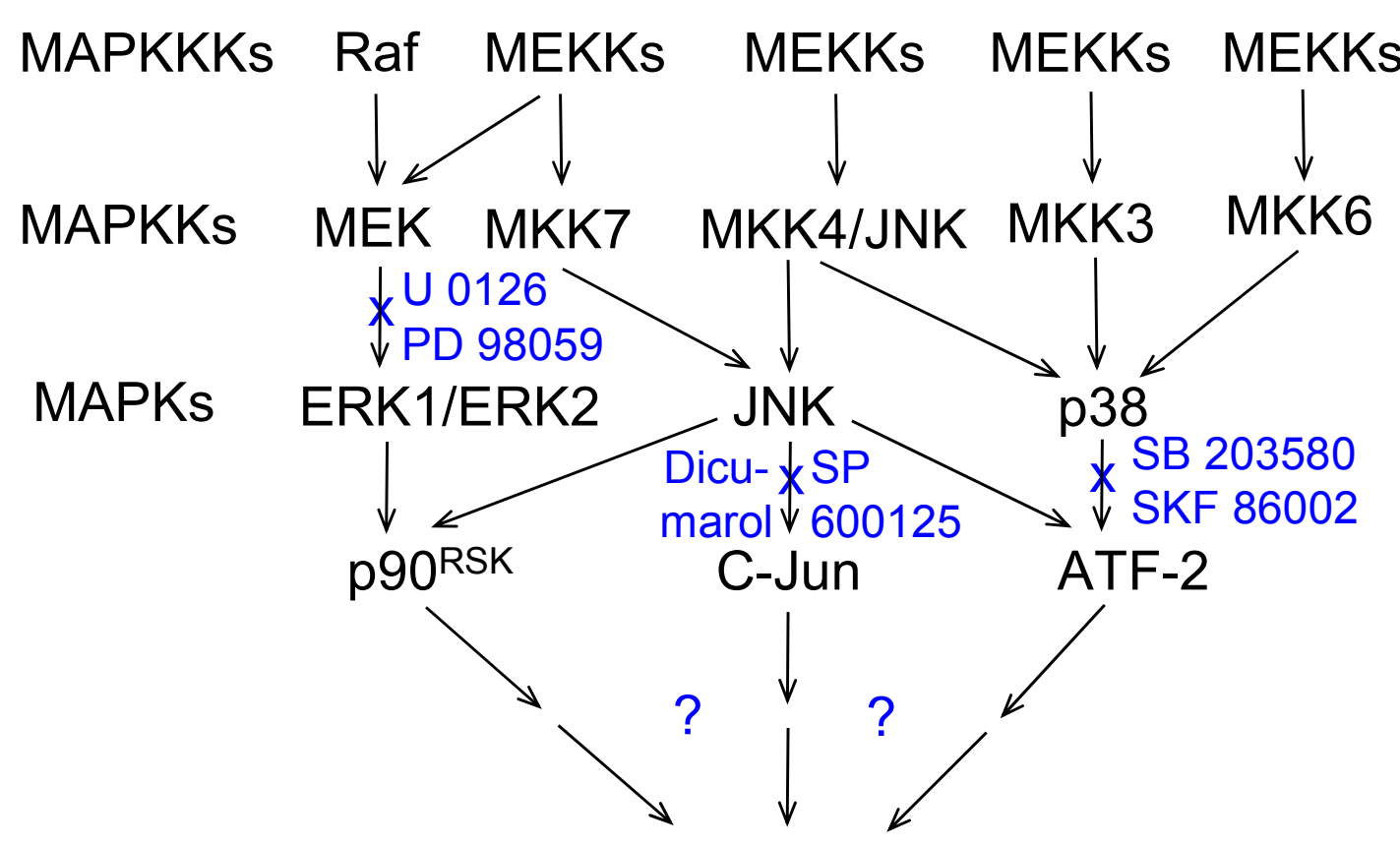

\section{EpDRF release}

Fig. GI-7. MAP kinase signaling pathways and the examined inhibitors. EpDRF release was assumed to be regulated by stress-sensitive MAP kinases. The examined specific inhibitors SB 203580, SKF 86002, SP 600125, dicumarol, PD 98059 and U 0126 block either up- or down-stream of p38, JNK and ERK pathways, as indicated in the scheme. 
Table GI-1. Properties of the kinase and phosphatase inhibitors and the stress inducer, $\mathrm{NaAsO}_{2}$

\begin{tabular}{|c|c|c|c|c|}
\hline Enzymes & Agents & $\mathrm{EC}_{50}(\mu \mathrm{M})$ & ${ }^{1}$ Conc. $(\mu \mathrm{M})$ & Mechanisms \\
\hline \multirow[t]{2}{*}{ p38 } & SB 203580 & $0.6^{a}$ & 30 & Competitive binding in the ATP pocket ${ }^{k}$ \\
\hline & SKF 86002 & $1^{b}$ & 30 & Competitive binding in the ATP pocket ${ }^{k}$ \\
\hline \multirow[t]{2}{*}{ JNK } & SP 600125 & $0.19^{a}$ & 30 & Competes with ATP to inhibit the enzyme ${ }^{a}$ \\
\hline & Dicumarol & $5^{c}$ & 15 & Blocks stress signaling by the inhibition of quinone reductase ${ }^{c}$ \\
\hline \multirow[t]{2}{*}{ ERK } & PD 98059 & $2^{a}$ & 50 & Inhibits activation of ERK by blocking upstream enzyme MEK' \\
\hline & U 0126 & $0.5^{d}$ & 30 & Inhibits activation of ERK by blocking upstream enzyme MEK' \\
\hline PKC & Chelerythrine & $0.66^{e}$ & 20 & Competitive binding to the phosphate acceptor of the enzyme ${ }^{e}$ \\
\hline PI-3-K & LY 294002 & $1.4^{f}$ & 50 & Blocks the ATP-binding site of the enzyme ${ }^{f}$ \\
\hline CaM-K-II & $\mathrm{KN}-62$ & $1^{g}$ & 20 & Binds directly to the calmodulin binding site of the enzyme ${ }^{m}$ \\
\hline MLCK & ML-7 & $0.3^{h}$ & 30 & Inhibits the binding of ATP to MLCK ${ }^{n}$ \\
\hline Phosphatase & $\mathrm{Na}_{3} \mathrm{VO}_{4}$ & $30-50^{i}$ & 300 & Analog to phosphate intermediates ${ }^{\circ}$ \\
\hline${ }^{2} \mathrm{SAPKs}$ & $\mathrm{NaAsO}_{2}$ & $60^{j}$ & 300 & Stress inducer (activates stress-sensitive protein kinases) ${ }^{p}$ \\
\hline
\end{tabular}

${ }^{1}$ Concentrations commonly reported in literature were used in this study. ${ }^{2}$ Stress-activated protein kinases.

${ }^{a}$ Woo et al. (2005). ${ }^{b}$ Prabhakar et al. (1993). ${ }^{c}$ Cross et al. (1999). ${ }^{d}$ Hirst et al. (2002). ${ }^{e}$ Herbert et al. (1990). ${ }^{\circ}$ Vlahos et al. (1994).

${ }^{9}$ Masse and Kelly (1997). ${ }^{h}$ Goggel and Uhlig (2005). 'Pugazhenthi et al. (1996). ${ }^{j}$ Flatman and Creanor (1999). ${ }^{k}$ Pelaia et al.

(2005). 'English and Cobb (2002). ${ }^{m}$ Tokumitsu et al. (1990). ${ }^{n}$ Shen et al. (2002). ${ }^{\circ}$ Gordon (1991). ${ }^{p}$ Ludwig et al. (1998). 


\title{
Chapter I
}

\section{Epithelial Kinase Signaling in Airway Bioelectric and Mechanical Responses Induced by Hyperosmolarity}

\author{
Yi Jing, Janet A. Dowdy, Michael R. Van Scott and Jeffrey S. Fedan \\ Department of Biochemistry and Molecular Pharmacology, Robert C. Byrd Health \\ Sciences Center, West Virginia University, Morgantown, West Virginia (Y.J., \\ J.S.F.); Department of Physiology, The Brody School of Medicine, East Carolina \\ University, Greenville, North Carolina (M.R.V.S.); and Pathology and Physiology \\ Research Branch, Health Effects Laboratory Division, National Institute for \\ Occupational Safety and Health, Morgantown, West Virginia (J.A.D., J.S.F.)
}


Running title: Epithelial Signaling in Hyperosmolarity-Induced Airway Responses

Corresponding author: Jeffrey S. Fedan, Health Effects Laboratory Division, National Institute for Occupational Safety and Health, 1095 Willowdale Road, Morgantown, WV 26505-2888. E-mail: jsf2@cdc.gov

Number of text pages: 32

Number of tables: 2

Number of figures: 12

Number of references: 50

Number of words in Abstract: 251

Number of words in Introduction: 777

Number of words in Discussion: 1,493

Abbreviations: ASL, airway surface liquid; EpDRF, epithelium-derived relaxing factor; $V_{t}$, transepithelial potential; $\triangle P$, inlet minus outlet perfusion pressure difference; MKH, modified Krebs-Henseleit; MCh, methacholine; D-M, D-mannitol; $\mathrm{IL}$, intraluminal; EL, extraluminal.

Section assignment: Pulmonary 


\begin{abstract}
Hyperventilation during exercise causes evaporative water loss and hyperosmolarity of the airway surface liquid (ASL). Mucosal hyperosmolar challenge elicits airway transepithelial potential $\left(V_{t}\right)$ changes followed by smooth muscle relaxation mediated by epithelium-derived relaxing factor (EpDRF). In guinea-pig isolated, perfused trachea we examined the relationship of $V_{t}$ and relaxation responses induced by hyperosmolarity, osmolarity was increased by adding D-mannitol (D-M). Using intraluminally-applied kinase inhibitors, the kinase-interfering agent, $\mathrm{NaASO}_{2}$, and the phosphatase inhibitor, $\mathrm{Na}_{3} \mathrm{VO}_{4}$, we investigated epithelial signaling roles of mitogen-activated protein (MAP) kinases (p38, JNK and ERK) and four other kinases (PKC, PI-3-K, CaM-K-II and MLCK) in response to hyperosmolarity. Western blots were used to confirm the activation of two MAP kinases, p38 and JNK, which were implicated in functional studies. When the increased osmolarity was less than 80 mosM, D-M-induced hyperpolarization and relaxation responses shared the same concentration-dependence. Challenging the tracheal epithelia with 30 mosM D-M ( $\left.E_{50}\right)$, the p38 inhibitors, SB 203580 and SKF 86002, potentiated the relaxation, while the JNK inhibitors, SP 600125 and dicumarol, the PKC inhibitor, chelerythrine, as well as $\mathrm{NaAsO}_{2}$ and $\mathrm{Na}_{3} \mathrm{VO}_{4}$, inhibited the hyperpolarization. There was an osmolarity concentration-dependent activation of p38 and JNK in western blots. The PI-3-K inhibitor, LY 294002, and $\mathrm{Na}_{3} \mathrm{VO}_{4}$ inhibited methylcholine (MCh)-induced contraction, while SP 600125 and dicumarol
\end{abstract}


potentiated and chelerythrine inhibited MCh-induced hyperpolarization. The results indicate that JNK, PKC and phosphatase affect the hyperosmolarity-induced hyperpolarization; p38 plays a role in the regulation of EpDRF-mediated relaxation to hyperosmolarity. A common kinase signaling pathway coordinating both of the responses was not identified. 


\section{Introduction}

The airway epithelium plays many important roles for the normal functioning of the pulmonary system (Munakata et al., 1989; Hamilton et al., 2001). In addition to its primary function as a protective barrier, it regulates the depth (normally 5-10 $\mu \mathrm{m})$ and molecular composition of the airway surface liquid (ASL) (Widdicombe, 2002). Under normal circumstances, the osmolarity of the ASL is finely maintained at an isotonic level, or slightly higher than that of the interstitium, 285 mosM (Boucher, 1999; Tarran, 2004). Hyperventilation during exercise causes evaporative water loss and hyperosmolarity of the ASL (Anderson and Daviskas, 2000). Using a canine model, about 130 and 40 mosM increase in osmolarity were calculated during and shortly after hyperventilation of dry air, respectively (Freed and Davis, 1999). In non-asthmatic subjects, respiratory resistance declines due to bronchial dilation following exercise (Silverman et al., 2005); but in asthmatics, exercise causes airway obstruction (Anderson and Daviskas, 2000). Studies on guinea-pig perfused trachea demonstrated that airway epithelium could detect an increase in lumen osmolarity and elicit airway relaxation by releasing epithelium-derived relaxing factor (EpDRF) (Munakata et al., 1988;

Fedan et al., 1990). This epithelium-dependent regulatory mechanism could participate in bronchodilation that occurs during exercise, a mechanism which may be defective in asthmatic patients.

Asthma is currently considered as a chronic inflammatory disorder of the airways characterized by airway hyperreactivity to a variety of stimuli (Hamilton et 
al., 2001; Elias et al., 2003). Exercise-induced airway obstruction in asthmatic patients is thought to be triggered by the hyperventilation and increased osmolarity of the ASL (Hallstrand et al., 2005a; Anderson, 2006). The pathogenesis of airway inflammation involves inflammatory cell infiltration, epithelial damage, subepithelial fibrosis and airway smooth muscle hyperplasia (Elias et al., 2003; Pelaia et al., 2005). Because the alteration of airway epithelium is prominent in severe asthmatic patients, asthma has been also considered as an epithelial disease (Chanez, 2005). The epithelial damage would result in two important consequences: 1) Epithelial shedding would expose the underlying airway wall to a variety of contractile mediators and environmental agents (Brannan et al., 2003; Anderson and Kippelen, 2005; Anderson, 2006); 2) epithelial damage would alter epithelium-mediated inflammatory suppression (Holgate et al., 2003; Hallstrand et al., 2005b) and hyperosmolarity-induced airway relaxation through EpDRF (Fedan et al., 2004a). The precise mechanism of EpDRF-mediated airway relaxation is poorly understood. The objective of this study was to investigate the epithelial signaling mechanism(s) involved in hyperosmolarity-induced EpDRF release.

The airway epithelium behaves as an osmometer that sensitively perceives osmolarity changes in the ASL (Matsui et al., 2000; Fedan et al., 2004a), and regulates the tone of underlying smooth muscle and mucosal vasculature. Experiments in vivo showed epithelium-mediated vasodilation in response to mucosal hyperosmolarity (Smith et al., 1993; Prazma et al., 1994). Experiments in 
vitro with guinea-pig perfused trachea and tracheal segment in the Ussing apparatus demonstrated that hyperosmolar challenge elicited depolarization and decreased transepithelial short-circuit current $\left(I_{s c}\right)$ (Dortch-Carnes et al., 1999; Wu et al., 2004); the depolarization response preceded epithelium-dependent airway relaxation (Dortch-Carnes et al., 1999). The hyperosmolarity-induced bioelectric and mechanical responses also were thought to be functionally linked because blockade of epithelial ion transport with $\mathrm{Na}^{+}$and $\mathrm{Cl}^{-}$channel blockers inhibited epithelium-mediated airway relaxation (Fedan et al., 1999).

Challenged by hyperosmolarity, airway epithelium undergoes shrinkage, volume-regulatory ion transport and releases mediators. Commonly involved signaling pathways underlying these adjustments in other types of cells are the three mitogen-activated protein (MAP) kinases, p38, c-Jun N-terminal kinase (JNK) and extracellular-regulated kinase (ERK) (Puddicombe and Davies, 2000; Sheikh-Hamad and Gustin, 2004). The induction of some epithelial-derived mediators in response to hyperosmolarity are regulated by stress-sensitive p38 and JNK (Hashimoto et al., 1999; Furuichi et al., 2002). Moreover, the activities of cell volume-related ion transport are regulated directly or indirectly by MAP kinases and other kinases, i.e., protein kinase C (PKC), calmodulin kinase-II (CaM-K-II), myosin light chain kinase (MLCK) and phosphatidylinositol 3-kinase (PI-3-K) (Shrode et al., 1998; Zhao et al., 2004).

The hypothesis of this study was hyperosmolar challenge activates signaling kinases in epithelia, and that the activities of kinases or phosphatases 
regulate epithelial bioelectric events and EpDRF release. Our aims were to elucidate the relationship of airway bioelectric and mechanical responses and epithelial signaling mechanism in response to hyperosmolar challenge. The guinea-pig isolated, perfused trachea apparatus, which allows simultaneously measuring epithelial bioelectric and smooth muscle mechanical responses, was utilized to investigate the role of appropriate kinases using specific inhibitors. The involvement of MAP kinases implicated in asthma (Pelaia et al., 2005) was examined using two structurally different inhibitors in each case and further confirmed by immunoblotting. To get a better understanding for the involvement of these kinases, the stress inducer, $\mathrm{NaAsO}_{2}$, and the phosphatase inhibitor, $\mathrm{Na}_{3} \mathrm{VO}_{4}$, were also examined. 


\section{Materials and Methods}

Animals. These studies were conducted in facilities accredited fully by the Association for the Assessment and Accreditation of Laboratory Animal Care International and were approved by the institutional Animal Care and Use Committee. Male guinea pigs (550 - 700 g), HsdPoc:DH, from Harlan (Indianapolis, IN), monitored free of endogenous viral pathogens, parasites, and bacteria were used in all experiments. The animals were acclimated before use and were housed in filtered ventilated cages on Alpha-Dri virgin cellulose chips and hardwood Beta-chips as bedding, provided HEPA-filtered air, Teklad 7006 diet and tap water ad libitum, under controlled light cycle (12 h light) and temperature $\left(22-25^{\circ} \mathrm{C}\right)$ conditions. The animals were anesthetized with sodium pentobarbital (65 mg/kg, i.p.) and sacrificed by thoracotomy and bleeding before removing the trachea.

Materials. Modified Krebs-Henseleit $(\mathrm{MKH})$ solution $\left(\mathrm{pH} 7.4\right.$ at $\left.37{ }^{\circ} \mathrm{C}\right)$ contained $113 \mathrm{mM} \mathrm{NaCl}, 4.8 \mathrm{mM} \mathrm{KCl}, 2.5 \mathrm{mM} \mathrm{CaCl}_{2}, 1.2 \mathrm{mM} \mathrm{KH_{2 }} \mathrm{PO}_{4}, 1.2 \mathrm{mM}$ $\mathrm{MgSO}_{4}, 25 \mathrm{mM} \mathrm{NaHCO}_{3}$, and $5.7 \mathrm{mM}$ glucose, and was saturated with $95 \% \mathrm{O}_{2}$

and $5 \% \mathrm{CO}_{2}$. The osmolarity of MKH was $281 \pm 5$ mosM. Acetyl- $\beta$-methylcholine chloride (methacholine, $\mathrm{MCh}$ ) and D-mannitol (D-M) were purchased from Sigma-Aldrich (St. Louis, MO). Stock solutions of MCh and D-M were prepared in saline.

Kinase inhibitors, SB 203580, SKF 86002, SP 600125, dicumarol, PD 98059, U 0126, chelerythrine, LY 294002, KN-62 and ML-7 were purchased from 
Calbiochem-Novabiochem (La Jolla, CA) and dissolved in dimethyl sulphoxide (DMSO, final concentration in $\mathrm{MKH}$ solution was $\leq 0.04 \%$ ). $\mathrm{NaAsO}_{2}$ and $\mathrm{Na}_{3} \mathrm{VO}_{4}$ were obtained from Mallinckrodt Laboratory Chemicals (Phillipsburg, NJ) and Sigma-Aldrich (St. Louis, MO), respectively, and prepared in MKH solution. RIPA cell lysis buffer was obtained from Santa Cruz Biotechnology (Santa Cruz, CA). Laemmli protein sample buffer and $10 \%$ SDS-polyacrylamide ready gels were purchased from Bio-Rad Laboratories (Hercules, CA). Phosphorylated and nonphosphorylated p38, JNK and ERK control proteins and their primary antibodies, horseradish peroxidase (HRP)-linked anti-rabbit secondary antibody and $\beta$-actin antibody were purchased from Cell Signaling Technology (Beverly, MA). BCA protein assay reagents and western-blot stripping buffer were purchased from Pierce Biotechnology (Rockford, IL). Enhanced chemiluminescence (ECL) solution was obtained from GE Healthcare Life Sciences (Piscataway, NJ).

Trachea Perfusion Preparation. The guinea-pig isolated, perfused trachea preparation (Dortch-Carnes et al., 1999) was utilized to measure the airway epithelial bioelectric and muscle mechanical responses induced by the various agents used in this study. A 4.2-cm segment of guinea-pig trachea was removed and mounted at its natural length onto a custom-designed plastic perfusion holder which allows indwelling cannulas with side-opening holes to be inserted into the lumen from either end of the trachea. The trachea holder was placed into an extraluminal $(E L)$ bath filled with MKH solution. The trachea lumen 
was perfused at constant flow (24 $\mathrm{ml} / \mathrm{min}$ ) with $\mathrm{MKH}$ solution from another bath, referred to as the intraluminal (IL) bath; the transmural pressure was adjusted to zero. MKH solution in the IL and EL baths was kept at $37^{\circ} \mathrm{C}$ and saturated with $95 \% \mathrm{O}_{2}$ and $5 \% \mathrm{CO}_{2}$ gas. Agents may be added separately to the IL or EL baths so that they can act directly on epithelia or airway smooth muscle, respectively. The inlet minus outlet perfusion pressure difference $(\triangle P)$ caused by tracheal diameter change was sampled through the side-holes in the indwelling cannulas, which were connected to a differential pressure transducer. Airway smooth muscle contraction decreases tracheal diameter and increases $\triangle P$, whereas $\triangle P$ decreases during relaxation. Voltage electrodes (filled with $4 \%$ agar/saline) were connected across the IL and EL baths to record transepithelial potential $\left(V_{t}\right)$. Thus, the trachea perfusion preparation allows simultaneously monitoring both $V_{t}$ and $\triangle P$ in the same trachea.

\section{Concentration-Response Curves for Hyperosmolar D-M-induced $V_{t}$} and $\triangle \mathbf{P}$ responses. The tracheal preparation was equilibrated by perfusing $\mathrm{MKH}$ solution for $2.5-3 \mathrm{~h}$ to allow stabilization of basal $V_{t}$ and $\triangle P$. To prepare the trachea for relaxation responses, the smooth muscle was precontracted by adding $\mathrm{MCh}\left(3 \times 10^{-7} \mathrm{M}, \mathrm{EC}_{50}\right)$ to the $\mathrm{EL}$ bath. $\mathrm{MCh}$ elicited epithelial hyperpolarization. When the $M C h$-induced $V_{t}$ and $\triangle P$ responses reached their plateaus, the osmolarity of the perfused solution was elevated cumulatively with stepwise addition of D-M to the IL bath. D-M was used to increase osmolarity of the MKH solution because it is an impermeant osmolyte. Each addition was made 
after the $V_{t}$ and $\triangle P$ responses to the previous concentrations reached their plateaus. After all the responses were concluded the preparation was washed with fresh $M K H$ solution to allow $V_{t}$ and $\triangle P$ recovering to their basal levels.

Effects of Kinase Inhibitors, $\mathrm{NaAsO}_{2}$, and $\mathrm{Na}_{3} \mathrm{VO}_{4}$, in the Trachea Perfusion Preparation. To avoid variability between individual animals and different shipments, a paired design was used, i.e., control responses and the effects of inhibitors were obtained from the same preparation. After stabilization of basal $V_{t}$ and $\triangle P$, the control responses were obtained after incubating with vehicle (DMSO) or MKH for 30 min in the IL bath. MCh was then added to the EL bath. When the MCh-responses reached their plateaus, the osmolarity of IL perfused MKH solution was elevated by adding 30 mosM ( EC $\left.\mathrm{E}_{50}\right) \mathrm{D}-\mathrm{M}$. After the $D$-M-induced $V_{t}$ and $\triangle P$ responses became stable, the preparation was washed with fresh $\mathrm{MKH}$ solution to allow $V_{t}$ and $\triangle P$ recover to their basal levels. Ninety min after the $V_{t}$ and $\triangle P$ baselines were re-established, the trachea was incubated with a test agent in the IL bath for 30 min, after which the trachea was challenged again with $\mathrm{MCh}$ and $\mathrm{D}-\mathrm{M}$ in the presence of the agent. The possible effects of DMSO on the two sets of responses to MCh and D-M were evaluated in a separate group of control preparations.

Western-Blot Analysis. The tracheas were challenged the same way as in the D-M concentration-response experiments except there was no exposure to MCh. The epithelia of control and test groups were obtained from the same trachea. Tracheas were removed and cut longitudinally into 3 strips. They were 
randomly assigned into 3 groups: 1) controls incubated in MKH solution, 2) D-Mexposed (20, 40, 80, 160, 240 and 320 mosM), and 3) $\mathrm{NaAsO}_{2}$-exposed (500 $\left.\mu \mathrm{M}\right)$ as a positive control. Each condition was investigated at least four times. After a 2-h period of equilibration the strips were exposed to $\mathrm{MKH}, \mathrm{D}-\mathrm{M}$, or $\mathrm{NaAsO}_{2}$ for 20 min. The exposure was stopped by transferring the strips into ice-cold $\mathrm{MKH}$ solution. At $0{ }^{\circ} \mathrm{C}$ the epithelia on the strips were scraped off with a scalpel blade, collected and centrifuged $600 \times \mathrm{g}$ for $3 \mathrm{~min}$ at $4{ }^{\circ} \mathrm{C}$; the pellets were sonicated in $50 \mu \mathrm{l}$ RIPA lysis buffer to lyse the cells and shear DNA. The protein concentration of the samples was measured with the BCA protein assay.

The samples were loaded, $20 \mu \mathrm{g} /$ well, on a 10\% SDS-polyacrylamide gel together with phosphorylated and nonphosphorylated p38 or JNK standards and subjected to electrophoresis. The proteins were then electrophoretically transferred to a nitrocellulose membrane. After blocking the nonspecific protein binding by incubating the membrane in phosphate-buffered saline (PBS) with $0.1 \%$ triton $\mathrm{X}-100$ and $5 \%$ nonfat milk at room temperature for $1 \mathrm{~h}$, the membrane was incubated with phosphorylated p38 or JNK primary antibodies at $4{ }^{\circ} \mathrm{C}$ overnight, followed by incubation with the HRP-linked anti-rabbit secondary antibody at room temperature for $1 \mathrm{~h}$. After washing the membrane in PBS, the blots were incubated with ECL for 1 min and exposed to Kodak BioMax XAR film. In order to determine the total amount of p38 and JNK proteins on the blots, the membrane was stripped and re-probed with nonphosphorylated p38 or JNK antibodies. At the same time the accuracy of sample loading was also determined 
using $\beta$-actin immunoblotting.

Data Analysis. The epithelial bioelectric responses were quantified as $V_{t}$ in $\mathrm{mV}$. MCh contractions were measured as $\triangle \mathrm{P}$ elevation in $\mathrm{cm} \mathrm{H}_{2} \mathrm{O}$. D-M-induced relaxations were normalized as the percent relaxation of the MCh response (\% MCh). The $E_{50}$ values for $V_{t}$ and $\triangle P$ responses to $D-M$ were derived from D-M concentration-response curves using least-squares analysis of four-parameter logit curve fit and are given along with 95\% confidence intervals. The effects of the test agents on basal $V_{t}$ and $\triangle P$ were also noted and quantified. The results are presented as means \pm SE, and differences were analyzed statistically using Student's paired $t$-test. $p<0.05$ was considered significant. The western-blot bands on the films were scanned with a General Electric Molecular Dynamics scanner and quantitated with image analysis program ImageQuant 5.2 from the intensity of their pixels. The effects of agents on the phosphorylated and total amounts of p38 and JNK were plotted as fold increases compared to their controls. 


\section{Results}

\section{Concentration-Response Relationships for Epithelial Bioelectric and}

Smooth Muscle Mechanical Responses Induced by Hyperosmolarity. To understand the relationship between epithelial bioelectric and muscle mechanical responses induced by hyperosmolarity, and to ascertain an appropriate D-M concentration to be used for testing the effects of kinase or phosphatase inhibitors, concentration-response curves for $V_{t}$ and $\triangle P$ responses induced by $D-M$ were obtained (Fig. $\mathrm{Cl}-1$ ). When the osmolarity increase was below 80 mosM, the bioelectric hyperpolarizing and relaxant responses shared the same concentration-dependence. When the osmolarity increase was higher than 80 mosM, the bioelectric response changed to depolarization, and the relaxation reached nearly the maximum response. The $\mathrm{EC}_{50}$ values obtained, $16.6(13-21.2)$ and $24.4(19.2$ - 31.3) mosM for the hyperpolarization and relaxation responses, respectively, were relevant to the osmolarity increase in the ASL that accompanies exercise hyperventilation and were not significantly different. It was decided to use 30 mosM D-M in subsequent experiments. This concentration of D-M always produced reliable relaxation and hyperpolarization responses.

\section{Effects of DMSO, Kinase Inhibitors, $\mathrm{NaAsO}_{2}$, and $\mathrm{Na}_{3} \mathrm{VO}_{4}$, on Basal $\mathrm{V}_{t}$} and $\triangle \mathbf{P}$. The average basal $V_{t}$ in these experiments was $-12.1 \pm 0.6 \mathrm{mV}(n=88)$. In the concentration range, $0.02-0.2 \%$, DMSO had no effect on basal $\triangle \mathrm{P}$ but hyperpolarized $\mathrm{V}_{\mathrm{t}}$ by $0.57 \pm 0.09 \mathrm{mV}$ when its concentration reached $0.1 \%(n=3)$. At a concentration of $0.04 \%$, DMSO had no effect on basal $V_{t}$ or $\triangle P$; therefore, 
this concentration was used in subsequent controls. Of the six MAP kinase inhibitors SB 203580, SKF 86002, SP 600125, dicumoral, PD 98059 and U 0126 , only SB 203580 decreased basal $V_{t}$ (by $0.8 \pm 0.3 \mathrm{mV}$ ); the other five inhibitors had no effect. SB 203580, dicumarol and PD 98059 slightly decreased basal $\triangle P(\mathrm{~cm}$ $\mathrm{H}_{2} \mathrm{O}$ ) by $0.06 \pm 0.02,0.46 \pm 0.13$ and $0.16 \pm 0.04$, respectively; the other three inhibitors had no effect on $\triangle P$ (Table 1). The other kinase inhibitors, chelerythrine, LY 294002, KN-62 and ML-7 decreased basal $V_{t}(\mathrm{mV})$ by $1.53 \pm 0.29,3.92 \pm 0.61$, $0.47 \pm 0.14$ and $0.60 \pm 0.46$, respectively, while, $\mathrm{Na}_{3} \mathrm{VO}_{4}$ and $\mathrm{NaAsO}_{2}$ increased basal $V_{t}(\mathrm{mV})$ by $0.70 \pm 0.22$ and $1.69 \pm 0.67$, respectively. Chelerythrine increased basal $\triangle \mathrm{P}$ by $0.22 \pm 0.06 \mathrm{~cm} \mathrm{H}_{2} \mathrm{O}$; the other kinase-interfering agents had no effect on basal $\triangle P($ Table 2).

Effects of DMSO, Kinase Inhibitors, $\mathrm{NaAsO}_{2}$, and $\mathrm{Na}_{3} \mathrm{VO}_{4}$, on MCh-induced Contraction and Hyperpolarization Responses. EL applied MCh $\left(3 \times 10^{-7} \quad \mathrm{M}\right)$ caused contraction accompanied by transepithelial hyperpolarization. DMSO and all the examined MAP kinase inhibitors (SB 203580, SKF 86002, SP 600125, dicumarol, PD 98059 and U 0126) had no effect on MCh-induced contraction $(n=6,7,6,10,6,6$, and 6 , respectively; data not shown). LY 294002 and $\mathrm{Na}_{3} \mathrm{VO}_{4}$ inhibited contractile responses to MCh (Figs. $\mathrm{Cl}-2$ and $\mathrm{Cl}-3)$; chelerythrine $(p=0.052)$ and $\mathrm{NaAsO}_{2}(p=0.093)$ had a considerable but not significant inhibitory effect; and KN-62 and ML-7 had no effect (Figs. $\mathrm{Cl}-2$ and $\mathrm{Cl}-3$ ).

SP 600125 and dicumarol potentiated MCh-induced hyperpolarization (Fig. 
$\mathrm{Cl}-4)$, while chelerythrine inhibited this response (Fig. Cl-5). DMSO and the other kinase inhibitors (Figs. Cl-4 and Cl-5), as well as $\mathrm{NaAsO}_{2}$ and $\mathrm{Na}_{3} \mathrm{VO}_{4}(n=9$ and 6 , respectively; data not shown) had no effect.

Effects of DMSO, Kinase Inhibitors, $\mathrm{NaAsO}_{2}$, and $\mathrm{Na}_{3} \mathrm{VO}_{4}$, on D-M-induced Hyperpolarization and Relaxation Responses. IL-applied D-M elicited transepithelial hyperpolarization and relaxation. SP 600125 and dicumarol (Fig. $\mathrm{Cl}-6$ ), chelerythrine (Fig. $\mathrm{Cl}-7$ ), $\mathrm{NaAsO}_{2}$ and $\mathrm{Na}_{3} \mathrm{VO}_{4}$ (Fig. $\mathrm{Cl}-8$ ) inhibited D-M-induced hyperpolarization. DMSO and the other kinase inhibitors had no effect (Figs. $\mathrm{Cl}-6$ and $\mathrm{Cl}-7$ ). The inhibition by $\mathrm{NaAsO}_{2}$ was complete (Fig. $\mathrm{Cl}-8$ ); this is the first time we have observed an agent nullifying the bioelectric response to hyperosmolar challenge.

SB 203580 and SKF 86002 potentiated D-M-induced relaxation (Fig. Cl-9). DMSO and the other kinase inhibitors SP 600125, dicumarol, PD 98059 and U 0126 (Fig. Cl-9); chelerythrine, LY 294002, KN-62 and ML-7 (Fig. Cl-10); as well as $\mathrm{NaAsO}_{2}$ and $\mathrm{Na}_{3} \mathrm{VO}_{4}$ ( $n=9$ and 6, respectively, data not shown), had no significant effect on the D-M-induced relaxation responses.

Epithelial p38 and JNK Phosphorylation Induced by Hyperosmolarity. Immunoblotting experiments with ERK were not performed because the above results indicated that ERK is not involved in the regulation of basal $V_{t}$ or responses to MCh and D-M. Western-blot analysis with specific antibodies to phosphorylated and nonphosphorylated p38 and JNK showed that after exposing epithelia to D-M (20, 40, 80, 160, 240 and $320 \operatorname{mosM})$ for $20 \mathrm{~min}$, the 
phosphorylation of p38 (Figs. $\mathrm{Cl}-11 \mathrm{~A}$ and $\mathrm{Cl}-11 \mathrm{~B}$ ) and JNK (Figs. Cl-12A and $\mathrm{Cl}-12 \mathrm{~B}$ ) was increased in an osmolarity concentration-dependent manner at the two and three highest concentrations, respectively, while the total amount of p38 and JNK proteins did not change significantly (Figs. $\mathrm{Cl}-11 \mathrm{~B}$ and $\mathrm{Cl}-12 \mathrm{~B}$ ). At 320 mosM D-M, the phosphorylation of p38 and JNK was increased by about 4- and 6-fold, respectively (Figs. $\mathrm{Cl}-11 \mathrm{~A}$ and $\mathrm{Cl}-12 \mathrm{~A}$ ). Interestingly, the positive control, $\mathrm{NaAsO}_{2}(500 \mu \mathrm{M})$, not only induced an increase in p38 phosphorylation but also reproducibly increased the total amount of p38 protein (Fig. Cl-11B). $\mathrm{NaAsO}_{2}$ caused an increase in JNK phosphorylation, but the total amount of JNK protein was not changed (Fig. Cl-12B). 


\section{Discussion}

Hyperventilation during exercise causes evaporative water loss and hyperosmolarity of the ASL (Anderson and Daviskas, 2000). The airway epithelium regulates the tone of the underlying smooth muscle by releasing EpDRF in response to hyperosmolar challenge (Fedan et al., 2004a). This epithelium-mediated airway relaxation may protect people from experiencing airway narrowing during exercise. The mechanism(s) involved in EpDRF release is not clear. Previous studies have suggested a link between epithelial bioelectric and muscle relaxation responses elicited by hyperosmolarity (Dortch-Carnes et al., 1999; Fedan et al., 1999). This study was conducted to understand in more detail the relationship between epithelium and smooth muscle and to probe epithelial signaling mechanisms involved in EpDRF release.

We obtained concentration-response curves for simultaneously-measured $V_{t}$ and $\triangle P$ responses induced by hyperosmolar $D-M$. When the increase in osmolarity was lower than 80 mosM, the curves for the hyperpolarization and relaxation shared the same concentration-dependence, suggesting a possible link between the two types of responses over an osmolar concentration range that is physiologicall relevant to exercise. However, when the osmolarity was elevated beyond 80 mosM, the $V_{t}$ response changed to depolarization, and the relaxation response reached maximum. Our earlier study conducted with 240 mosM sucrose also demonstrated a transient hyperpolarization that preceded depolarization (Dortch-Carnes et al., 1999). Thus, the $V_{t}$ response was qualitatively related to the 
concentration of osmolytes. The transition from hyperpolarization to depolarization occurred at around 80 mosM. The concentration-response curves revealed that the epithelium is very sensitive to small changes in luminal osmolarity. A considerable airway relaxation could be elicited in response to small osmolarity increases.

In the face of hyperosmolar challenge (lower than 80 mosM) the hyperpolarization is likely to be a consequence of $\mathrm{Cl}^{-}$and $\mathrm{K}^{+}$secretion as the cells shrink (Russell, 2000). Since cells adjust their volume principally through activation of $\mathrm{Na}^{+}-\mathrm{K}^{+}-2 \mathrm{Cl}^{-}$cotransporter after shrinkage (O'Neill, 1999), the secondary $\mathrm{Cl}^{-}$and $\mathrm{K}^{+}$secretion and $\mathrm{Na}^{+}$extrusion caused by this event may also partially contribute to the hyperpolarization. We currently do not know the precise mechanism for the large depolarization evoked by D-M higher than 80 mosM. In the Ussing apparatus, apical D-M (120 mosM) decreased $I_{s c}$ (Wu et al., 2004), suggesting the primary driving force, $\mathrm{Na}^{+}-\mathrm{K}^{+}$-pump, for $I_{s c}$ or $\mathrm{V}_{t}$ was inhibited. However, the depolarization caused solely by the $\mathrm{Na}^{+}-\mathrm{K}^{+}$-pump inhibitor, ouabain, needs much longer time to reach plateau (Chapter II, Figs. CII-2A and CII-4A), indicating that an additional mechanism must be involved. In rat hepatocytes, increased $\mathrm{Na}^{+}$channel conductance became prominent in response to 80 mosM sucrose and upwards (Wehner et al., 2000); the activation of $\mathrm{Na}^{+}$conductance and $\mathrm{Na}^{+}-\mathrm{K}^{+}-2 \mathrm{Cl}^{-}$cotransporter is mediated by PKC (Heinzinger et al., 2001). Combined $\mathrm{Na}^{+}$influx (perhaps with the reduction of $\mathrm{Cl}^{-}$efflux) and $\mathrm{Na}^{+}-\mathrm{K}^{+}$-pump inhibition could depolarize the epithelium. In addition, a decrease in $V_{t}$ could also 
result from a decrease in transepithelial resistance $\left(R_{t}\right)$. Earlier studies using the Ussing apparatus demonstrated that the depolarization caused by hyperosmolar D-M was not due to a decrease in $R_{t}$ (Wu et al., 2004).

Using kinase-interfering agents, we investigated the mechanisms of epithelial signaling involved in the regulation of basal $V_{t}$ and $\triangle P$, and their responses to MCh and D-M. Our primary focus was the stress-sensitive MAP kinases; $\mathrm{p38}$, JNK and ERK were each examined using two structurally-different inhibitors. Of the six MAP kinase inhibitors only SB 203580 decreased basal $V_{t}$; because SKF 86002 did not produce the same effect, the effect of SB 203580 might not involve p38. Other kinase inhibitors, i.e., chelerythrine, LY 294002, $\mathrm{KN}-62$ and ML-7, all decreased basal $\mathrm{V}_{\mathrm{t}}$. In contrast, $\mathrm{NaAsO}_{2}$ and $\mathrm{Na}_{3} \mathrm{VO}_{4}$ increased basal $\mathrm{V}_{\mathrm{t}}$. Although $\mathrm{NaAsO}_{2}$ and $\mathrm{Na}_{3} \mathrm{VO}_{4}$ are not kinase-specific in their actions, their general effects are to elevate protein phosphorylation and produce responses opposite to those of the kinase inhibitors if epithelial ion transport is regulated by phosphorylation. These results support the hypothesis that PKC, PI-3-K, CaM-K-II and MLCK play some roles in regulating basal epithelial ion transport.

The MAP kinase inhibitors, SB 203580, dicumarol and PD 98059, slightly decreased basal $\triangle P$, suggesting that the regulation of basal smooth muscle tone may involve p38, JNK and ERK. However, a solid conclusion can not be reached because SKF 86002, SP 600125 and U 0126, which are thought to inhibit p38, JNK and ERK, respectively, had no effect. Chelerythrine elevated basal $\triangle P$ in 
this study; another PKC inhibitor, Ro31-8220, completely abolished guinea-pig tracheal relaxation induced by the PKC activator, PMA (Liu et al., 1998a, b), indicating that PKC plays a role in the regulation of airway smooth muscle tone. Because the epithelial diffusion barrier would reduce the concentration of IL applied agents at the smooth muscle by 400 - 800 fold (Fedan and Frazer, 1992), the basal $\triangle P$ elevation in response to chelerythrine was likely an epithelium-dependant effect.

The MAP kinase inhibitors were generally without effect on the contractile responses to MCh. The inhibition caused by LY 294002 was likely due to its inhibitory effect on L-type $\mathrm{Ca}^{2+}$ channels activated by $\mathrm{M}_{2}$ receptors (Callaghan et al., 2004). $\mathrm{Na}_{3} \mathrm{VO}_{4}$ inhibited contractile responses to $\mathrm{MCh}$ in this study; it has been reported to inhibit contractile responses in guinea-pig vascular smooth muscle, and the mechanism was not due to its inhibition of the $\mathrm{Na}^{+}-\mathrm{K}^{+}-$pump (Ozaki et al., 1982).

Studies performed on the Ussing apparatus investigating the mechanisms of MCh-induced hyperpolarization found that the hyperpolarization resulted primarily from $\mathrm{Cl}^{-}$secretion and the activation of $\mathrm{Na}^{+}-\mathrm{K}^{+}-2 \mathrm{Cl}^{-}$cotransporter (Phillips et al., 2002; Wu et al., 2004). MCh activated JNK in Chinese hamster ovary cells expressing $M_{3}$ muscarinic receptors, and the activation of JNK was negatively regulated by PKC (Wylie et al., 1999), suggesting that PKC and JNK could have differential regulatory effects on MCh-induced responses. These findings help to explain the opposite effects between SP 600125, dicumarol and 
chelerythrine on the MCh-induced hyperpolarization. PKC down-regulation of the activity of JNK was also observed in Rat-1 fibroblasts (Cadwallader et al., 1997). Because the activity of $\mathrm{Na}^{+}-\mathrm{K}^{+}-2 \mathrm{Cl}^{-}$cotransporter is modulated by phosphorylation, the mechanisms of PKC and JNK could be through their regulation of the cotransporter (Flatman, 2002).

SP 600125, dicumarol and chelerythrine inhibited D-M-induced hyperpolarization. The mechanism may have involved inhibition of the $\mathrm{Na}^{+}-\mathrm{K}^{+}-2 \mathrm{Cl}^{-}$ cotransporter and secondary secretion of $\mathrm{Cl}^{-}$and $\mathrm{K}^{+}$, because hyperosmolar sucrose-induced activation of the $\mathrm{Na}^{+}-\mathrm{K}^{+}-2 \mathrm{Cl}^{-}$cotransporter occurred through the regulation of JNK and PKC in endothelial and epithelial cells, respectively (Klein et al., 1999; Liedtke and Cole, 2002b). Our further studies conducted with simultaneous $\mathrm{R}_{\mathrm{t}}$ analysis (Chapter $\mathrm{II}$ ) demonstrated that the inhibited hyperpolarization caused by SP 600125 and dicumarol was not only through the inhibition of epithelial ion transport but also involved significant decreases in $R_{t}$. The effects of $\mathrm{NaAsO}_{2}$ and $\mathrm{Na}_{3} \mathrm{VO}_{4}$ may have resulted from their interactions with multiple kinase pathways which are involved in the regulation of the $\mathrm{Na}^{+}-\mathrm{K}^{+}-2 \mathrm{Cl}^{-}$ cotransporter. Similar to the JNK inhibitors, the inhibition of hyperpolarization caused by $\mathrm{NaAsO}_{2}$ also involved significant decreases in $\mathrm{R}_{\mathrm{t}}$ (Chapter II). Although $\mathrm{Na}_{3} \mathrm{VO}_{4}$ was reported to have an inhibitory effect on the $\mathrm{Na}^{+}-\mathrm{K}^{+}$-pump (Dafnis and Sabatini, 1994), it increased basal $V_{t}$ during the 30 min exposure, which is evidence that the activity of the $\mathrm{Na}^{+}-\mathrm{K}^{+}$-pump was not inhibited in our experiments. Because $\mathrm{Na}_{3} \mathrm{VO}_{4}$ had no effect on $\mathrm{R}_{\mathrm{t}}$ (Chapter II), its inhibition on the 
D-M-induced hyperpolarization resulted from decreased epithelial ion transport.

SB 203580 and SKF 86002 potentiated D-M-induced relaxation. This result suggests that p38 inhibition may potentiate hyperosmolarity-induced EpDRF release; conceivably, p38 inhibitors could provide therapeutic benefits for the prevention of bronchoconstriction induced by exercise. It is known that p38 signaling contributes to the pathogenesis of airway inflammation and hyperreactivity (Adams et al., 2001). Thus, the findings of this study lead support to the notion that p38 inhibitors can be developed as anti-asthma medicines (Adcock et al., 2006).

Activation of epithelial p38 and JNK induced by hyperosmolar D-M was examined in western blots. Their phosphorylation levels were elevated in an osmolarity concentration-dependant manner, reaching 4- and 6-fold at 320 mosM, respectively. However, the concentrations that elicited maximal hyperpolarization and relaxation responses in the functional perfused trachea studies were lower than those required to induce significant phosphorylation in western blots. The differences suggest that kinase signaling leading to the bioelectric and mechanical responses either do not involve p38 or JNK, or that only small increases in phosphorylation are sufficient, over the physiological osmolarity range. Meanwhile, other signaling mechanisms may also contribute to the functional responses to hyperosmolarity. We are planning to use antibodies of pan-phosphotyrosine and pan-phosphothreonine to investigate whether other kinases could also be involved. In addition, 2-dimensional PAGE analysis and 
proteomics may also help us to identify the potentially involved signaling proteins.

Taken together, the results indicate that airway hyperosmolar challenge relevant to exercise elicits epithelial hyperpolarization and smooth muscle relaxation; the two responses share the same osmolarity concentration-dependence. The hyperosmolarity-induced hyperpolarization is possibly regulated by JNK, PKC and phosphatase through the activity of $\mathrm{Na}^{+}-\mathrm{K}^{+}-2 \mathrm{Cl}^{-}$cotransporter; whereas, p38 plays a role in the EpDRF-mediated relaxation. ERK is not involved in either response. A common signaling pathway coordinating both of the responses was not identified. 


\section{References}

Adams JL, Badger AM, Kumar S and Lee JC (2001) p38 MAP kinase: molecular target for the inhibition of pro-inflammatory cytokines. Prog Med Chem 38:1-60.

Adcock IM, Chung KF, Caramori G and Ito K (2006) Kinase inhibitors and airway inflammation. Eur J Pharmacol 533:118-132.

Anderson SD (2006) How does exercise cause asthma attacks? Curr Opin Allergy Clin Immunol 6:37-42.

Anderson SD and Daviskas E (2000) The mechanism of exercise-induced asthma is... J Allergy Clin Immunol 106:453-459.

Anderson SD and Kippelen P (2005) Exercise-induced bronchoconstriction: pathogenesis. Curr Allergy Asthma Rep 5:116-122.

Boucher RC (1999) Molecular insights into the physiology of the "thin film" of airway surface liquid. J Physiol 516:631-638.

Brannan JD, Gulliksson M, Anderson SD, Chew N and Kumlin M (2003) Evidence of mast cell activation and leukotriene release after mannitol inhalation. Eur Respir J 22:491-496.

Cadwallader K, Beltman J, McCormick F and Cook S (1997) Differential regulation of extracellular signal-regulated protein kinase 1 and Jun $\mathrm{N}$-terminal kinase 1 by $\mathrm{Ca}^{2+}$ and protein kinase $\mathrm{C}$ in endothelin-stimulated Rat-1 cells. Biochem J 321:795-804.

Callaghan B, Koh SD and Keef KD (2004) Muscarinic $M_{2}$ receptor stimulation of 
Cav1.2b requires phosphatidylinositol 3-kinase, protein kinase $\mathrm{C}$, and c-Src. Circ Res 94:626-633.

Chanez P (2005) Severe asthma is an epithelial disease. Eur Respir J 25:945-946.

Dafnis E and Sabatini S (1994) Biochemistry and pathophysiology of vanadium. Nephron 67:133-143.

Dortch-Carnes J, Van Scott MR and Fedan JS (1999) Changes in smooth muscle tone during osmotic challenge in relation to epithelial bioelectric events in guinea pig isolated trachea. J Pharmacol Exp Ther 289:911-917.

Elias JA, Lee CG, Zheng T, Ma B, Homer RJ and Zhu Z (2003) New insights into the pathogenesis of asthma. J Clin Invest 111:291-297.

Fedan JS, Dowdy JA, Johnston RA and Van Scott MR (2004a) Hyperosmolar solution effects in guinea pig airways. I. Mechanical responses to relative changes in osmolarity. J Pharmacol Exp Ther 308:10-18.

Fedan JS and Frazer DG (1992) Influence of epithelium on the reactivity of guinea pig isolated, perfused trachea to bronchoactive drugs. J Pharmacol Exp Ther 262:741-750.

Fedan JS, Nutt ME and Frazer DG (1990) Reactivity of guinea-pig isolated trachea to methacholine, histamine and isoproterenol applied serosally versus mucosally. Eur J Pharmacol 190:337-345.

Fedan JS, Yuan LX, Chang VC, Viola JO, Cutler D and Pettit LL (1999) Osmotic regulation of airway reactivity by epithelium. J Pharmacol Exp Ther 
289:901-910.

Flatman PW (2002) Regulation of $\mathrm{Na}-\mathrm{K}-2 \mathrm{Cl}$ cotransport by phosphorylation and protein-protein interactions. Biochim Biophys Acta 1566:140-151.

Freed AN and Davis MS (1999) Hyperventilation with dry air increases airway surface fluid osmolality in canine peripheral airways. Am J Respir Crit Care Med 159:1101-1107.

Furuichi S, Hashimoto S, Gon Y, Matsumoto K and Horie T (2002) p38 mitogen-activated protein kinase and c-Jun-NH2-terminal kinase regulate interleukin-8 and RANTES production in hyperosmolarity stimulated human bronchial epithelial cells. Respirology 7:193-200.

Hallstrand TS, Moody MW, Aitken ML and Henderson WR, Jr. (2005b) Airway immunopathology of asthma with exercise-induced bronchoconstriction. $J$ Allergy Clin Immunol 116:586-593.

Hallstrand TS, Moody MW, Wurfel MM, Schwartz LB, Henderson WR, Jr. and Aitken ML (2005a) Inflammatory basis of exercise-induced bronchoconstriction. Am J Respir Crit Care Med 172:679-686.

Hamilton LM, Davies DE, Wilson SJ, Kimber I, Dearman RJ and Holgate ST (2001) The bronchial epithelium in asthma-much more than a passive barrier. Monaldi Arch Chest Dis 56:48-54.

Hashimoto S, Matsumoto K, Gon Y, Nakayama T, Takeshita I and Horie T (1999) Hyperosmolarity-induced interleukin-8 expression in human bronchial epithelial cells through p38 mitogen-activated protein kinase. Am J Respir 
Crit Care Med 159:634-640.

Heinzinger $\mathrm{H}$, van den Boom F, Tinel $\mathrm{H}$ and Wehner $\mathrm{F}$ (2001) In rat hepatocytes, the hypertonic activation of $\mathrm{Na}^{+}$conductance and $\mathrm{Na}^{+}-\mathrm{K}^{+}-2 \mathrm{Cl}^{-}$symport-but not $\mathrm{Na}^{+}-\mathrm{H}^{+}$antiport-is mediated by protein kinase C. J Physiol 536:703-715.

Holgate ST, Davies DE, Puddicombe S, Richter A, Lackie P, Lordan J and Howarth P (2003) Mechanisms of airway epithelial damage: epithelial-mesenchymal interactions in the pathogenesis of asthma. Eur Respir J Suppl 44:24s-29s.

Klein JD, Lamitina ST and O'Neill WC (1999) JNK is a volume-sensitive kinase that phosphorylates the $\mathrm{Na}-\mathrm{K}-2 \mathrm{Cl}$ cotransporter in vitro. Am J Physiol 277:C425-431.

Liedtke CM and Cole TS (2002b) Activation of NKCC1 by hyperosmotic stress in human tracheal epithelial cells involves PKC- $\delta$ and ERK. Biochim Biophys Acta 1589:77-88.

Liu X, Xu Y and Zhang Z (1998b) [The regulating effect of protein kinase C pathway on the airway tone]. Zhonghua Jie He He Hu Xi Za Zhi 21:745-748.

Liu X, Xu Y, Zhang Z and Ni W (1998a) The regulating effects of protein kinase C on the tone of guinea-pig trachea and human lobus bronchi. J Tongji Med Univ 18:94-96, 100.

Matsui H, Davis CW, Tarran R and Boucher RC (2000) Osmotic water 
permeabilities of cultured, well-differentiated normal and cystic fibrosis airway epithelia. J Clin Invest 105:1419-1427.

Munakata M, Huang I, Mitzner W and Menkes H (1989) Protective role of epithelium in the guinea pig airway. J Appl Physiol 66:1547-1552.

Munakata M, Mitzner W and Menkes H (1988) Osmotic stimuli induce epithelial-dependent relaxation in the guinea pig trachea. J Appl Physiol 64:466-471.

O'Neill WC (1999) Physiological significance of volume-regulatory transporters. Am J Physiol 276:C995-C1011.

Ozaki H, Ueda F and Urakawa N (1982) Inhibitory effects of vanadate on the contractile responses in vascular smooth muscle. Eur J Pharmacol 80:317-322.

Pelaia G, Cuda G, Vatrella A, Gallelli L, Caraglia M, Marra M, Abbruzzese A, Caputi M, Maselli R, Costanzo FS and Marsico SA (2005) Mitogen-activated protein kinases and asthma. J Cell Physiol 202:642-653. Phillips JE, Hey JA and Corboz MR (2002) Effects of ion transport inhibitors on MCh-mediated secretion from porcine airway submucosal glands. J Appl Physiol 93:873-881.

Prazma J, Coleman CC, Shockley WW and Boucher RC (1994) Tracheal vascular response to hypertonic and hypotonic solutions. J Appl Physiol 76:2275-2280.

Puddicombe SM and Davies DE (2000) The role of MAP kinases in intracellular 
signal transduction in bronchial epithelium. Clin Exp Allergy 30:7-11.

Russell JM (2000) Sodium-potassium-chloride cotransport. Physiol Rev 80:211-276.

Sheikh-Hamad D and Gustin MC (2004) MAP kinases and the adaptive response to hypertonicity: functional preservation from yeast to mammals. Am J Physiol Renal Physiol 287:F1102-1110.

Shrode LD, Krump E and Grinstein S (1998) Activation of protein kinases upon volume changes: role in cellular homeostasis. Contrib Nephrol 123:79-93.

Silverman NK, Johnson AT, Scott WH and Koh FC (2005) Exercise-induced respiratory resistance changes as measured with the airflow perturbation device. Physiol Meas 26:29-38.

Smith TL, Prazma J, Coleman CC, Drake AF and Boucher RC (1993) Control of the mucosal microcirculation in the upper respiratory tract. Otolaryngol Head Neck Surg 109:646-652.

Tarran R (2004) Regulation of airway surface liquid volume and mucus transport by active ion transport. Proc Am Thorac Soc 1:42-46.

Wehner F, Bohmer C, Heinzinger H, van den Boom F and Tinel H (2000) The hypertonicity-induced $\mathrm{Na}^{+}$conductance of rat hepatocytes: physiological significance and molecular correlate. Cell Physiol Biochem 10:335-340.

Widdicombe JH (2002) Regulation of the depth and composition of airway surface liquid. J Anat 201:313-318.

Wu DX, Johnston RA, Rengasamy A, Van Scott MR and Fedan JS (2004) 
Hyperosmolar solution effects in guinea pig airways. II. Epithelial bioelectric responses to relative changes in osmolarity. J Pharmacol Exp Ther 308:19-29.

Wylie PG, Challiss RA and Blank JL (1999) Regulation of extracellular-signal regulated kinase and c-Jun $\mathrm{N}$-terminal kinase by G-protein-linked muscarinic acetylcholine receptors. Biochem J 338 (Pt 3):619-628.

Zhao H, Hyde R and Hundal HS (2004) Signalling mechanisms underlying the rapid and additive stimulation of NKCC activity by insulin and hypertonicity in rat L6 skeletal muscle cells. J Physiol 560:123-136. 


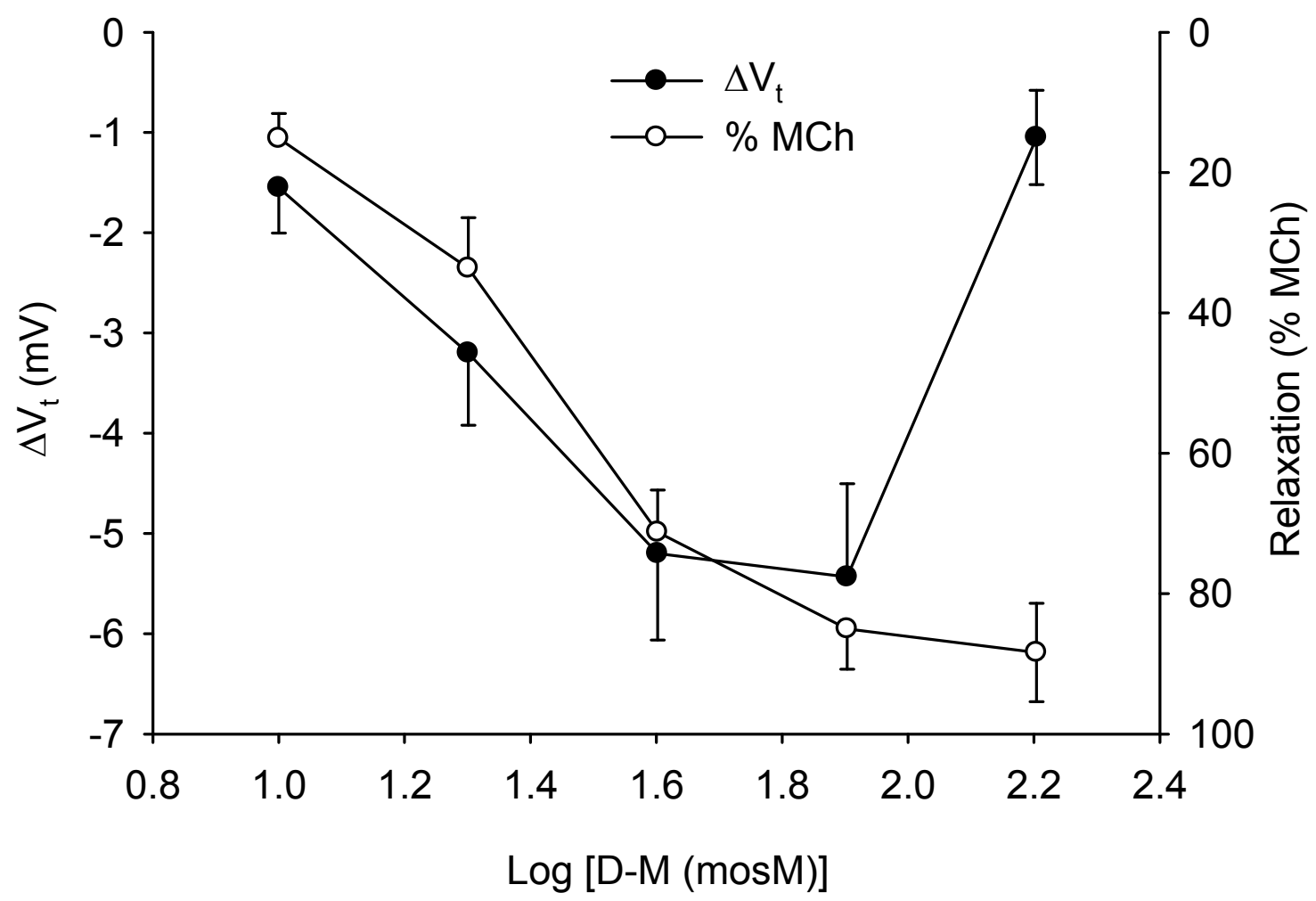

Fig. Cl-1. Concentration-response relationship for D-M-induced bioelectric and mechanical responses. $\Delta V_{t}$, changes in $V_{t}$ from baseline $(-11.33 \pm 2.81 \mathrm{mV})$. Relaxation (\% MCh): percent relaxation of $3 \times 10^{-7} \mathrm{M}$ MCh-induced contraction. Osmolarity elevation always induced relaxation. When the osmolarity increase was below 80 mosM D-M increased $V_{t}$, and, at higher concentrations, D-M decreased $V_{t}$. The transition from hyperpolarization to depolarization occurred at around 80 mosM. Coincidently, this concentration also induced nearly maximum relaxation. The $\mathrm{EC}_{50}$ values for the $\mathrm{D}-\mathrm{M}$-induced hyperpolarization and relaxation responses were 16.6 (13 - 21.2) and $24.4(19.2$ - 31.3) mosM, respectively; and were not significantly different. $n=6$. 


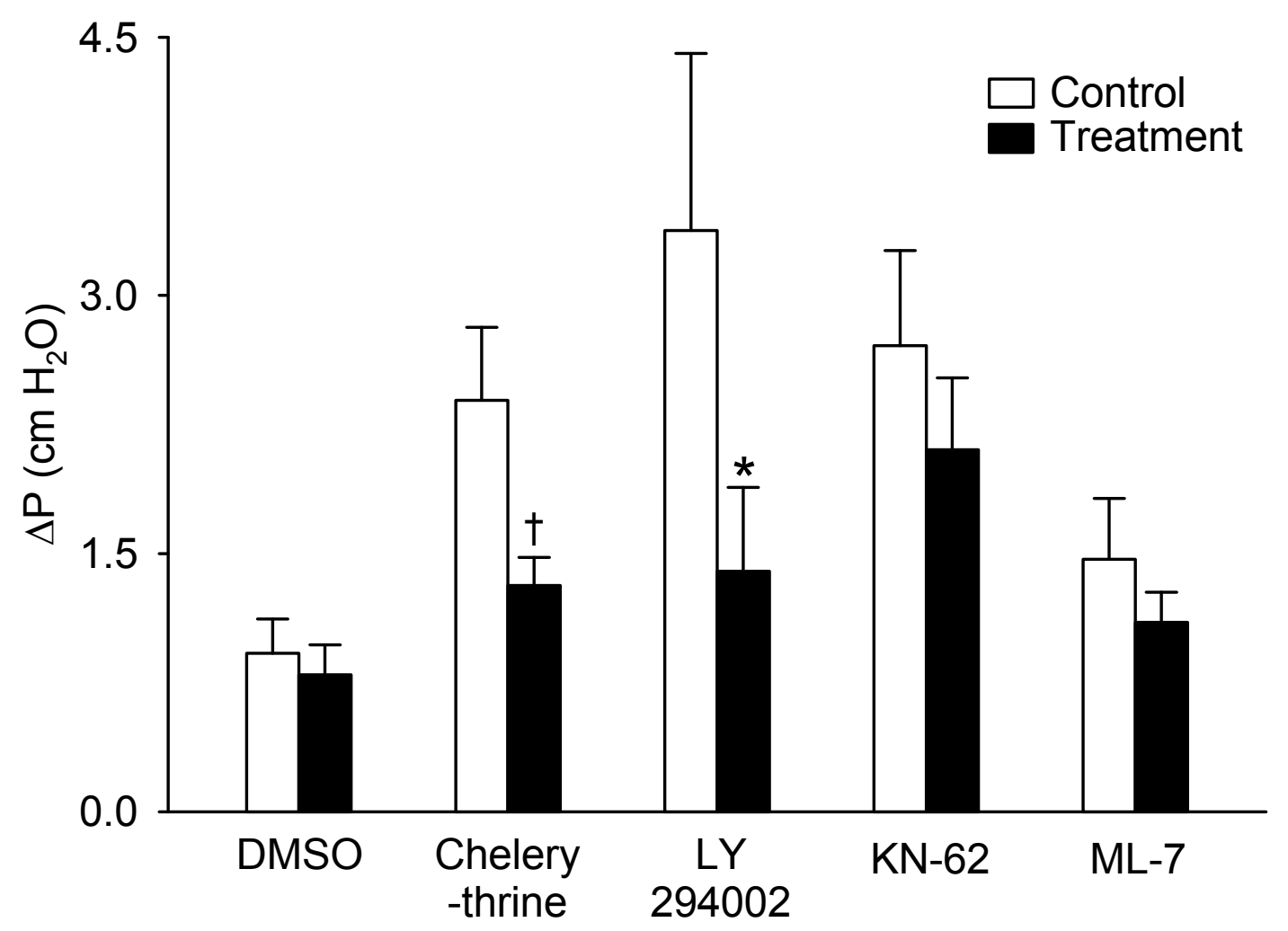

Fig. Cl-2. Effects of the kinase inhibitors on MCh-induced contraction. LY 294002 $(n=6)$ inhibited the contractile responses. DMSO and the other inhibitors, chelerythrine, KN-62 and ML-7 ( $n=6,8,6$ and 6 , respectively) had no effect ( $\dagger p=$ 0.052). ${ }^{*} p<0.05$. 


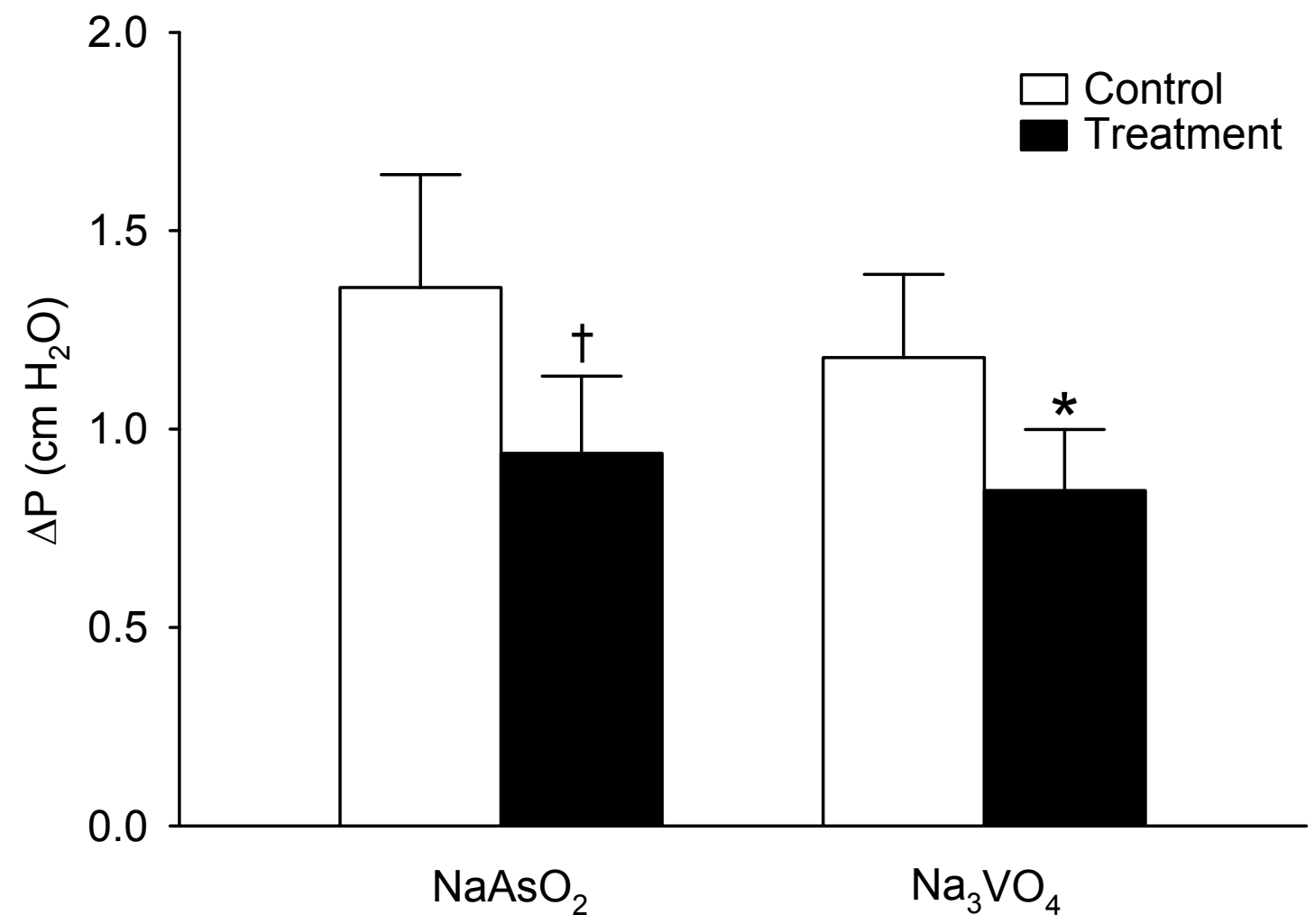

Fig. Cl-3. Effects of $\mathrm{NaAsO}_{2}$ and $\mathrm{Na}_{3} \mathrm{VO}_{4}$ on $\mathrm{MCh}$-induced contraction. $\mathrm{Na}_{3} \mathrm{VO}_{4}(n$ $=6)$ inhibited the contractile responses, while the effect of $\mathrm{NaAsO}_{2}(n=9)$ was not significant $(\dagger p=0.093) .{ }^{*} p<0.05$. 


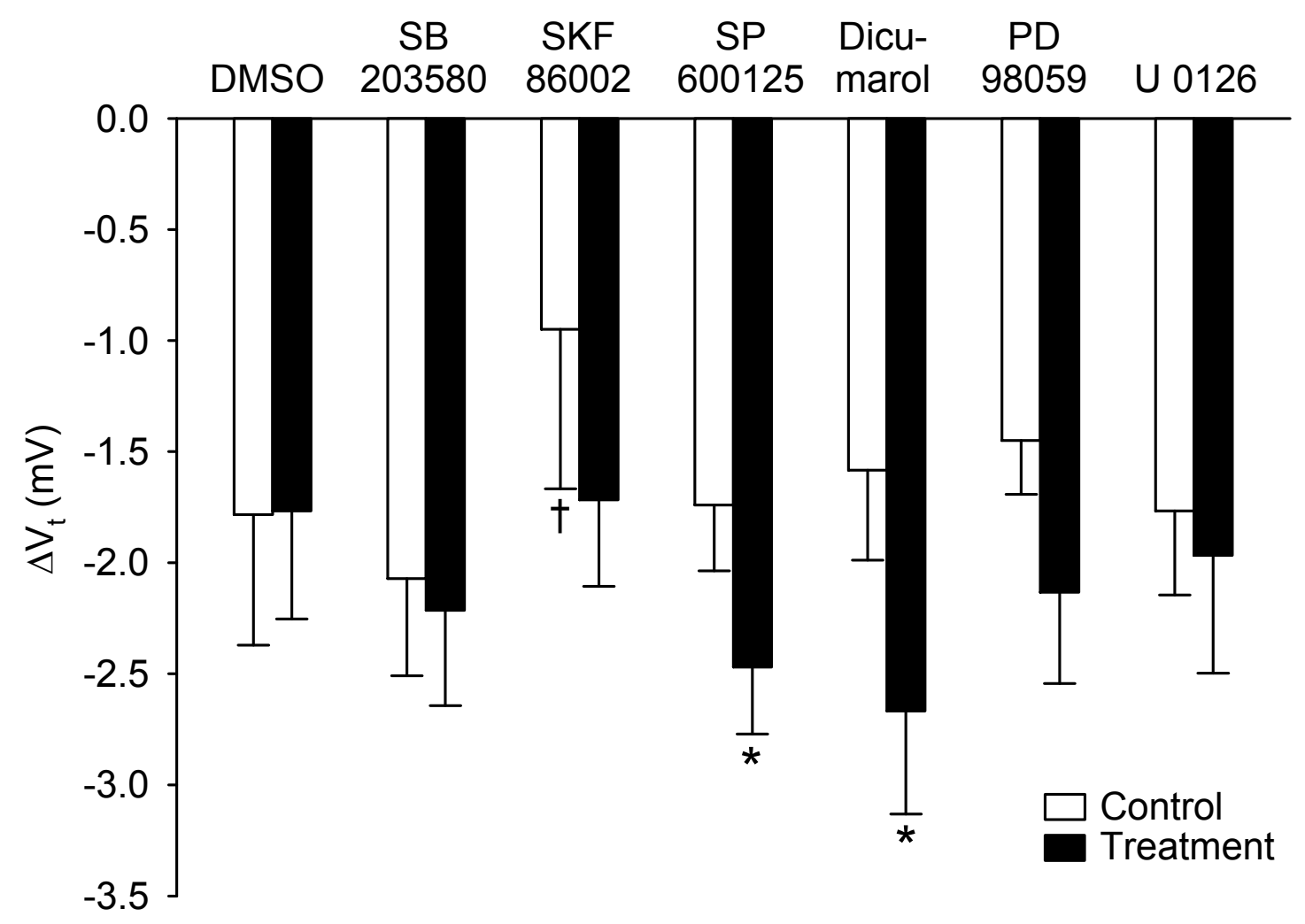

Fig. Cl-4. Effects of the MAP kinase inhibitors on MCh-induced hyperpolarization. SP 600125 and dicumarol ( $n=10$ and 6, respectively) potentiated the hyperpolarization responses. The effects of DMSO and the other inhibitors, SB 203580, SKF 86002, PD 98059 and U 0126 ( $n=6,7,6,6$ and 6, respectively) were not significant. ${ }^{*} p<0.05 . \dagger p=0.11$. 


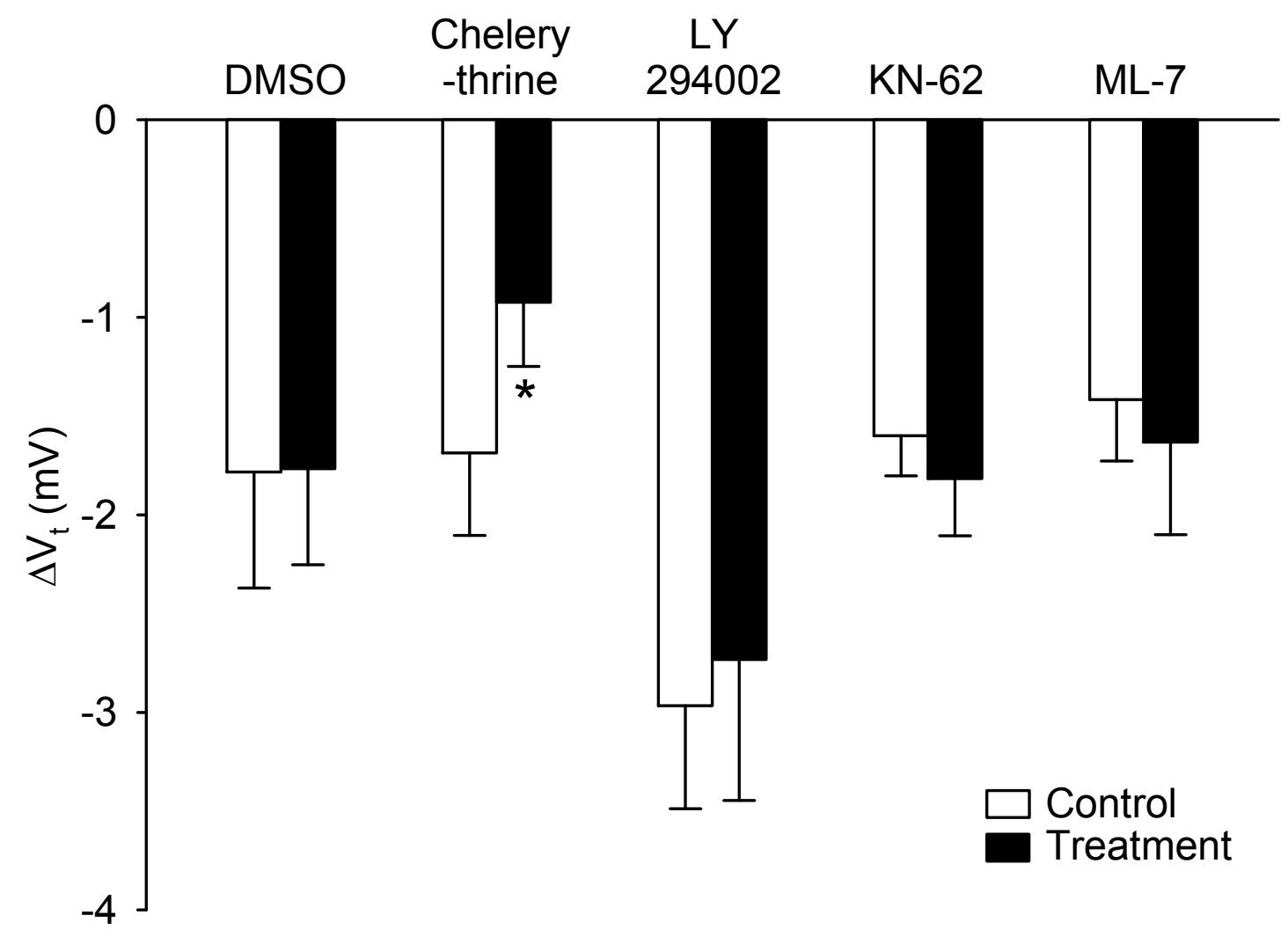

Fig. Cl-5. Effects of the kinase inhibitors on MCh-induced hyperpolarization. Chelerythrine $(n=8)$ inhibited the hyperpolarization responses. DMSO and the other inhibitors, LY 294002, KN-62 and ML-7 $(n=6)$ had no effect. * $p<0.05$. 


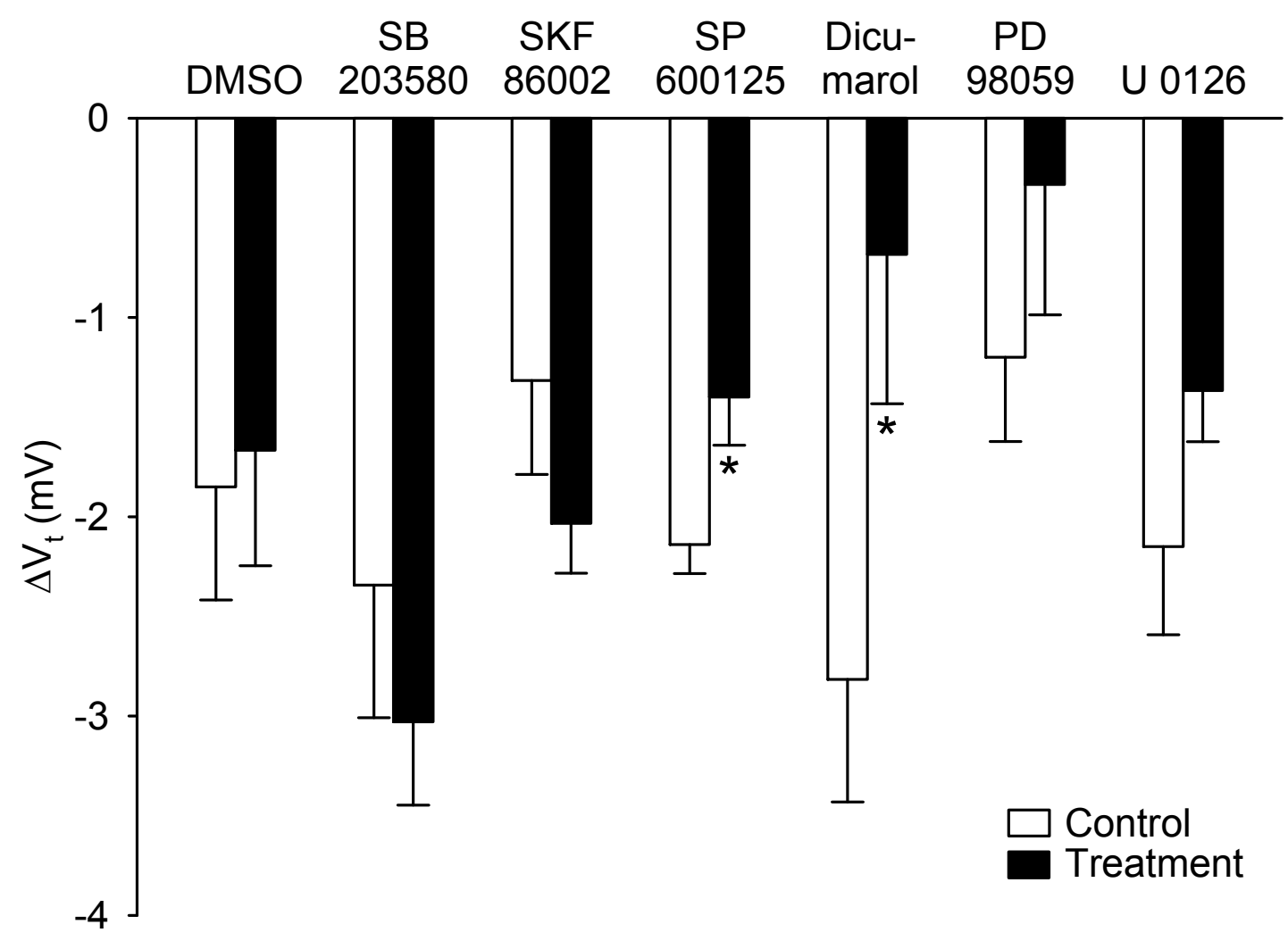

Fig. Cl-6. Effects of the MAP kinase inhibitors on D-M-induced hyperpolarization. SP 600125 and dicumarol $(n=10$ and 6 , respectively) inhibited the hyperpolarization responses. The effects of DMSO and the other inhibitors, SB 203580, SKF 86002, PD 98059 and U 0126 ( $n=6,7,6,6$ and 6, respectively) were not significant. ${ }^{*} p<0.05$. 


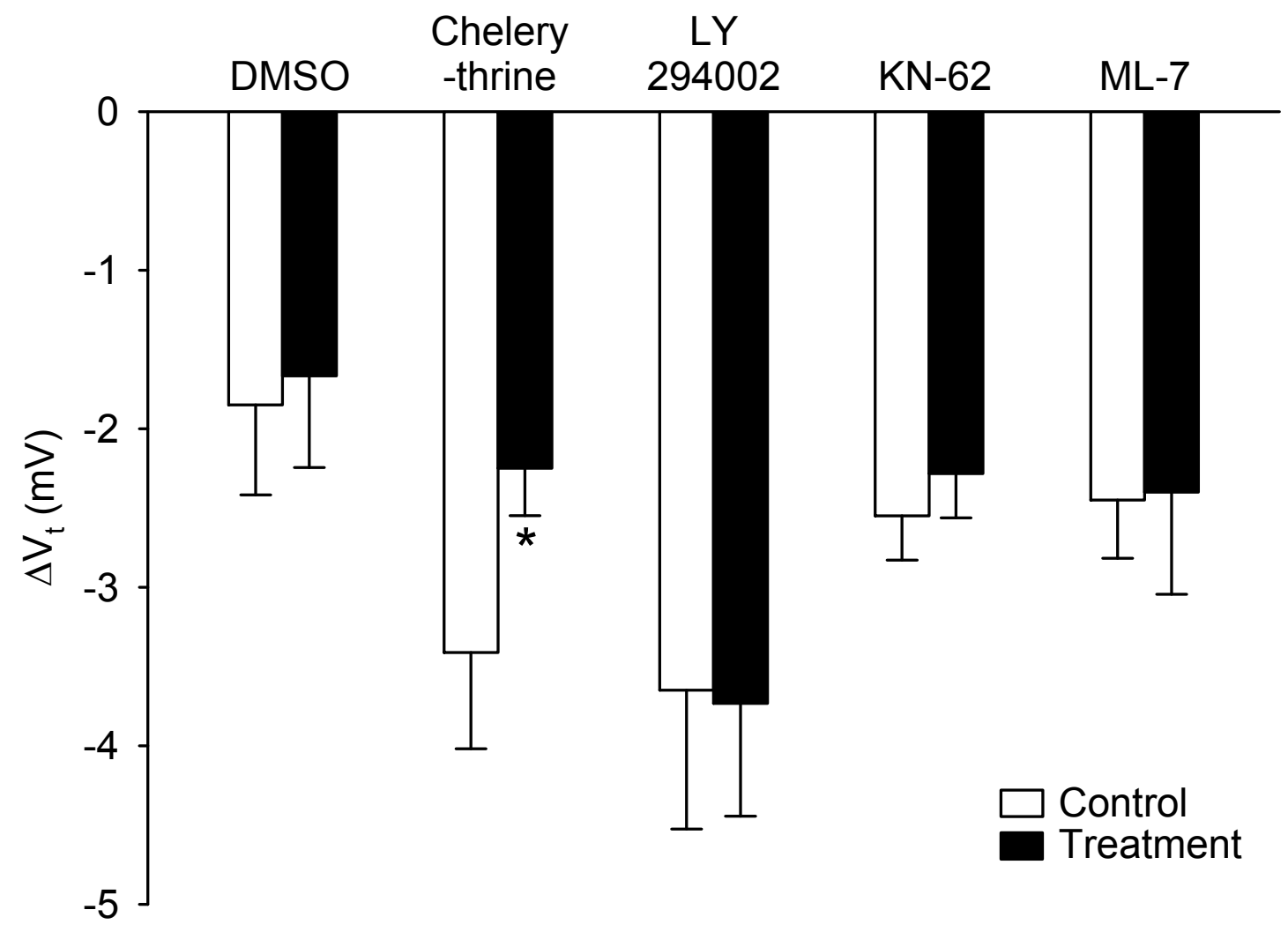

Fig. Cl-7. Effects of the kinase inhibitors on D-M-induced hyperpolarization. Chelerythrine $(n=8)$ inhibited the hyperpolarization responses. DMSO and the other inhibitors, LY 294002, KN-62 and ML-7 $(n=6)$ had no effect. ${ }^{*} p<0.05$. 


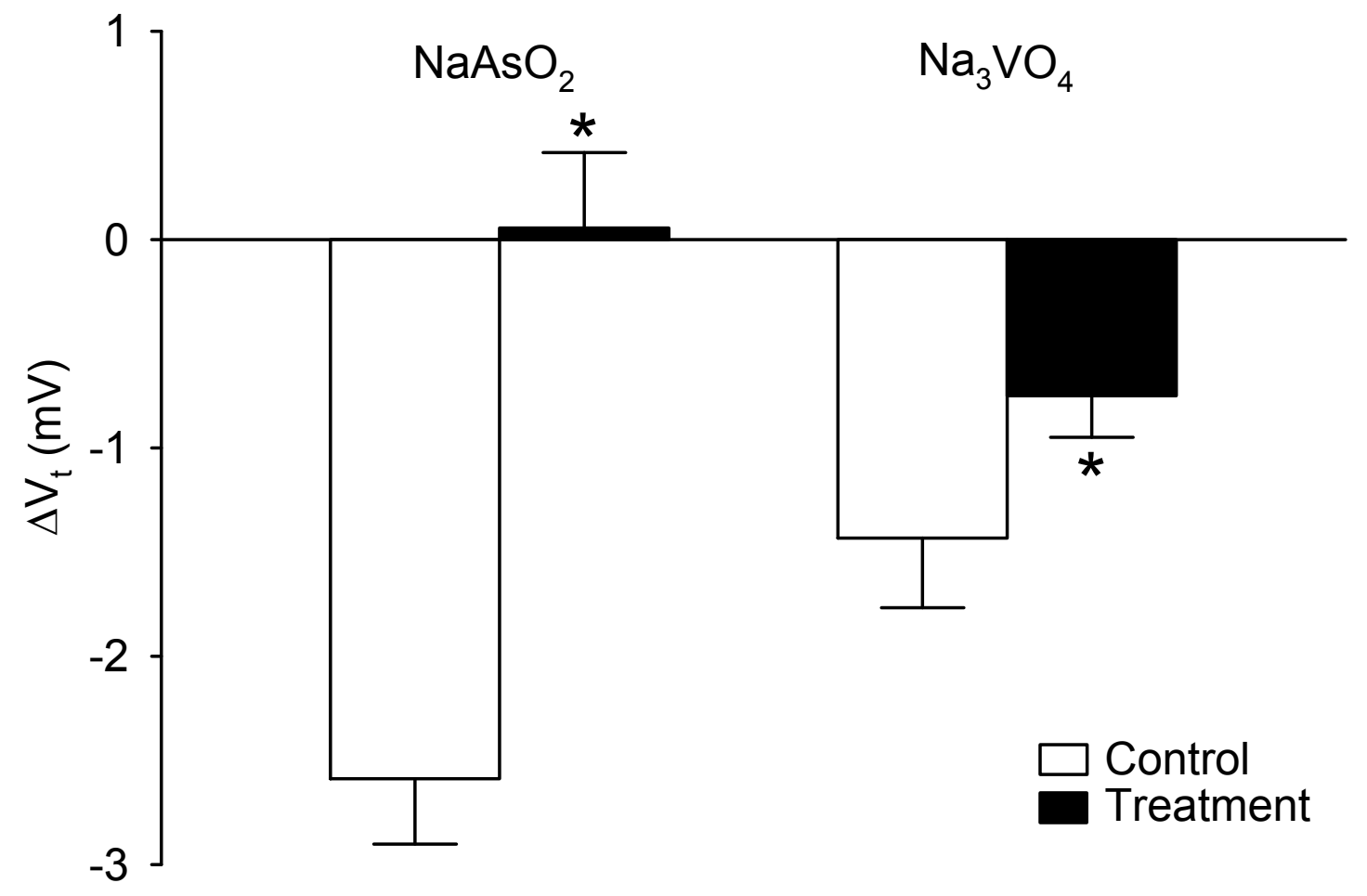

Fig. Cl-8. Effects of $\mathrm{NaAsO}_{2}$ and $\mathrm{Na}_{3} \mathrm{VO}_{4}$ on $\mathrm{D}$-M-induced hyperpolarization. Both $\mathrm{NaAsO}_{2}$ and $\mathrm{Na}_{3} \mathrm{VO}_{4}$ ( $n=9$ and 6, respectively) inhibited the hyperpolarization responses. The inhibition by $\mathrm{NaAsO}_{2}$ was complete. ${ }^{*} p<0.05$. 


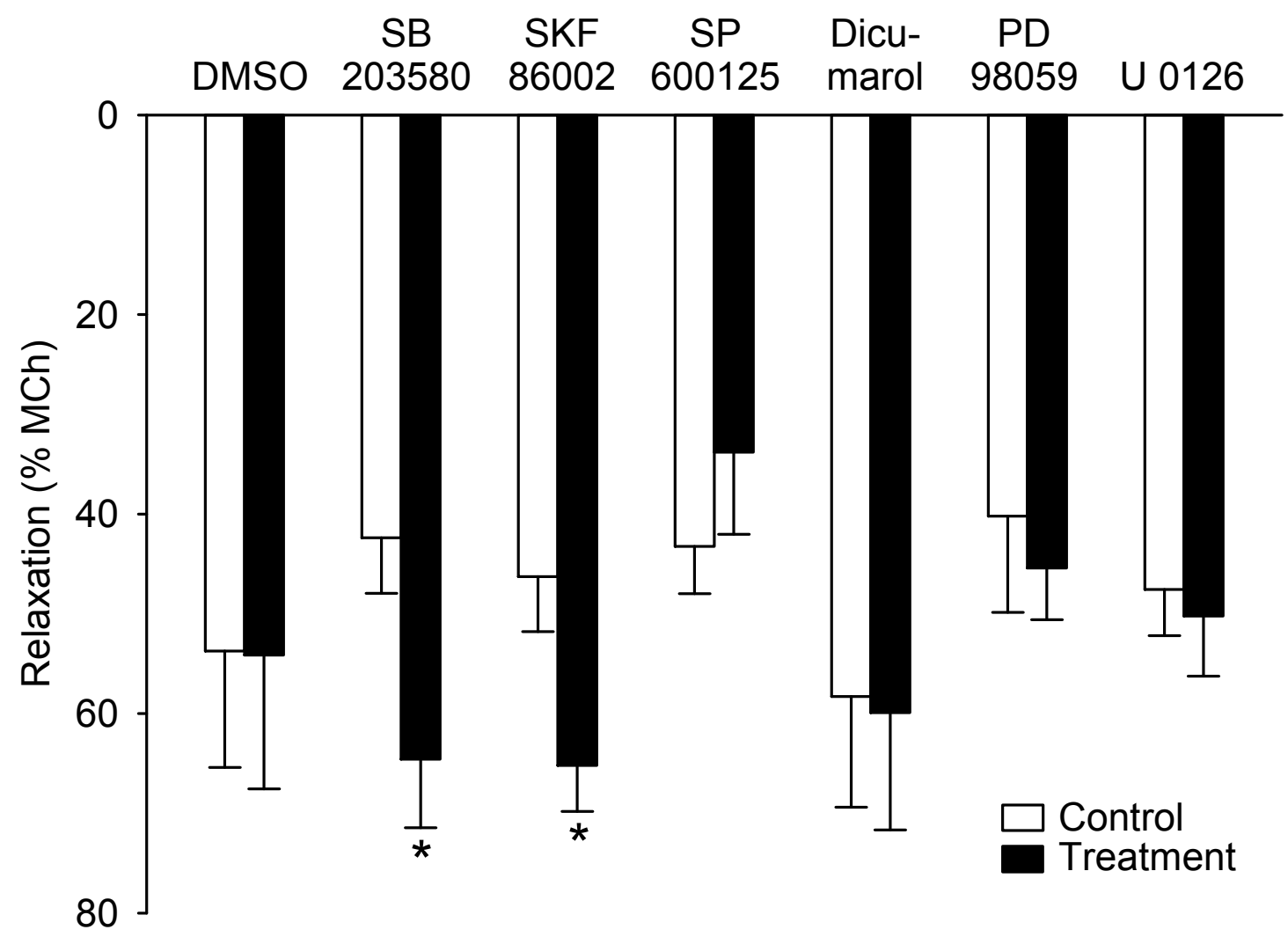

Fig. Cl-9. Effects of the MAP kinase inhibitors on D-M-induced airway relaxation. SB 203580 and SKF 86002 ( $n=7$ and 6, respectively) potentiated the relaxation responses. DMSO and the other inhibitors, SP 600125, dicumarol, PD 98059 and U 0126 ( $n=6,10,6,6$ and 6 , respectively) had no effect. * $p<0.05$. 


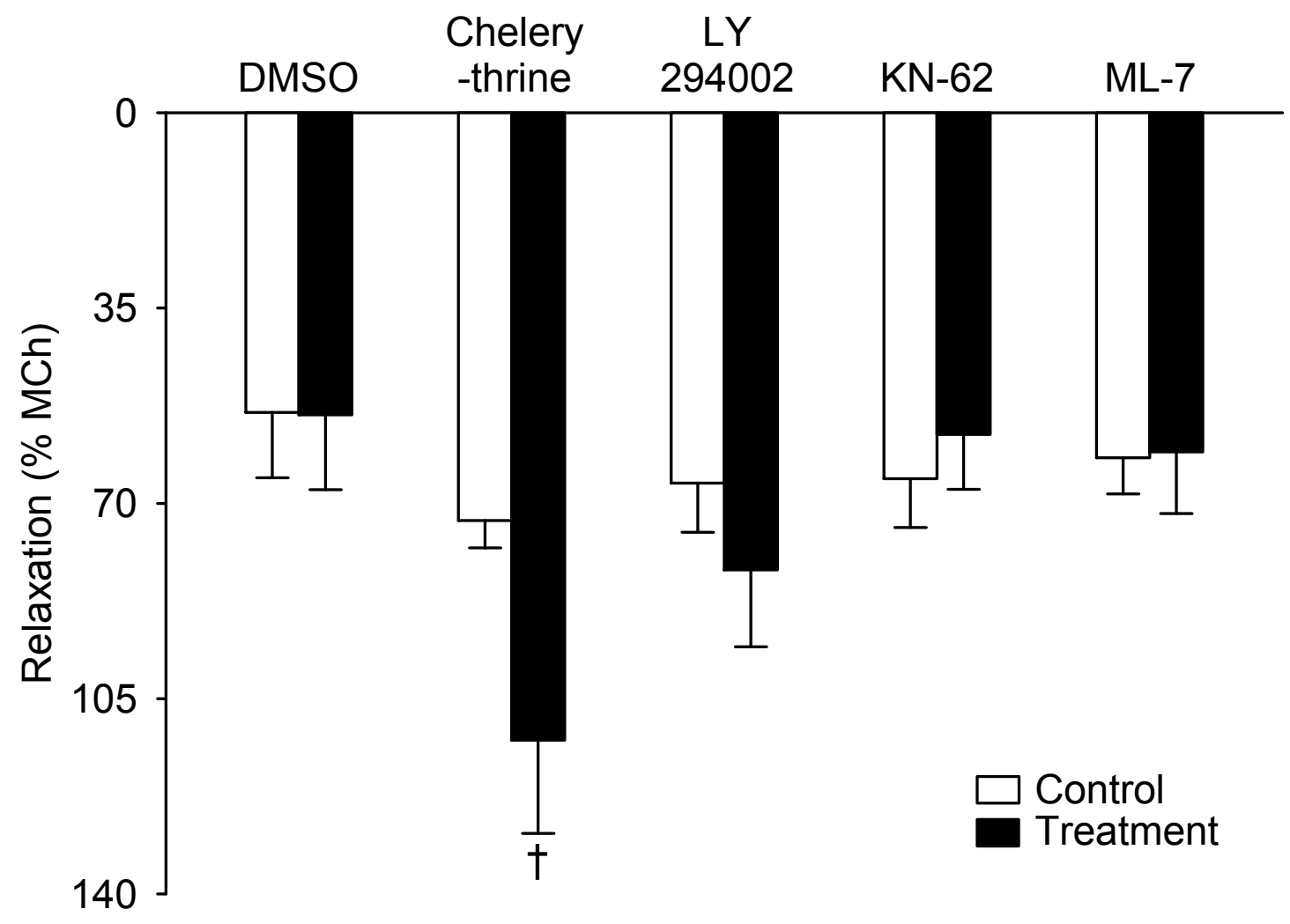

Fig. Cl-10. Effects of the kinase inhibitors on D-M-induced airway relaxation. DMSO and the kinase inhibitors, chelerythrine, LY 294002, KN-62 and ML-7 ( $n=$ $6,8,6,6$ and 6 , respectively) had no significant effect on the relaxation responses $(\dagger p=0.065)$. 


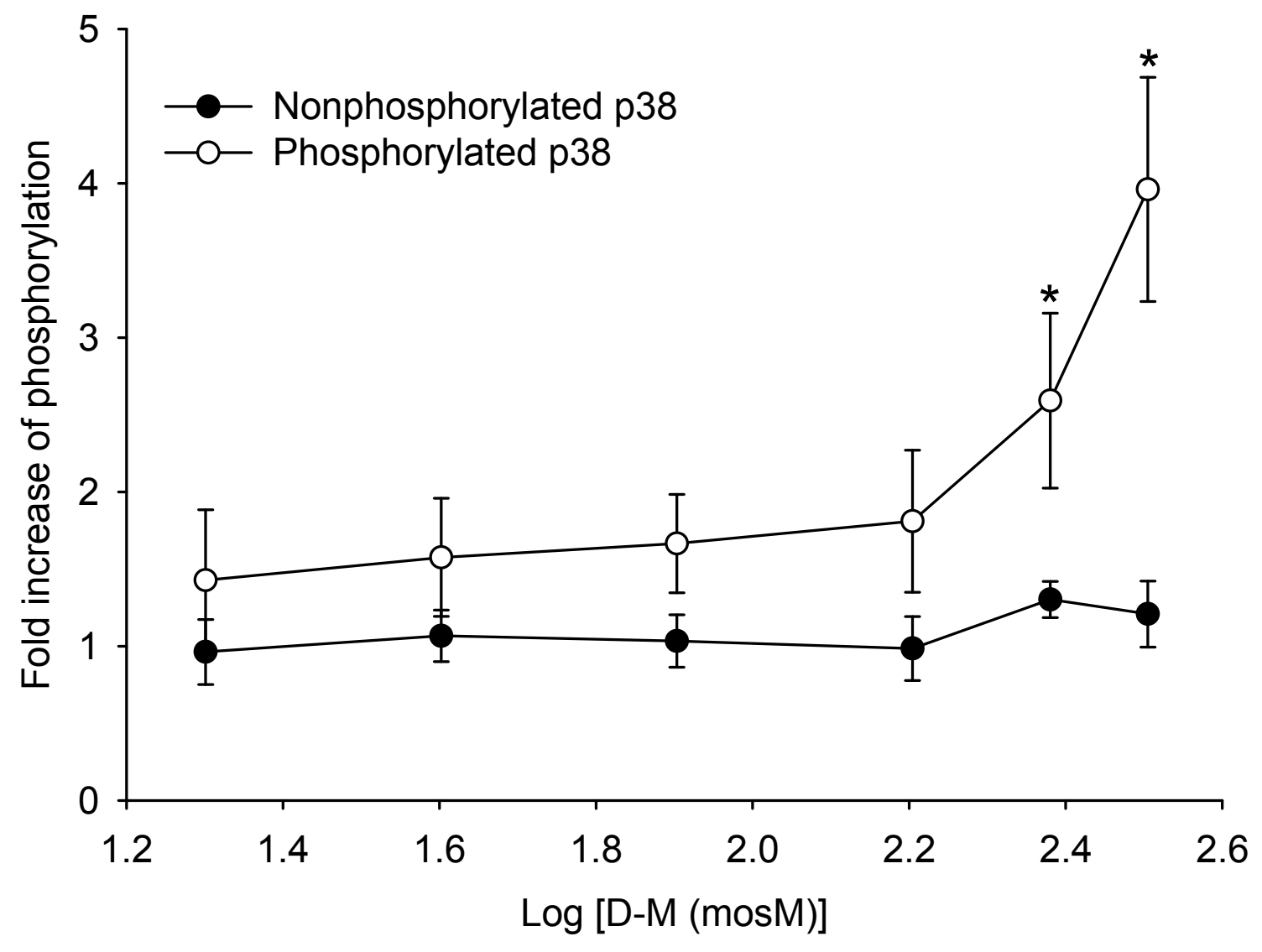

A

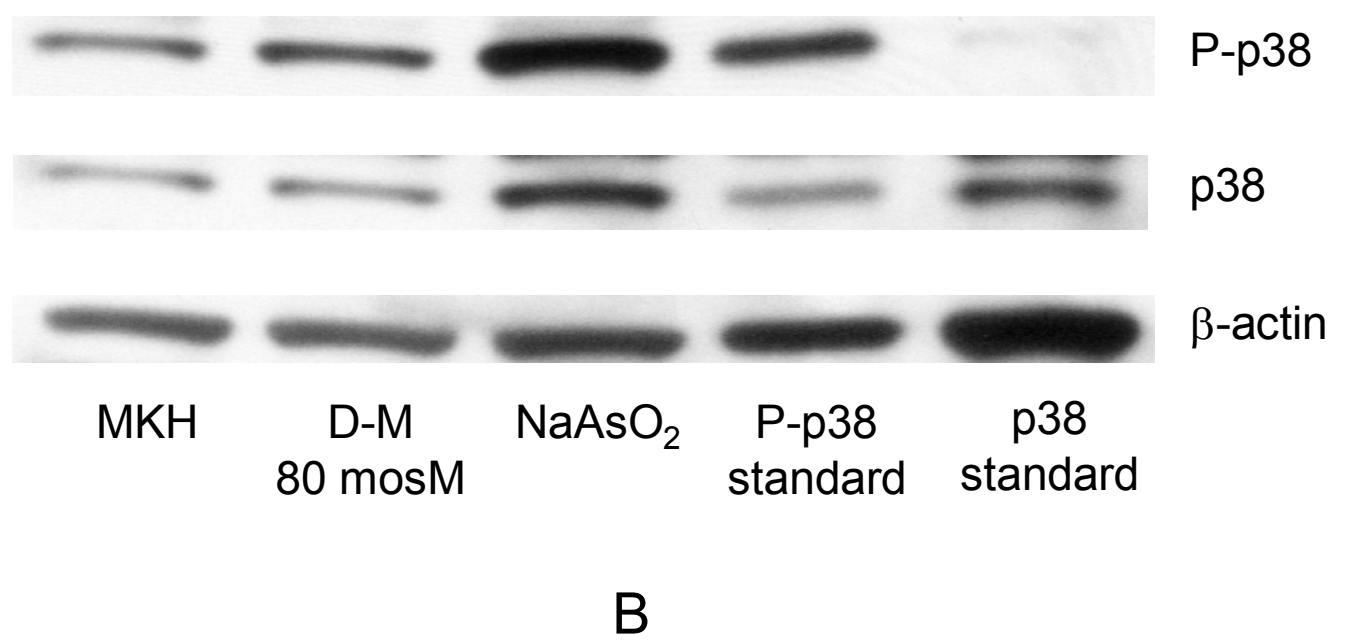


Fig. Cl-11. Phosphorylation of p38 induced by hyperosmolar D-M. (A) After exposing epithelia to D-M for 20 min the phosphorylation of p38 was increased in an osmolarity concentration-dependant manner, while the total amount of p38 was not affected. (B) Example of p38 phosphorylation induced by 80 mosM D-M. $\mathrm{NaAsO}_{2}$ not only induced p38 phosphorylation but also increased the total available p38 protein. $n=4$. 


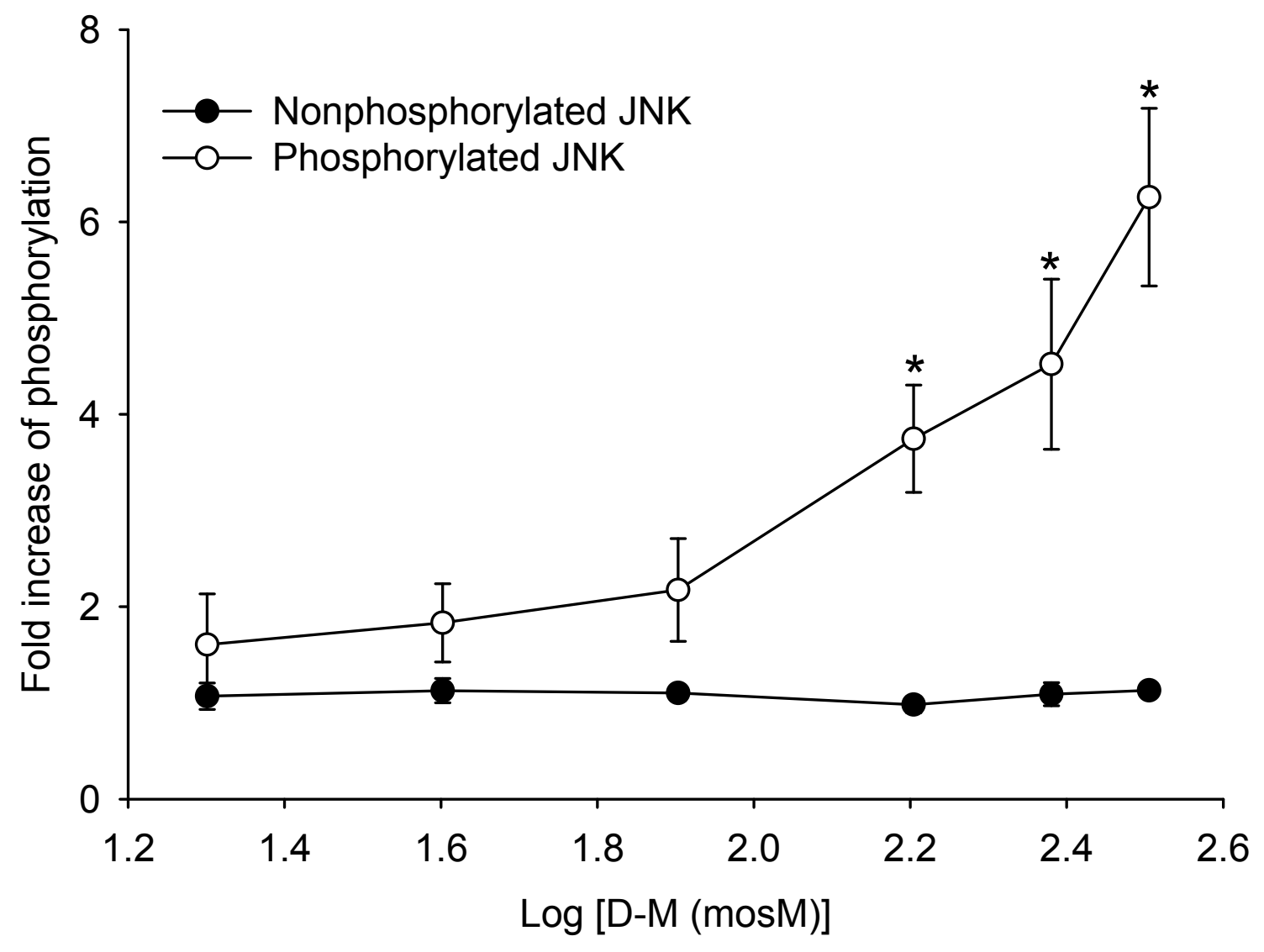

A

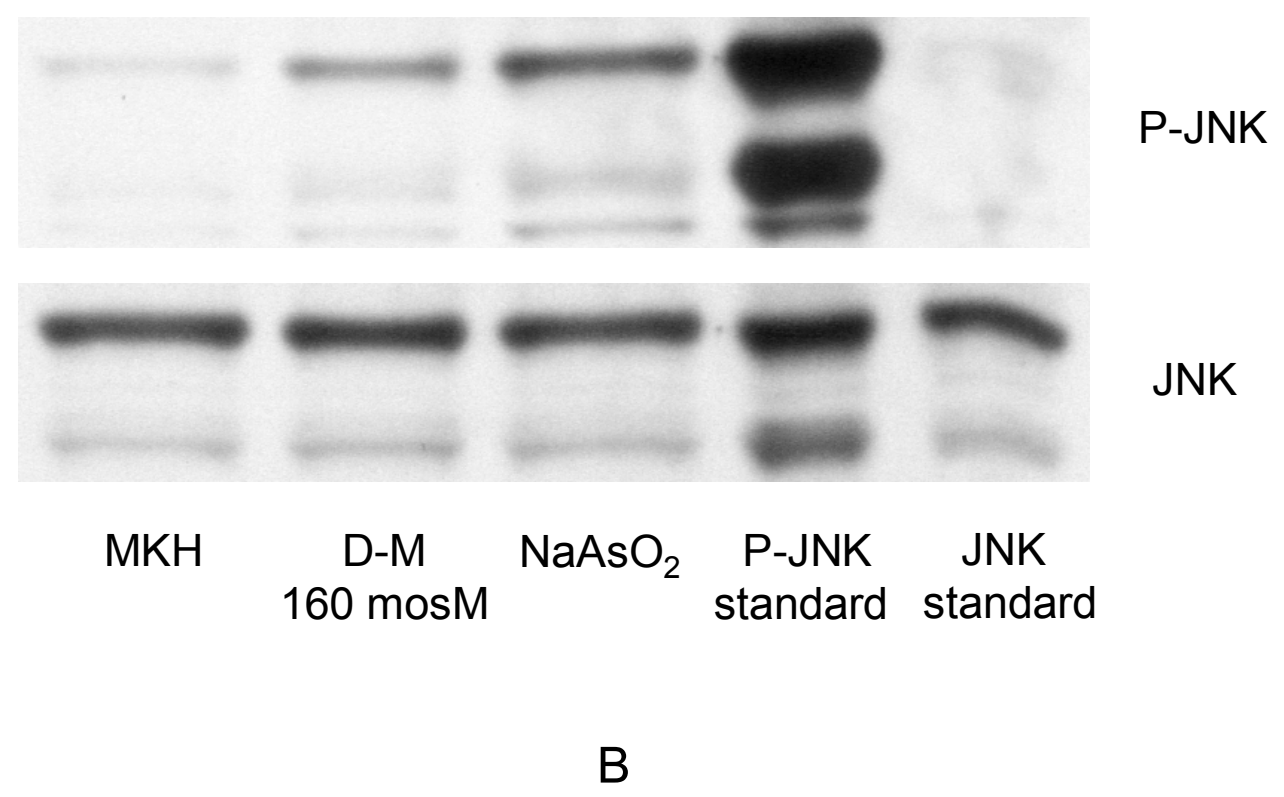


Fig. Cl-12. Phosphorylation of JNK induced by hyperosmolar D-M. (A) After exposing epithelia to D-M for 20 min the phosphorylation of JNK was increased in an osmolarity concentration-dependant manner, while the total amount of JNK was not affected. (B) Example of JNK phosphorylation induced by 160 mosM D-M. $\mathrm{NaAsO}_{2}$ induced $\mathrm{JNK}$ phosphorylation but the total available $\mathrm{JNK}$ protein was not increased. $n=4$. 
Table Cl-1. Effects of MAP kinase inhibitors on basal $V_{t}(\mathrm{mV})$ and $\triangle P\left(\mathrm{~cm} \mathrm{H}_{2} \mathrm{O}\right)$

\begin{tabular}{|c|c|c|c|c|c|c|}
\hline Target & \multicolumn{2}{|c|}{ p38 } & \multicolumn{2}{|c|}{ JNK } & \multicolumn{2}{|c|}{ ERK } \\
\hline Inhibitors & SB 203580 & SKF 86002 & SP 600125 & Dicumarol & PD 98059 & U 0126 \\
\hline $\operatorname{Conc}^{a}(\mu \mathrm{M})$ & 30 & 30 & 30 & 15 & 50 & 30 \\
\hline$n$ & 7 & 6 & 10 & 6 & 6 & 6 \\
\hline $\mathrm{V}_{\mathrm{t}}(\mathrm{mV})$ & $\begin{array}{c}\text { Depol }^{b} \\
0.8 \pm 0.3\end{array}$ & $-^{c}$ & - & - & - & - \\
\hline $\begin{array}{c}\triangle \mathrm{P} \\
\left(\mathrm{cm} \mathrm{H} \mathrm{H}_{2} \mathrm{O}\right)\end{array}$ & $\begin{array}{l}\text { Relaxation } \\
0.06 \pm 0.02\end{array}$ & - & - & $\begin{array}{l}\text { Relaxation } \\
0.46 \pm 0.13\end{array}$ & $\begin{array}{l}\text { Relaxation } \\
0.16 \pm 0.04\end{array}$ & - \\
\hline
\end{tabular}

${ }^{a}$ Concentration; ${ }^{b}$ Depolarization; ${ }^{c}$ No effect.

Table $\mathrm{Cl}$-2. Effects of other kinase inhibitors, $\mathrm{NaAsO}_{2}$ and $\mathrm{Na}_{3} \mathrm{VO}_{4}$ on basal $\mathrm{V}_{\mathrm{t}}(\mathrm{mV})$ and $\triangle \mathrm{P}\left(\mathrm{cm} \mathrm{H}_{2} \mathrm{O}\right)$

\begin{tabular}{|c|c|c|c|c|c|c|}
\hline Effects & $\begin{array}{c}\text { PKC } \\
\text { inhibitor }\end{array}$ & $\begin{array}{l}\text { PI-3-K } \\
\text { Inhibitor }\end{array}$ & $\begin{array}{l}\text { CaM-K-II } \\
\text { inhibitor }\end{array}$ & $\begin{array}{l}\text { MLCK } \\
\text { inhibitor }\end{array}$ & $\begin{array}{c}\text { Phosphatase } \\
\text { inhibitor }\end{array}$ & $\begin{array}{l}\text { Stress } \\
\text { inducer }\end{array}$ \\
\hline Agents & Chelerythrine & LY 294002 & $\mathrm{KN}-62$ & ML-7 & $\mathrm{Na}_{3} \mathrm{VO}_{4}$ & $\mathrm{NaAsO}_{2}$ \\
\hline $\operatorname{Conc}^{a}(\mu \mathrm{M})$ & 20 & 50 & 20 & 30 & 300 & 300 \\
\hline$n$ & 8 & 6 & 6 & 6 & 6 & 9 \\
\hline $\mathrm{V}_{\mathrm{t}}(\mathrm{mV})$ & $\begin{array}{c}\text { Depol }^{b} \\
1.53 \pm 0.29\end{array}$ & $\begin{array}{c}\text { Depol } \\
3.92 \pm 0.61\end{array}$ & $\begin{array}{c}\text { Depol } \\
0.47 \pm 0.14\end{array}$ & $\begin{array}{c}\text { Depol } \\
0.60 \pm 0.46\end{array}$ & $\begin{array}{c}\text { Hyperpol } \\
0.70 \pm 0.22\end{array}$ & $\begin{array}{l}\text { Hyperpol }^{C} \\
1.69 \pm 0.67\end{array}$ \\
\hline $\begin{array}{c}\triangle \mathrm{P} \\
\left(\mathrm{cm} \mathrm{H} \mathrm{H}_{2} \mathrm{O}\right)\end{array}$ & $\begin{array}{l}\text { Contraction } \\
0.22 \pm 0.06\end{array}$ & $-{ }^{d}$ & - & - & - & - \\
\hline
\end{tabular}

${ }^{a}$ Concentration; ${ }^{b}$ Depolarization; ${ }^{c}$ Hyperpolarization; ${ }^{d}$ No effect. 


\section{Chapter II}

\section{Epithelial Mechanisms in Airway Bioelectric and Mechanical Responses Induced by Hyperosmolarity: Studies on a Novel Tracheal Perfusion Apparatus}

Yi Jing, Janet A. Dowdy, Michael R. Van Scott and Jeffrey S. Fedan

Department of Biochemistry and Molecular Pharmacology, Robert C. Byrd Health Sciences Center, West Virginia University, Morgantown, West Virginia (Y.J., J.S.F.); Department of Physiology, The Brody School of Medicine, East Carolina University, Greenville, North Carolina (M.R.V.S.); and Pathology and Physiology Research Branch, Health Effects Laboratory Division, National Institute for Occupational Safety and Health, Morgantown, West Virginia (J.A.D., J.S.F.) 
Running title: Epithelial Mechanisms in Airway Responses to Hyperosmolarity

Corresponding author: Jeffrey S. Fedan, Health Effects Laboratory Division, National Institute for Occupational Safety and Health, 1095 Willowdale Road, Morgantown, WV 26505-2888. E-mail: jsf2@cdc.gov

Number of text pages: 32

Number of tables: 0

Number of figures: 10

Number of references: 44

Number of words in Abstract: 247

Number of words in Introduction: 699

Number of words in Discussion: 1533

Abbreviations: ASL, airway surface liquid; EpDRF, epithelium-derived relaxing factor; $V_{t}$, transepithelial potential; $R_{t}$, transepithelial resistance; $\triangle P$, inlet minus outlet perfusion pressure difference; MKH, modified Krebs-Henseleit; MCh, methacholine; D-M, D-mannitol; IL, intraluminal; EL, extraluminal.

Section assignment: Pulmonary 


\begin{abstract}
In the preceding study (Chapter I) we investigated the effects of kinase-interfering agents on hyperosmolar D-mannitol (D-M)-induced airway epithelial bioelectric response and smooth muscle relaxation mediated by epithelium-derived relaxing factor (EpDRF), using the tracheal perfusion apparatus. Some of the kinase and phosphatase inhibitors altered transepithelial potential $\left(V_{t}\right)$ responses. The release of EpDRF has been thought to be linked to epithelial ion transport. Because $V_{t}$ responses could result from changes in epithelial ion transport and/or transepithelial resistance $\left(R_{t}\right)$, to understand better the mechanism of EpDRF release we modified the tracheal perfusion apparatus so that $V_{t}, R_{t}$ and airway diameter changes could be monitored simultaneously. To validate the apparatus, selected ion transport inhibitors, bronchoactive agonists and osmolytes were examined for their specific pharmacological effects. The kinase-interfering agents that were observed previously to affect $V_{t}$ responses were subsequently examined. The protein kinase C (PKC) inhibitor, chelerythrine, inhibited $V_{t}$ responses to methacholine and D-M. The c-Jun N-terminal kinase (JNK) inhibitors, SP 600125 and dicumarol, the phosphatase inhibitor, $\mathrm{Na}_{3} \mathrm{VO}_{4}$, and the stress inducer, $\mathrm{NaAsO}_{2}$, altered $\mathrm{V}_{\mathrm{t}}$ responses as well as $\mathrm{R}_{\mathrm{t}}$. None of the kinase-interfering agents affected airway relaxation to D-M. The results indicate that this novel apparatus is useful for the study of airway pharmacology. PKC, JNK and phosphatase are involved in the regulation of epithelial ion transport. The permeability of tight junctions could be regulated by protein phosphorylation.
\end{abstract}


Evidence was not obtained to suggest that the bioelectric and mechanical responses to $\mathrm{D}-\mathrm{M}$ are regulated by a common kinase signaling pathway. 


\section{Introduction}

Hyperventilation during exercise is thought to cause evaporative dehydration and hyperosmolarity of the airway surface liquid (ASL) (Anderson and Daviskas, 2000). In a canine model the elevation of osmolarity in the ASL reached 130 mosM during and 40 mosM shortly after hyperventilation of dry air (Freed and Davis, 1999). The airway epithelium can detect an increase in osmolarity of the ASL and modulate the underlying smooth muscle tone by releasing epithelium-derived relaxing factor (EpDRF) (Munakata et al., 1988; Fedan et al., 1999). The EpDRF-mediated airway relaxation could contribute to bronchodilation during exercise. However, in asthmatic patients inhalation of mannitol dry powder to elevate the osmolarity of the ASL elicits airway obstruction (Anderson et al., 1997a; Brannan et al., 1998), indicating that the mechanism of hyperosmolarity-induced EpDRF release could be altered. In the bronchial epithelium of asthmatic patients altered protein tyrosine phosphorylation has been reported (Hamilton et al., 2005).

Exercise-induced airway obstruction is a highly prevalent disorder among asthmatics (Cabral et al., 1999; Hallstrand et al., 2002). Asthma is considered as an airway chronic inflammatory disease characterized by hyperractivity to a variety of environmental stimuli and periodic episodes of airflow obstruction

caused by airway spasm (Hamilton et al., 2001; Elias et al., 2003). The inflammation results in inflammatory cell infiltration, smooth muscle proliferation, and epithelial damage and shedding (Homer and Elias, 2005; Hallstrand et al., 
2005a). Epithelial damage would expose the underlying smooth muscle to contractile mediators during hyperventilation (Brannan et al., 2003; Anderson and Kippelen, 2005; Anderson, 2006), and disrupt the EpDRF-mediated airway relaxation in response to hyperosmolar challenge (Fedan et al., 2004a).

Using the guinea-pig isolated, perfused trachea apparatus we previously observed that relaxation responses to hyperosmolarity were inhibited by blockers of epithelial $\mathrm{Na}^{+}$and $\mathrm{Cl}^{-}$channels (Fedan et al., 1999). While simultaneously monitoring both transepithelial potential $\left(\mathrm{V}_{\mathrm{t}}\right)$ and airway diameter, we observed that the epithelial bioelectric responses to hyperosmolar solution occurred before the relaxation responses (Dortch-Carnes et al., 1999). These findings suggested that the bioelectric events may initiate the release of EpDRF. Recent concentration-dependence studies (Chapter I) using D-mannitol (D-M) to elevate osmolarity in the tracheal lumen revealed that the relaxation response was nearly maximal at 80 mosM and was accompanied by a hyperpolarization response at and below this concentration. At higher D-M concentrations maximal relaxation was achieved, but $\mathrm{V}_{\mathrm{t}}$ decreased.

Because hyperosmolar challenge of many cells stimulates activation of mitogen-activated protein (MAP) kinase pathways, p38, c-Jun $\mathrm{N}$-terminal kinase (JNK) and extracellular-regulated kinase (ERK) (Hashimoto et al., 1999; Duzgun et al., 2000), and production of epithelium-derived mediators as well as cell volume-related ion transport in response to hyperosmolarity are regulated by stress-sensitive protein kinases (Shrode et al., 1998; Furuichi et al., 2002), the 
roles of these MAP kinases as well as some other signaling pathways in the response to D-M were examined (Chapter I). Using kinase-interfering agents we found that protein kinase $C(P K C)$, phosphatidylinositol 3-kinase (PI-3-K), calmodulin kinase-II (CaM-K-II), myosin light chain kinase (MLCK) and protein-phosphotyrosine phosphatases may play a role in the regulation of basal $V_{\text {t. }}$ In addition, some of these agents, particularly those targeting PKC, JNK and phosphatases, modified the $V_{t}$ responses to D-M. Such changes could have originated from alterations in epithelial ion transport and/or from alterations of the transepithelial resistance $\left(R_{t}\right)$, i.e., the permeability of paracellular pathway across tight junctions (Tsukita et al., 2001).

To understand better whether kinase-modifying agents affected bioelectric responses to hyperosmolarity by altering epithelial ion transport or $\mathrm{R}_{\mathrm{t}}$, we further modified the tracheal perfusion apparatus so as to be able to measure $V_{t}, R_{t}$ and mechanical responses of the trachea simultaneously. To validate the apparatus, we examined the effects of well-characterized ion channel blockers, ion pump and cotransporter inhibitors, bronchoactive agonists and osmolytes. The objectives of this study were: 1) to evaluate the performance of this novel perfusion apparatus with four categories of the selected pharmacological agents and to study the relationship between their bioelectric and mechanical effects on airways; and 2) to examine the effects of the JNK inhibitors, SP 600125 and dicumarol, the PKC inhibitor, chelerythrine, the stress inducer, $\mathrm{NaAsO}_{2}$ and the phosphatase inhibitor, $\mathrm{Na}_{3} \mathrm{VO}_{4}$. These agents were observed in our previous study to alter basal $\mathrm{V}_{t}$ and 
$V_{t}$ responses induced by hyperosmolar challenge (Chapter $I$ ). 


\section{Materials and Methods}

Animals. These studies were conducted in facilities accredited fully by the Association for the Assessment and Accreditation of Laboratory Animal Care International and were approved by the institutional Animal Care and Use Committee. Male guinea pigs (550 - 700 g), HsdPoc:DH, from Harlan (Indianapolis, IN), monitored free of endogenous viral pathogens, parasites, and bacteria were used in all experiments. The animals were acclimated before use and were housed in filtered ventilated cages on Alpha-Dri virgin cellulose chips and hardwood Beta-chips as bedding, provided HEPA-filtered air, Teklad 7006 diet and tap water ad libitum, under controlled light cycle (12 h light) and temperature $\left(22-25^{\circ} \mathrm{C}\right)$ conditions. The animals were anesthetized with sodium pentobarbital (65 mg/kg, i.p.) and sacrificed by thoracotomy and bleeding before removing the trachea.

Materials. Modified Krebs-Henseleit $(\mathrm{MKH})$ solution $\left(\mathrm{pH} 7.4\right.$ at $\left.37{ }^{\circ} \mathrm{C}\right)$ contained $113 \mathrm{mM} \mathrm{NaCl}, 4.8 \mathrm{mM} \mathrm{KCl}, 2.5 \mathrm{mM} \mathrm{CaCl}_{2}, 1.2 \mathrm{mM} \mathrm{KH}{ }_{2} \mathrm{PO}_{4}, 1.2 \mathrm{mM}$ $\mathrm{MgSO}_{4}, 25 \mathrm{mM} \mathrm{NaHCO}_{3}$ and $5.7 \mathrm{mM}$ glucose was saturated with $95 \% \mathrm{O}_{2}$ and $5 \%$ $\mathrm{CO}_{2}$. The osmolarity of MKH solution was $281 \pm 5$ mosM.

Acetyl- $\beta$-methylcholine chloride (methacholine, MCh), dimethyl sulphoxide (DMSO), amiloride, 5-nitro-2-(3-phenylpropylamino) benzoic acid (NPPB), ouabain, bumetanide, histamine, terbutaline, $\mathrm{NaCl}$ and $\mathrm{D}-\mathrm{M}$ were purchased from Sigma-Aldrich (St. Louis, MO). Stock solutions of MCh and D-M were prepared in saline. Amiloride, NPPB and bumetanide were dissolved in DMSO (final 
concentration, $0.01 \%)$. Other agents were prepared in $\mathrm{MKH}$. Hyperosmolar solutions were prepared by adding osmolytes to the MKH solution.

SP 600125, dicumarol and chelerythrine were purchased from Calbiochem-Novabiochem (La Jolla, CA) and dissolved in DMSO (final concentration, $0.01 \%) \cdot \mathrm{NaAsO}_{4}$ and $\mathrm{Na}_{3} \mathrm{VO}_{4}$ were obtained from Mallinckrodt Laboratory Chemicals (Phillipsburg, NJ) and Sigma-Aldrich (St. Louis, MO), respectively, and prepared in MKH solution.

Tracheal Perfusion Preparation. The preparation was further modified from the perfused trachea apparatus employed in the previous study (Chapter I) by adding current electrodes mounted across the tracheal wall to deliver current pulses so that $R_{t}$ could be calculated. A 4.2-cm segment of guinea-pig trachea was removed and mounted at its natural length onto a custom-designed plastic perfusion holder which allows cannulas with side-opening holes to be inserted into the lumen from either end of the trachea. The tracheal holder was placed into an extraluminal (EL) bath filled with MKH solution. The tracheal lumen was perfused at constant flow $(24 \mathrm{ml} / \mathrm{min})$ with $\mathrm{MKH}$ solution from another bath, referred to as the intraluminal (IL) bath. The transmural pressure was adjusted to zero. MKH solution in the IL and EL baths was kept at $37{ }^{\circ} \mathrm{C}$ and saturated with $95 \% \mathrm{O}_{2}$ and $5 \% \mathrm{CO}_{2}$. Agents may be added separately to the IL or EL baths so that they can act directly on epithelia or airway smooth muscle, respectively. The inlet minus outlet perfusion pressure difference $(\triangle P)$ caused by tracheal diameter change was sampled through side-holes in the indwelling cannulas which were connected 
to a differential pressure transducer. Airway smooth muscle contraction decreases tracheal diameter and increases $\triangle P$, whereas $\triangle P$ decreases during relaxation. Current and voltage electrodes (filled with $4 \%$ agar/saline) were connected to the lumen and EL sides of the trachea. Current pulses $(20 \mu \mathrm{A}, 5 \mathrm{~s}$ duration and $50 \mathrm{~s}$ interval) were delivered through current electrodes, while $V_{t}$ and the voltage deflections caused by the current pulses, were monitored under open-circuit conditions. Because the current pulse was delivered from a point source, the field of current is not evenly distributed to the whole surface area of epithelium; therefore, the value of $R_{t}$ measured with this method is not connected for unit area, as measured with the Ussing apparatus. In the present study $R_{t}$ was assessed as changes in $R_{t}\left(\triangle R_{t}\right)$ before and after a treatment. $R_{t}$ was calculated from the voltage responses caused by $20 \mu \mathrm{A}$ pulses using Ohm's law.

Effects of Ion Transport Inhibitors, Bronchoactive Agonists and Osmolytes on $\mathbf{V}_{\mathbf{t}}, \triangle \mathbf{P}$ and $\mathbf{R}_{\mathbf{t}}$. The tracheal preparations were equilibrated by perfusing MKH solution for a $2.5-3 \mathrm{~h}$ period to allow stabilization of basal $\mathrm{V}_{\mathrm{t}}$ and $\triangle \mathrm{P}$; then current pulses were delivered. Agents dissolved either in DMSO or MKH were added to the IL or EL bath, as appropriate. Relaxation responses were elicited after the tracheas had first been precontracted with $\mathrm{EL} 3 \times 10^{-7} \mathrm{M} \mathrm{MCh}$ and reached the plateau. Because $240 \operatorname{mosM~NaCl}$ and D-M added to the perfusing MKH solution elicited depolarization and relaxation of the airways (Dortch-Carnes et al., 1999), and added 294 mosM NaCl caused an increase of tight junction permeability in airway epithelium (Hogman et al., 2002), 300 mosM NaCl and D-M 
were used as osmolytes in this study to evaluate the performance of the apparatus.

Effects of Kinase Inhibitors, $\mathrm{NaAsO}_{2}$ and $\mathrm{Na}_{3} \mathrm{VO}_{4}$ on $\mathrm{V}_{\mathrm{t}}, \mathrm{R}_{\mathrm{t}}$ and $\triangle P$ Responses Induced by Hyperosmolar D-M. To reduce variability, the control responses and responses obtained in the presence of agents were obtained successively from the same trachea, i.e., a paired design was employed. After perfusing the trachea with MKH solution for a $2.5-3 \mathrm{~h}$ period to stabilize basal $\mathrm{V}_{\mathrm{t}}$ and $\triangle P$, current pulses were delivered. To obtain control responses the trachea was incubated with vehicle (DMSO or MKH) for 30 min in the IL bath, and then exposed to MCh in the EL bath. When the MCh-induced contraction and hyperpolarization responses reached their plateaus, the osmolarity of IL perfused MKH solution was elevated by adding 30 mosM D-M $\left(\sim E_{50}\right)$ to induce relaxation. D-M also caused hyperpolarization at this concentration. After the D-M-induced $V_{t}$ and $\triangle P$ responses reached their plateaus, the trachea was washed with fresh $\mathrm{MKH}$ solution to allow the $\mathrm{V}_{\mathrm{t}}$ and $\triangle \mathrm{P}$ recover to their basal levels.

Ninety min after the $V_{t}$ and $\triangle P$ baselines were re-established, the trachea was incubated with an agent in the IL bath for $30 \mathrm{~min}$. Then the trachea was exposed to EL MCh and challenged with IL D-M again in the presence of the agent. To evaluate whether changes occurred in responses to MCh and D-M in these two cycles, control experiments using tracheas exposed only to DMSO were run in parallel.

Data Analysis. $V_{t}$ was quantified in $\mathrm{mV}$. $\mathrm{R}_{\mathrm{t}}$ was quantified in Ohms. The 
magnitude of $V_{t}$ responses induced by MCh and D-M are presented as changes in $V_{t}\left(\triangle V_{t}\right)$ before and after exposure to the agents; likewise, $\triangle R_{t}$ was also calculated. Airway contraction and relaxation responses were measured as changes in $\triangle P$, in $\mathrm{cm} \mathrm{H}_{2} \mathrm{O}$. Values are presented as means $\pm S E$. Differences were analyzed statistically using Student's paired t-test. $p<0.05$ was considered significant. 


\section{Results}

At the conclusion of the $2.5-3 \mathrm{~h}$ equilibration in $\mathrm{MKH}$ solution, basal $\mathrm{V}_{\mathrm{t}}$ was $14.8 \pm 0.8 \mathrm{mV}(n=32)$.

Effects of Amiloride and NPPB on $\mathbf{V}_{t}, \mathbf{R}_{\mathbf{t}}$ and $\triangle P$. IL-applied $\mathrm{Na}^{+}$and $\mathrm{Cl}^{-}$ channel blockers, amiloride $\left(3 \times 10^{-5} \mathrm{M}\right)$ and NPPB $\left(10^{-4} \mathrm{M}\right)$, respectively, decreased $V_{t}$. The effect of amiloride was immediate, and the effect of NPPB was slower to develop and gave rise to a larger depolarization (Fig. Cll-1A). Amiloride caused small but significant increase in $R_{t}$, while NPPB had no effect (Fig. CII-1B). Both amiloride and NPPB had no effect on $\triangle P(n=4$, data not shown).

Effects of Ouabain and Bumetanide on $V_{t}, R_{t}$ and $\triangle P$. Applied to the $E L$ bath, the $\mathrm{Na}^{+}-\mathrm{K}^{+}$-pump inhibitor, ouabain $\left(10^{-5} \mathrm{M}\right)$, and the $\mathrm{Na}^{+}-\mathrm{K}^{+}-2 \mathrm{Cl}^{-}$ cotransporter inhibitor, bumetanide $\left(10^{-5} \mathrm{M}\right)$, decreased $\mathrm{V}_{\mathrm{t}}$. Ouabain caused an immediate depolarization, decrease in $\mathrm{R}_{\mathrm{t}}$ and a delayed contraction; it completely depolarized the epithelium. Bumetanide caused a slight relaxation (Fig. CII-2A). The depolarization caused by bumetanide was relatively small, and it did not affect $R_{t}$ (Fig. CII-2B).

Effects of Histamine and Terbutaline on $V_{t}, R_{t}$ and $\triangle P$. EL-applied

histamine $\left(7.4 \times 10^{-5} \mathrm{M}\right)$ and terbutaline $\left(10^{-7} \mathrm{M}\right)$, an $\mathrm{H}_{1}$-receptor agonist and a $\beta_{2}$-receptor agonist, respectively, caused contraction and relaxation (Fig. CII-3A). Both histamine and terbutaline caused variable and small changes in $V_{t}$; on average, they did not affect $V_{t}$ appreciably. Both agonists had no effect on $R_{t}$ (Figs. CII-3A and CII-3B). 
Effects of Hyperosmolarity on $V_{t}, R_{t}$ and $\triangle P$. Hyperosmolarity elicited with IL NaCl and D-M (300 mosM each) caused relaxation and depolarization (Figs. CII-4A and CII-4B). NaCl decreased $R_{t}$, while D-M increased $R_{t}$ (Fig. CII-4B).

Effects of DMSO, SP 600125, Dicumarol, Chelerythrine, $\mathrm{NaAsO}_{2}$ and $\mathrm{Na}_{3} \mathrm{VO}_{4}$ on Basal $\mathrm{V}_{\mathrm{t}}, \mathbf{R}_{\mathrm{t}}$ and $\triangle \mathrm{P}$, and Their Responses Induced by MCh and Hyperosmolar D-M.

Baseline effects on $V_{t}, R_{t}$ and $\triangle P$. DMSO (0.04\%) and the JNK inhibitors, SP $600125(30 \mu \mathrm{M})$ and dicumarol $(15 \mu \mathrm{M})$, had no effect on basal $\mathrm{V}_{\mathrm{t}}$. The PKC inhibitor, chelerythrine $(20 \mu \mathrm{M})$, decreased basal $V_{t}$ by $1.45 \pm 0.40 \mathrm{mV}$. The phosphatase inhibitor, $\mathrm{Na}_{3} \mathrm{VO}_{4}(300 \mu \mathrm{M})$, increased basal $\mathrm{V}_{\mathrm{t}}$ by $2.58 \pm 0.21 \mathrm{mV}$. The stress inducer, $\mathrm{NaAsO}_{2}(300 \mu \mathrm{M})$, caused a transient increase in $\mathrm{V}_{t}$ followed by a decrease; it also caused a $36.1 \pm 8.9 \Omega$ increase in $R_{t}$. Dicumarol decreased basal $\triangle P$ by $0.46 \pm 0.13 \mathrm{~cm} \mathrm{H}_{2} \mathrm{O}$. DMSO and the other agents had no effect on $R_{t}$ and $\triangle P(n=6$, data not shown $)$.

Effects of DMSO on MCh- and D-M-induced $V_{t}$ and $R_{t}$ responses. To evaluate if DMSO had any effect, control experiments were performed to examine whether it alters $\mathrm{MCh}$ - and $\mathrm{D}-\mathrm{M}$-induced $\mathrm{V}_{\mathrm{t}}$ and $\mathrm{R}_{\mathrm{t}}$ responses. At a concentration of $0.04 \%$, DMSO had no effect on MCh- and D-M-induced hyperpolarization (Figs. CII-5A and CII-5C); it also had no effect on $R_{t}$ (Figs. CII-5B and CII-5D).

Effects of SP 600125 on MCh- and D-M-induced $V_{t}$ and $R_{t}$ responses. SP 600125 potentiated MCh-induced hyperpolarization (Fig. CII-6A), and there was 
no significant change in $R_{t}$ (Fig. Cll-6B), indicating the observed $V_{t}$ responses were caused primarily by increased epithelial ion transport. SP 600125 inhibited D-M-induced hyperpolarization (Fig. ClI-6C). It also caused a decrease in $\mathrm{R}_{t}$ (Fig. CII-6D). Because both decreases in $R_{t}$ and epithelial ion transport could lead to the inhibition of $\mathrm{D}$-M-induced hyperpolarization, the changes in $V_{t}$ and $R_{t}$ responses were normalized as percentage changes. The $\% \triangle V_{t}$ and $\% \triangle R_{t}$ were $11.8 \pm 1.9$ and $8.0 \pm 3.5$, respectively, and were not significantly different. Therefore, the inhibition of D-M-induced hyperpolarization in the presence of SP 600125 may be attributable to an increase in tight junction permeability.

Effects of dicumarol on MCh- and D-M-induced $V_{t}$ and $R_{t}$ responses. Dicumarol potentiated MCh-induced hyperpolarization responses (Fig. Cll-7A), and there was no change in $\mathrm{R}_{t}$ (Fig. Cll-7B), indicating that a stimulation of ion transport was the cause of the observed $V_{t}$ responses. Dicumarol inhibited D-M-induced hyperpolarization (Fig. CII-7C), and caused a decrease in $\mathrm{R}_{t}$ (Fig. Cll-7D). Bacause the $\% \triangle V_{t}$ and $\% \triangle R_{t}$ induced by D-M were $14.09 \pm 4.21$ and $6.83 \pm 1.55$, respectively, and were not significantly different, the inhibition of D-M-induced hyperpolarization in the presence of dicumarol was probably not attributable to a decrease in ion transport.

Effects of chelerythrine on MCh- and D-M-induced $V_{t}$ and $R_{t}$ responses. Chelerythrine inhibited MCh- and D-M-induced hyperpolarization responses (Figs. CII-8A and CII-8C), and it had no effect on $R_{t}$ (Figs. Cll-8B and CII-8D). The results suggest that the inhibited $V_{t}$ responses in the presence of chelerythrine 
were caused primarily by a decrease in ion transport.

Effects of $\mathrm{NaAsO}_{2}$ on MCh- and D-M-induced $V_{t}$ and $R_{t}$ responses. $\mathrm{NaAsO}_{2}$ had a considerable but not significant inhibitory effect $(p=0.056)$ on MCh-induced hyperpolarization responses (Fig. Cll-9A). At the same time, its effect on $R_{t}$ was not significant (Fig. Cll-9B). $\mathrm{NaAsO}_{2}$ completely inhibited D-M-induced hyperpolarization (Fig. Cll-9C); it also decreased $R_{t}$ (Fig. Cll-9D). The $\% \triangle V_{t}$ and $\% \triangle R_{t}$ of the $D-M$-induced responses were $15.6 \pm 2.5$ and $9.6 \pm$ 2.2, respectively, and were not significantly different. Therefore, the significant inhibition of D-M-induced hyperpolarization in the presence of $\mathrm{NaAsO}_{2}$ was primarily caused by the decreased $\mathrm{R}_{\mathrm{t}}$, and cannot be attributed to a decrease in epithelial ion transport.

Effects of $\mathrm{Na}_{3} \mathrm{VO}_{4}$ on MCh- and D-M-induced $V_{t}$ and $R_{t}$ responses. $\mathrm{Na}_{3} \mathrm{VO}_{4}$ inhibited MCh-induced hyperpolarization responses (Fig. CII-10A), and caused a decrease in $R_{t}$ (Fig. Cll-10B). Because the $\% \triangle V_{t}$ and $\% \triangle R_{t}$ were $9.82 \pm 2.19$ and $9.50 \pm 3.56$, respectively, and were not significantly different, the equivalent changes in $\% \triangle V_{t}$ and $\% \triangle R_{t}$ suggest that the inhibition of MCh-induced hyperpolarization in the presence of $\mathrm{Na}_{3} \mathrm{VO}_{4}$ was caused by the decreased $\mathrm{R}_{\mathrm{t}}$. $\mathrm{Na}_{3} \mathrm{VO}_{4}$ inhibited D-M-induced hyperpolarization responses (Fig. Cll-10C), and there was no significant change in $R_{t}$ (Fig. Cll-10D), indicating that the inhibited $V_{t}$ response in the presence of $\mathrm{Na}_{3} \mathrm{VO}_{4}$ was caused by a decrease in ion transport.

Effects of the agents on MCh- and D-M-induced $\triangle P$ responses. DMSO and all the kinase-interfering agents had no effect on MCh- and D-M-induced $\triangle P$ 
responses ( $n=6$, data not shown). 


\section{Discussion}

In order to understand the role of the airway epithelium in the hyperosmolarity-induced bioelectric response and the subsequent relaxation, we have been investigating the relationship between the two responses and the possible involvement of protein phosphorylation in epithelial signaling using the perfused trachea apparatus. Evidence was obtained earlier that epithelial bioelectric events and the EpDRF-mediated relaxation are functionally linked (Dortch-Carnes et al., 1999; Fedan et al., 1999). Kinases and phosphatases may be involved in the regulation of epithelial $V_{t}$ (Chapter I). Because agents that affect $R_{t}$ could secondarily affect basal $V_{t}$ and evoked $V_{t}$ responses, and our previously employed tracheal perfusion apparatus was unable to discriminate between changes in $R_{t}$ and epithelial ion transport, we conducted the present study to examine further the mechanisms of bioelectric and mechanical responses to hyperosmolar challenge.

The Ussing chamber (Reuss, 2001) had been employed to provide $R_{t}$ information in response to ion transport inhibitors and hyperosmolarity in our previous studies (Wu et al., 2004); since tracheal segments are rigidly clamped in the Ussing apparatus, responses of the tracheal smooth muscle and the possible correlations between epithelial bioelectric and muscle mechanical responses could not be made. Moreover, the basal $V_{t}$ measured with the Ussing preparation was reduced by two third compare to that obtained from the perfusion apparatus (Dortch-Carnes et al., 1999; Fedan et al., 2006a). The lower potential measured 
with the Ussing apparatus may be a consequence of the distortion brought about by fixing a cylindrical organ into a flat mount. Apparently, this results in a decrease in epithelial ion transport or a permeability increase across tight junctions. To better understand the airway physiology and epithelial regulatory mechanism, we further modified the tracheal perfusion apparatus so that $V_{t}, R_{t}$ and $\triangle P$ could be obtained simultaneously under conditions in which the in vivo configuration of the organ is maintained. The performance of the apparatus was validated using ion transport inhibitors, bronchoactive agonists and hyperosmolar challenge. After characterization of the apparatus, we then utilized it to examine the bioelectric effects of the kinase-interfering agents.

Both amiloride and NPPB decreased basal $V_{t}$. The increase in $R_{t}$ caused by amiloride, which was also observed in rabbit airways (Poulsen et al., 2006), could partially offset the decrease in $\mathrm{V}_{\mathrm{t}}$. The larger depolarization caused by NPPB suggests that guinea-pig tracheal epithelium is primarily a $\mathrm{Cl}^{-}$-secreting rather than a $\mathrm{Na}^{+}$-absorbing epithelium (Wu et al., 2004). Both amiloride and NPPB had no effect on basal $\triangle P$, indicating that, at rest, ion transport through $\mathrm{Na}^{+}$and $\mathrm{Cl}^{-}$channels is not involved in the regulation of smooth muscle tone.

Ouabain and bumetanide depolarized basal $V_{t}$. Although ouabain also decreased $R_{t}$, it is not difficult to conclude that the abolition of $V_{t}$ was primarily due to the inhibition of the $\mathrm{Na}^{+}-\mathrm{K}^{+}$-pump. The activity of $\mathrm{Na}^{+}-\mathrm{K}^{+}-2 \mathrm{Cl}^{-}$cotransporter in guinea-pig tracheal epithelium supports $\sim 10 \%$ of transepithelial short-circuit current $\left(I_{s c}\right)$ in the Ussing apparatus (Wu et al., 2004). Bumetanide, which had no 
effect on $R_{t}$, caused a $\sim 20 \%$ decrease in $V_{t}$. This effect is comparable with that obtained in cultured guinea-pig tracheal epithelium (Robison and Kim, 1994). The ouabain-induced muscle contraction occurred because decreased $\mathrm{Na}^{+}$extrusion reduced $\mathrm{Na}^{+}, \mathrm{Ca}^{2+}$-exchange, causing intracellular $\mathrm{Ca}^{2+}$ accumulation in the smooth muscle (Chideckel et al., 1987). The bumetanide-induced relaxation can be attributed, in part, to its inhibition of the $\mathrm{Na}^{+}-\mathrm{K}^{+}-2 \mathrm{Cl}^{-}$cotransporter (Lavallee et al., 1997).

Histamine and terbutaline caused, as expected, contraction and relaxation of the tracheas, respectively. Because both receptors are located on muscle cells, their mechanisms are not mediated by epithelium. Although histamine increased $V_{t}$ and $I_{s c}$ in canine tracheas (Yamada et al., 1994) and terbutaline increased $I_{s c}$ in cultured guinea-pig epithelia (Robison and Kim, 1994), the two agonists used in $E_{50}$ concentrations caused, surprisingly, small and variable changes in $V_{t}$ in the guinea-pig perfused trachea. Overall, they had no effect on basal $V_{t}$ and $R_{t}$.

Hyperosmolar $\mathrm{NaCl}$ and D-M elicited depolarization and relaxation, as reported earlier (Dortch-Carnes et al., 1999). Similar to the observations made with the Ussing apparatus (Wu et al., 2004; Poulsen et al., 2006), and microelectrode and microscopy studies (Willumsen et al., 1994; Hogman et al., 2002), $\mathrm{NaCl}$ decreased $\mathrm{R}_{t}$ but $\mathrm{D}-\mathrm{M}$ increased $\mathrm{R}_{\mathrm{t}}$. Because the $\mathrm{NaCl}$-induced $\% \triangle R_{t}(20.0 \%)$ was less than the $\% \triangle V_{t}(84.7 \%)$, the depolarization induced by $\mathrm{NaCl}$ was probably the result of decreased ion transport. In contrast, D-M induced an increase in $R_{t}$ in the face of depolarization; therefore, a decrease in ion 
transport is responsible for the D-M-induced depolarization. Decreased ion transport to hypertonic $\mathrm{NaCl}$ and $\mathrm{D}-\mathrm{M}$ was also observed in other studies (Willumsen et al., 1994; Wu et al., 2004). Moreover, increased $\mathrm{Na}^{+}$influx, as reported in hepatocytes, may potentially contribute to the depolarization obtained at this high $\mathrm{NaCl}$ concentration (Wehner et al., 2000). These results indicate that hyperosmolar $\mathrm{NaCl}$ and $\mathrm{D}-\mathrm{M}$ oppositely alter tight junction permeability of the tracheal epithelium.

To investigate the role of kinase signaling in the responses of the epithelium to MCh and physiologically-relevant increases in osmolarity using D-M (30 mosM), the effects of SP 600125, dicumarol, chelerythrine, $\mathrm{NaAsO}_{2}$ and $\mathrm{Na}_{3} \mathrm{VO}_{4}$ were examined. MCh and D-M both induced hyperpolarization. Activation of the $\mathrm{Na}^{+}-\mathrm{K}^{+}-2 \mathrm{Cl}^{-}$cotransporter and $\mathrm{Cl}^{-}$secretion were reported to play a role in maintaining basal $V_{t}$ and $M C h$-induced hyperpolarization (Phillips et al., 2002; Wu et al., 2004). Since activation of $\mathrm{Na}^{+}-\mathrm{K}^{+}-2 \mathrm{Cl}^{-}$cotransporter is common in cells exposed to hyperosmolarity and undergoing regulatory volume increase (O'Neill, 1999), its activation and secondary $\mathrm{Cl}^{-}$secretion could also be involved in the D-M-induced hyperpolarization.

MCh activated JNK in Chinese hamster ovary cells expressing $M_{3}$ muscarinic receptors, and the activation of JNK was negatively regulated by PKC (Wylie et al., 1999). This finding implies that PKC and JNK could have differential regulatory effects on MCh-induced responses. In accord with this observation, chelerythrine inhibited, while SP 600125 and dicumarol potentiated, MCh-induced 
hyperpolarization. PKC negatively regulates activation of JNK in Rat-1 fibroblasts as well (Cadwallader et al., 1997). The inhibitory effects of chelerythrine on basal $V_{t}$ and $M C h$-induced hyperpolarization suggest that PKC regulates epithelial ion transport, possibly through $\mathrm{Na}^{+}-\mathrm{K}^{+}-2 \mathrm{Cl}^{-}$cotransporter (Liedtke et al., 2002a).

In our earlier investigation, $\mathrm{NaAsO}_{2}$ significantly inhibited $\mathrm{MCh}$-induced hyperpolarization (Chapter I); in the present study this effect was less pronounced $(p=0.056)$. $\mathrm{NaAsO}_{2}$ caused a considerable increase in $\mathrm{R}_{\mathrm{t}}$, which offset the $\mathrm{V}_{t}$ response. $\mathrm{Na}_{3} \mathrm{VO}_{4}$ also inhibited $\mathrm{MCh}$-induced hyperpolarization, but decreased $R_{t}$. Because the $\% \triangle V_{t}$ and $\% \triangle R_{t}$ were not different, the inhibited hyperpolarization was caused primarily by the decreased $R_{t} . N a_{3} V_{4}$ was also found to decrease transepithelial resistance in kidney monolayer cells and brain endothelial cells through inhibition of phosphatase, and alteration of tyrosine phosphorylation of tight junction proteins (Collares-Buzato et al., 1998; Lohmann et al., 2004).

Although chelerythrine, SP 600125 and dicumarol inhibited D-M-induced hyperpolarization, chelerythrine did not affect $R_{t}$, while SP 600125 and dicumarol decreased $R_{t}$. Because the $\% \triangle V_{t}$ and $\% \triangle R_{t}$ caused by SP 600125 and dicumarol were comparable, the inhibited hyperpolarization was probably attributable to the decrease in $\mathrm{R}_{\mathrm{t}}$. JNK signaling has not been reported to be intimately involved in the regulation of transepithelial resistance. However, a recent study (Wong et al., 2005) demonstrated that the JNK inhibitor, dimethylaminopurine, worsened the $\mathrm{CdCl}_{2}$-induced damage to the blood-testis 
barrier, indicating that in response to hyperosmolarity JNK inhibition might cause an increase in the permeability of tight junctions. The results suggest that PKC, but not JNK, regulates epithelial ion transport during D-M-induced hyperpolarization, possibly through $\mathrm{Na}^{+}-\mathrm{K}^{+}-2 \mathrm{Cl}^{-}$cotransporter. This finding is consistent with the observation that hyperosmolar sucrose activates the $\mathrm{Na}^{+}-\mathrm{K}^{+}-2 \mathrm{Cl}^{-}$cotransporter in human tracheal epithelia, and that this activation is regulated by PKC $\delta$ and not affected by JNK (Liedtke and Cole, 2002b).

$\mathrm{NaAsO}_{2}$ significantly inhibited D-M-induced hyperpolarization and decreased $R_{t}$. Because the $\% \triangle V_{t}$ and $\% \triangle R_{t}$ were comparable, the inhibited hyperpolarization is likely to have been caused by the decrease in $R_{t}$. We were unable to find an earlier report of an effect of $\mathrm{NaAsO}_{2}$ on tight junction permeability. Because $\mathrm{NaAsO}_{2}$ activates stress-sensitive kinases, the decrease in $R_{t}$ could be a reflection of regulation of tight junctions by kinases. $\mathrm{Na}_{3} \mathrm{VO}_{4}$ inhibited D-M-induced hyperpolarization without affecting $R_{t}$, indicating that protein-phosphotyrosine phosphatase regulates the ion transport stimulated by D-M. Although $\mathrm{Na}_{3} \mathrm{VO}_{4}$ has an inhibitory effect on the $\mathrm{Na}^{+}-\mathrm{K}^{+}$-pump (Dafnis and Sabatini, 1994), we cannot conclude that the inhibited hyperpolarization occurred as a result of decreased activity of the $\mathrm{Na}^{+}-\mathrm{K}^{+}$-pump, for the reason that $\mathrm{Na}_{3} \mathrm{VO}_{4}$ did not decrease basal $V_{t}$, and it hyperpolarized the epithelium during the $30 \mathrm{~min}$ exposure.

In summary, we have developed a useful new method for the study of airway physiology and pharmacology using tracheas that retain their in situ shape. 
Information obtained with this apparatus has had to be collected separately from different methods previously. Using this technology we were able not only to evaluate the relationship between epithelial bioelectric and mechanical responses directly, but also to gain information on the contribution of changes in $R_{t}$ to bioelectric responses. The results obtained with kinase and phosphatase inhibitors indicate that PKC is intimately involved in the regulation of epithelial ion transport. JNK and protein-phosphotyrosine phosphatase regulate the epithelial ion transport induced by MCh and D-M, respectively; they also play a role in the regulation of epithelial tight junctions. Studies with the kinase-modifying agents did not identify a common signaling pathway that regulates both of the bioelectric and mechanical responses to hyperosmolar challenge. 


\section{References}

Anderson SD (2006) How does exercise cause asthma attacks? Curr Opin Allergy Clin Immunol 6:37-42.

Anderson SD, Brannan J, Spring J, Spalding N, Rodwell LT, Chan K, Gonda I, Walsh A and Clark AR (1997a) A new method for bronchial-provocation testing in asthmatic subjects using a dry powder of mannitol. Am J Respir Crit Care Med 156:758-765.

Anderson SD and Daviskas E (2000) The mechanism of exercise-induced asthma is... J Allergy Clin Immunol 106:453-459.

Anderson SD and Kippelen P (2005) Exercise-induced bronchoconstriction: pathogenesis. Curr Allergy Asthma Rep 5:116-122.

Brannan JD, Gulliksson M, Anderson SD, Chew N and Kumlin M (2003) Evidence of mast cell activation and leukotriene release after mannitol inhalation. Eur Respir J 22:491-496.

Brannan JD, Koskela H, Anderson SD and Chew N (1998) Responsiveness to mannitol in asthmatic subjects with exercise- and hyperventilation-induced asthma. Am J Respir Crit Care Med 158:1120-1126.

Cabral AL, Conceicao GM, Fonseca-Guedes CH and Martins MA (1999) Exercise-induced bronchospasm in children: effects of asthma severity. Am J Respir Crit Care Med 159:1819-1823.

Cadwallader K, Beltman J, McCormick F and Cook S (1997) Differential regulation of extracellular signal-regulated protein kinase 1 and Jun $\mathrm{N}$-terminal kinase 
1 by $\mathrm{Ca} 2+$ and protein kinase $\mathrm{C}$ in endothelin-stimulated Rat-1 cells. Biochem J 321 ( Pt 3):795-804.

Chideckel EW, Frost JL, Mike P and Fedan JS (1987) The effect of ouabain on tension in isolated respiratory tract smooth muscle of humans and other species. Br J Pharmacol 92:609-614.

Collares-Buzato CB, Jepson MA, Simmons NL and Hirst BH (1998) Increased tyrosine phosphorylation causes redistribution of adherens junction and tight junction proteins and perturbs paracellular barrier function in MDCK epithelia. Eur J Cell Biol 76:85-92.

Dafnis E and Sabatini S (1994) Biochemistry and pathophysiology of vanadium. Nephron 67:133-143.

Dortch-Carnes J, Van Scott MR and Fedan JS (1999) Changes in smooth muscle tone during osmotic challenge in relation to epithelial bioelectric events in guinea pig isolated trachea. J Pharmacol Exp Ther 289:911-917.

Duzgun SA, Rasque H, Kito H, Azuma N, Li W, Basson MD, Gahtan V, Dudrick SJ and Sumpio BE (2000) Mitogen-activated protein phosphorylation in endothelial cells exposed to hyperosmolar conditions. J Cell Biochem 76:567-571

Elias JA, Lee CG, Zheng T, Ma B, Homer RJ and Zhu Z (2003) New insights into the pathogenesis of asthma. J Clin Invest 111:291-297.

Fedan JS, Dowdy JA, Johnston RA and Van Scott MR (2004a) Hyperosmolar solution effects in guinea pig airways. I. Mechanical responses to relative 
changes in osmolarity. J Pharmacol Exp Ther 308:10-18.

Fedan JS, Wu DX and Van Scott MR (2006a) Altered ion transport and responsiveness to methacholine and hyperosmolarity in air interface-cultured guinea-pig tracheal epithelium. J Pharmacol Toxicol Methods.

Fedan JS, Yuan LX, Chang VC, Viola JO, Cutler D and Pettit LL (1999) Osmotic regulation of airway reactivity by epithelium. J Pharmacol Exp Ther 289:901-910.

Freed AN and Davis MS (1999) Hyperventilation with dry air increases airway surface fluid osmolality in canine peripheral airways. Am J Respir Crit Care Med 159:1101-1107.

Furuichi S, Hashimoto S, Gon Y, Matsumoto K and Horie T (2002) p38 mitogen-activated protein kinase and c-Jun- $\mathrm{NH} 2$-terminal kinase regulate interleukin-8 and RANTES production in hyperosmolarity stimulated human bronchial epithelial cells. Respirology 7:193-200.

Hallstrand TS, Curtis JR, Koepsell TD, Martin DP, Schoene RB, Sullivan SD, Yorioka GN and Aitken ML (2002) Effectiveness of screening examinations to detect unrecognized exercise-induced bronchoconstriction. $J$ Pediatr 141:343-348.

Hallstrand TS, Moody MW, Wurfel MM, Schwartz LB, Henderson WR, Jr. and Aitken ML (2005a) Inflammatory basis of exercise-induced bronchoconstriction. Am J Respir Crit Care Med 172:679-686. 
Hamilton LM, Davies DE, Wilson SJ, Kimber I, Dearman RJ and Holgate ST (2001) The bronchial epithelium in asthma-much more than a passive barrier. Monaldi Arch Chest Dis 56:48-54.

Hamilton LM, Puddicombe SM, Dearman RJ, Kimber I, Sandstrom T, Wallin A, Howarth PH, Holgate ST, Wilson SJ and Davies DE (2005) Altered protein tyrosine phosphorylation in asthmatic bronchial epithelium. Eur Respir $\mathrm{J}$ 25:978-985

Hashimoto S, Matsumoto K, Gon Y, Nakayama T, Takeshita I and Horie T (1999) Hyperosmolarity-induced interleukin-8 expression in human bronchial epithelial cells through p38 mitogen-activated protein kinase. Am J Respir Crit Care Med 159:634-640.

Hogman M, Mork AC and Roomans GM (2002) Hypertonic saline increases tight junction permeability in airway epithelium. Eur Respir J 20:1444-1448.

Homer RJ and Elias JA (2005) Airway remodeling in asthma: therapeutic implications of mechanisms. Physiology (Bethesda) 20:28-35.

Lavallee SL, Iwamoto LM, Claybaugh JR, Dressel MV, Sato AK and Nakamura KT (1997) Furosemide-induced airway relaxation in guinea pigs: relation to Na-K-2Cl cotransporter function. Am J Physiol 273:L211-216.

Liedtke CM and Cole TS (2002b) Activation of NKCC1 by hyperosmotic stress in human tracheal epithelial cells involves PKC- $\delta$ and ERK. Biochim Biophys Acta 1589:77-88.

Liedtke CM, Papay R and Cole TS (2002a) Modulation of Na-K-2Cl cotransport by 
intracellular $\mathrm{Cl}^{-}$and protein kinase $\mathrm{C}-\delta$ in Calu-3 cells. Am J Physiol Lung Cell Mol Physiol 282:L1151-1159.

Lohmann C, Krischke M, Wegener J and Galla HJ (2004) Tyrosine phosphatase inhibition induces loss of blood-brain barrier integrity by matrix metalloproteinase-dependent and -independent pathways. Brain Res 995:184-196.

Munakata M, Mitzner W and Menkes H (1988) Osmotic stimuli induce epithelial-dependent relaxation in the guinea pig trachea. J Appl Physiol 64:466-471.

O'Neill WC (1999) Physiological significance of volume-regulatory transporters. Am J Physiol 276:C995-C1011.

Phillips JE, Hey JA and Corboz MR (2002) Effects of ion transport inhibitors on MCh-mediated secretion from porcine airway submucosal glands. J Appl Physiol 93:873-881.

Poulsen AN, Klausen TL, Pedersen PS, Willumsen NJ and Frederiksen O (2006) Nucleotide regulation of paracellular $\mathrm{Cl}^{-}$permeability in natural rabbit airway epithelium. Pflugers Arch 452:188-198.

Reuss L (2001) Ussing's two-membrane hypothesis: the model and half a century of progress. J Membr Biol 184:211-217.

Robison TW and Kim KJ (1994) Air-interface cultures of guinea pig airway epithelial cells: effects of active sodium and chloride transport inhibitors on bioelectric properties. Exp Lung Res 20:101-117. 
Shrode LD, Krump E and Grinstein S (1998) Activation of protein kinases upon volume changes: role in cellular homeostasis. Contrib Nephrol 123:79-93.

Tsukita S, Furuse M and Itoh M (2001) Multifunctional strands in tight junctions. Nat Rev Mol Cell Biol 2:285-293.

Wehner F, Bohmer C, Heinzinger H, van den Boom F and Tinel H (2000) The hypertonicity-induced $\mathrm{Na}^{+}$conductance of rat hepatocytes: physiological significance and molecular correlate. Cell Physiol Biochem 10:335-340.

Willumsen NJ, Davis CW and Boucher RC (1994) Selective response of human airway epithelia to luminal but not serosal solution hypertonicity. Possible role for proximal airway epithelia as an osmolality transducer. J Clin Invest 94:779-787.

Wong CH, Mruk DD, Siu MK and Cheng CY (2005) Blood-testis barrier dynamics are regulated by $\alpha_{2}$-macroglobulin via the c-Jun $\mathrm{N}$-terminal protein kinase pathway. Endocrinology 146:1893-1908.

Wu DX, Johnston RA, Rengasamy A, Van Scott MR and Fedan JS (2004) Hyperosmolar solution effects in guinea pig airways. II. Epithelial bioelectric responses to relative changes in osmolarity. J Pharmacol Exp Ther 308:19-29.

Wylie PG, Challiss RA and Blank JL (1999) Regulation of extracellular-signal regulated kinase and c-Jun $\mathrm{N}$-terminal kinase by G-protein-linked muscarinic acetylcholine receptors. Biochem J 338:619-628.

Yamada K, Shimura S, Satoh M, Sasaki T, Yamauchi K and Takishima T (1994) 
HMT regulates histamine-induced $\mathrm{Cl}^{-}$secretion across the canine tracheal epithelium. Respir Physiol 97:105-109. 

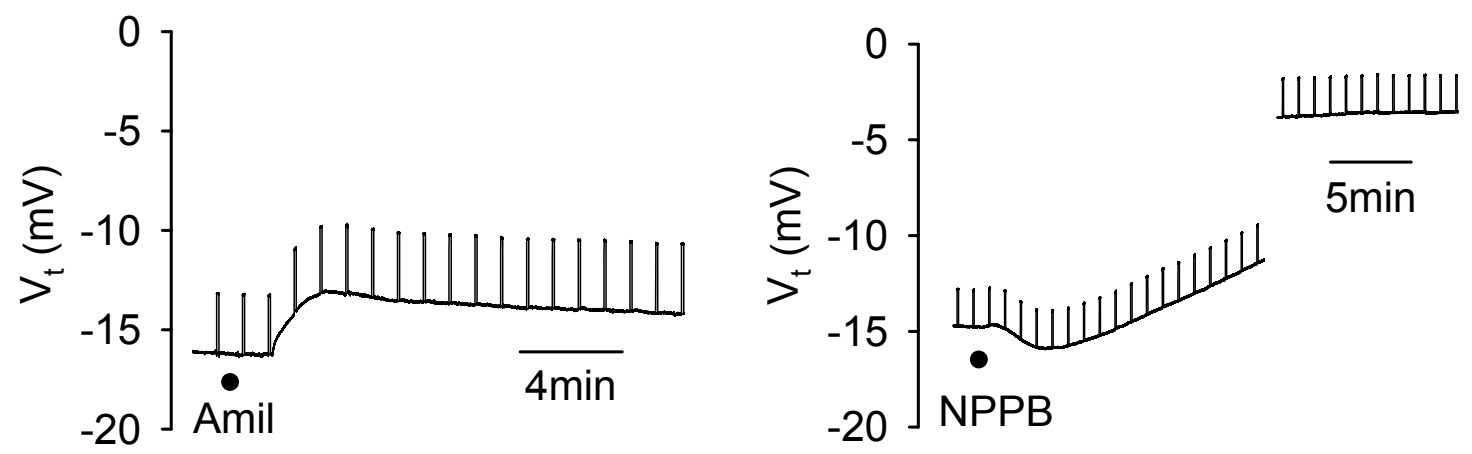

A
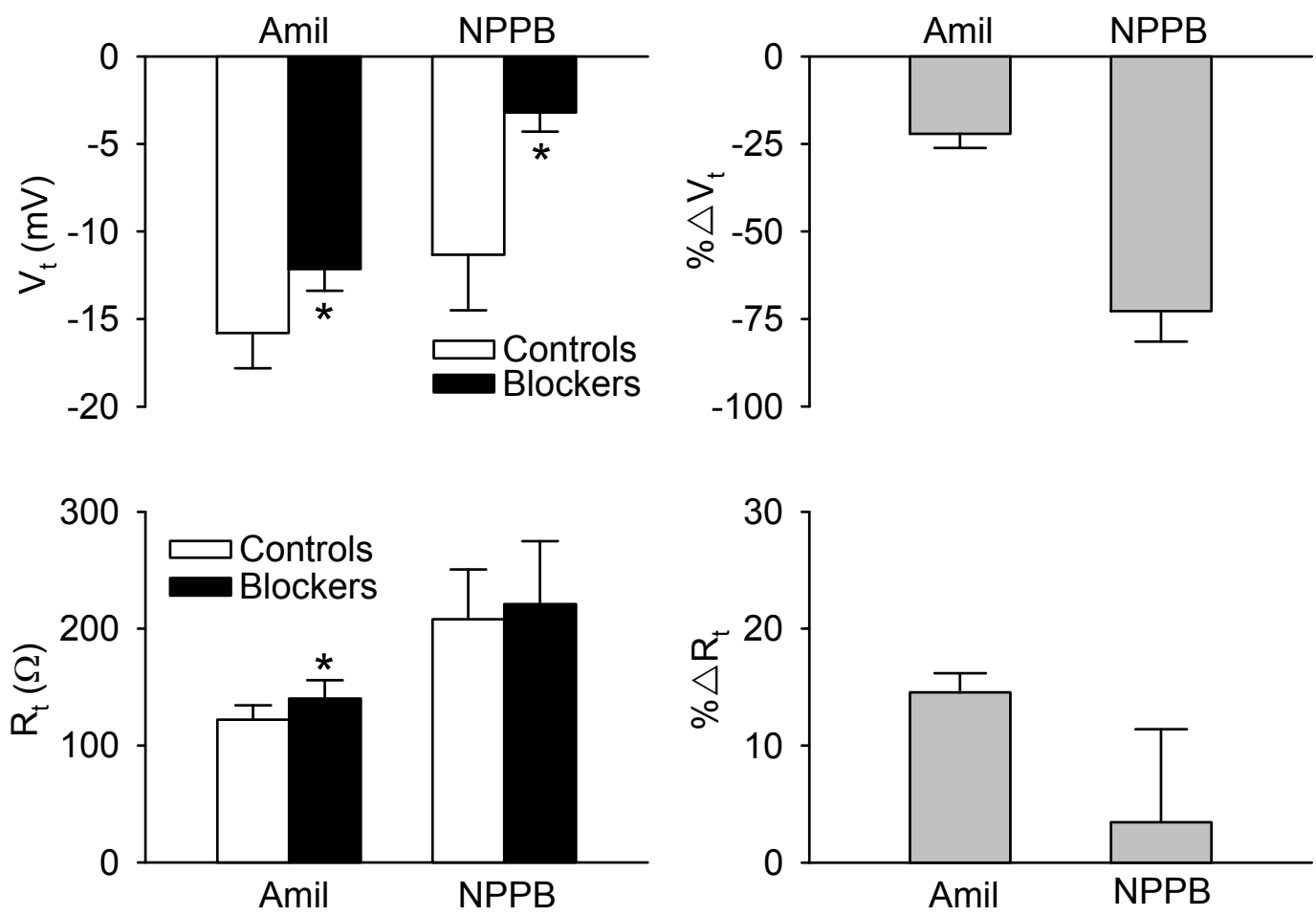

B 
Fig. CII-1. Effects of amiloride $\left(3 \times 10^{-5} \mathrm{M}, \mathrm{IL}\right)$ and NPPB $\left(10^{-4} \mathrm{M}\right.$, IL) on $\mathrm{V}_{\mathrm{t}}, \mathrm{R}_{\mathrm{t}}$ and $\triangle \mathrm{P}$. (A) Representative tracings. Both amiloride and NPPB caused depolarization. The gap in the NPPB tracing represents 20 min. (B) Summary of the effects of amiloride and NPPB on $\mathrm{V}_{t}$ and $\mathrm{R}_{\mathrm{t}}$. The depolarization caused by amiloride was accompanied by an increase in $R_{t}$, while NPPB had no significant effect on $R_{t}$. Neither agent affected $\triangle \mathrm{P}$ (data not shown). $n=4,{ }^{*} p<0.05$. 

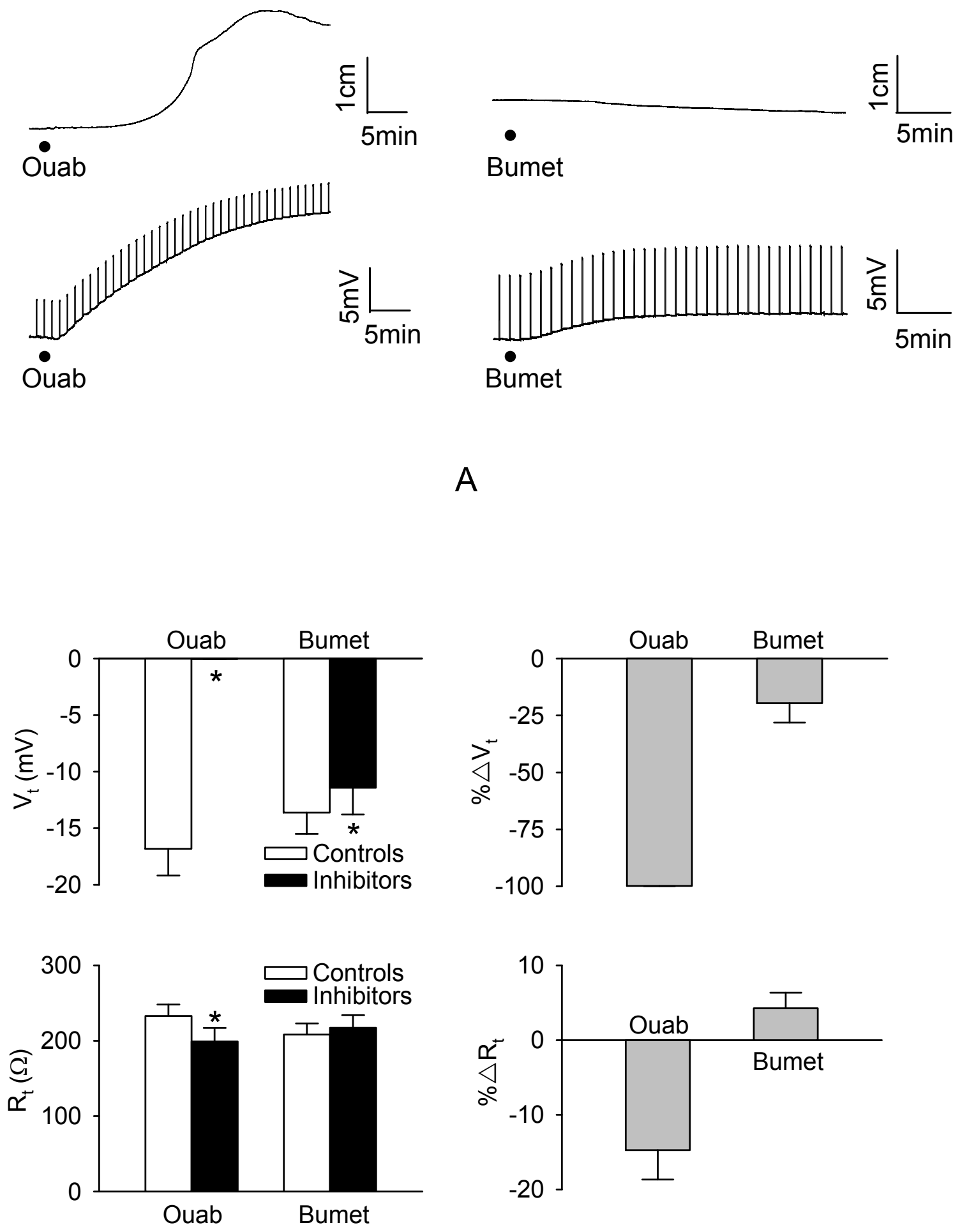

B 
Fig. Cll-2. Effects of ouabain $\left(10^{-5} \mathrm{M}, \mathrm{EL}\right)$ and bumetanide $\left(10^{-5} \mathrm{M}, \mathrm{EL}\right)$ on $\mathrm{V}_{\mathrm{t}}, \mathrm{R}_{\mathrm{t}}$ and $\triangle \mathrm{P}$. (A) Representative tracings. Ouabain caused an immediate depolarization and a delayed contraction; bumetanide caused depolarization and a slight relaxation. (B) Summary of the effects on $V_{t}$ and $R_{t}$. Ouabain abolished $V_{t}$ and decreased $\mathrm{R}_{\mathrm{t}}$. Bumetanide caused a smaller depolarization and had no effect on $\mathrm{R}_{\mathrm{t}} \cdot n=4,{ }^{*} p<0.05$. 

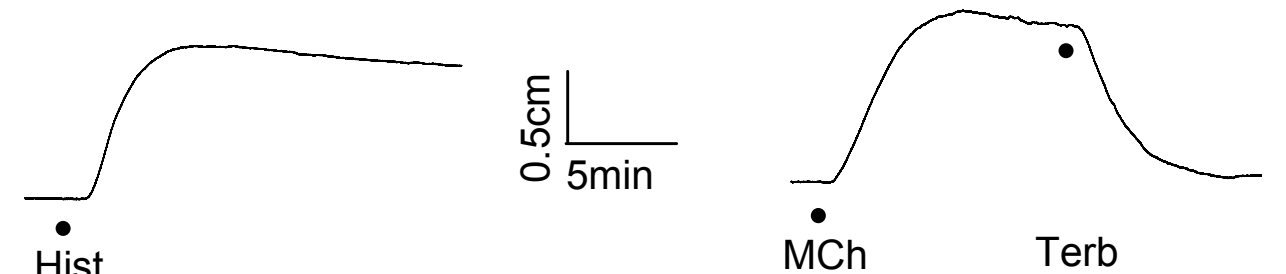

$\stackrel{\varepsilon}{\circ} \bigsqcup_{5 \mathrm{~min}}$

Hist

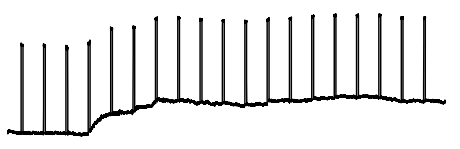

$\bullet$

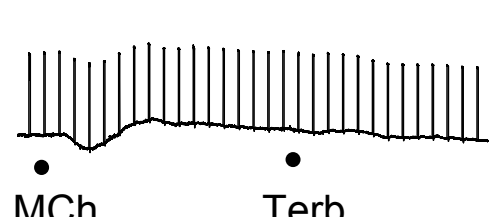

$\underset{5 \mathrm{~min}}{\text { हो }}$

Hist

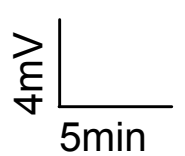

MCh

Terb

A
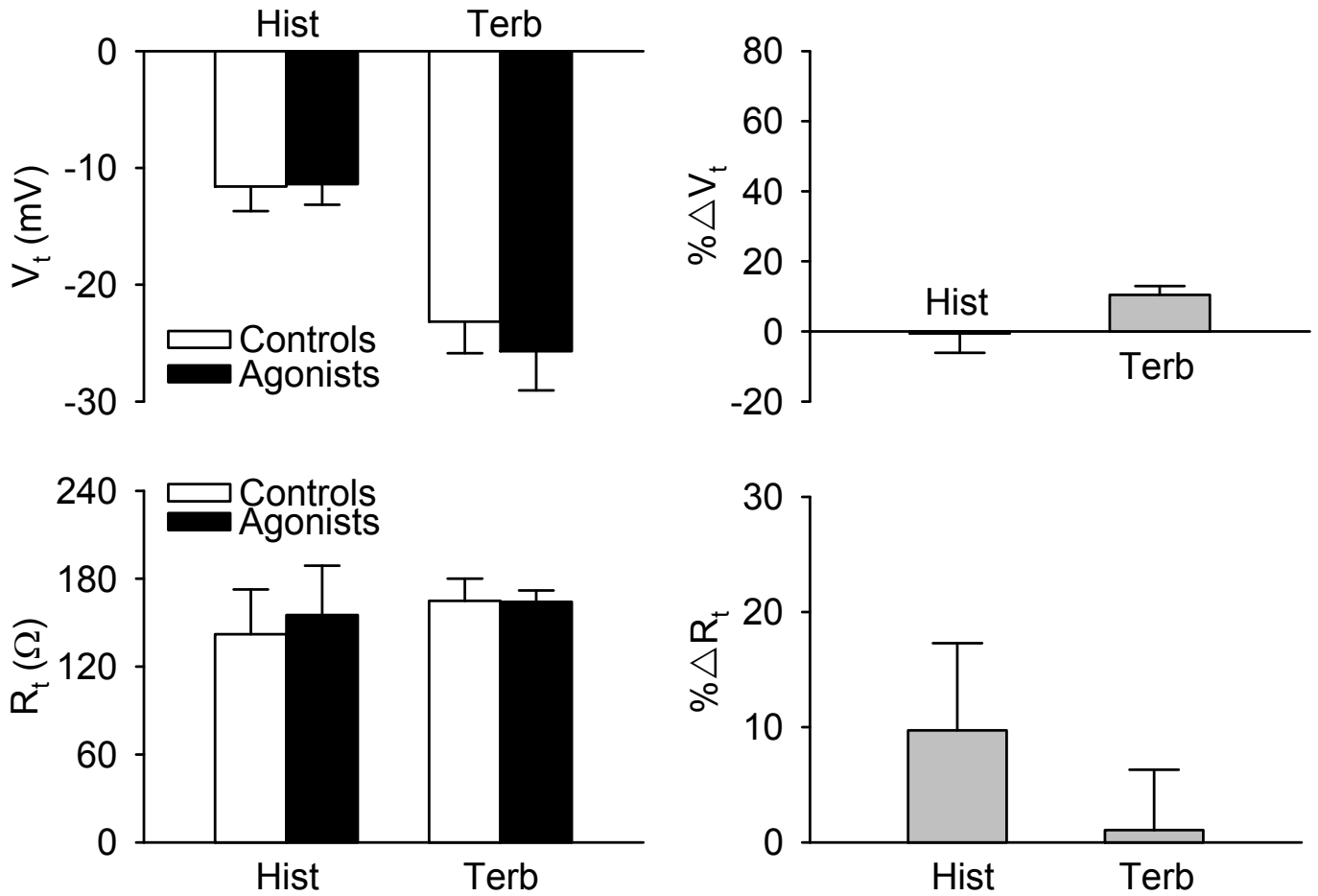

B 
Fig. CII-3. Effects of histamine $\left(7.4 \times 10^{-5} \mathrm{M}, \mathrm{EL}\right)$ and terbutaline $\left(10^{-7} \mathrm{M}, \mathrm{EL}\right)$ on $\mathrm{V}_{\mathrm{t}}$, $R_{t}$ and $\triangle P$. (A) Representative tracings. Histamine caused contraction and variable $V_{t}$ effects. Terbutaline caused relaxation and a transient depolarization in three out of four preparations followed by slow hyperpolarization. (B) Summary of the effects on $V_{t}$ and $R_{t}$. Overall, histamine and terbutaline did not affect $V_{t}$ appreciably. Both agents had no significant effect on $\mathrm{R}_{\mathrm{t} .} n=4,{ }^{*} p<0.05$. 


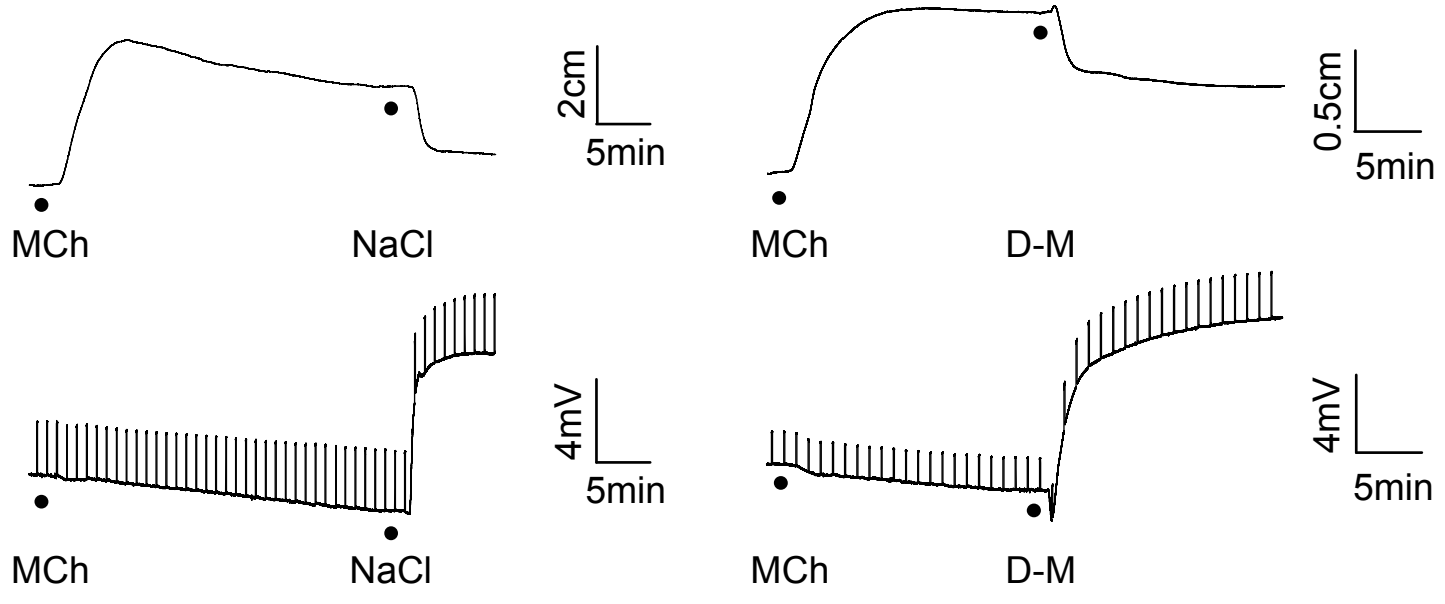

A
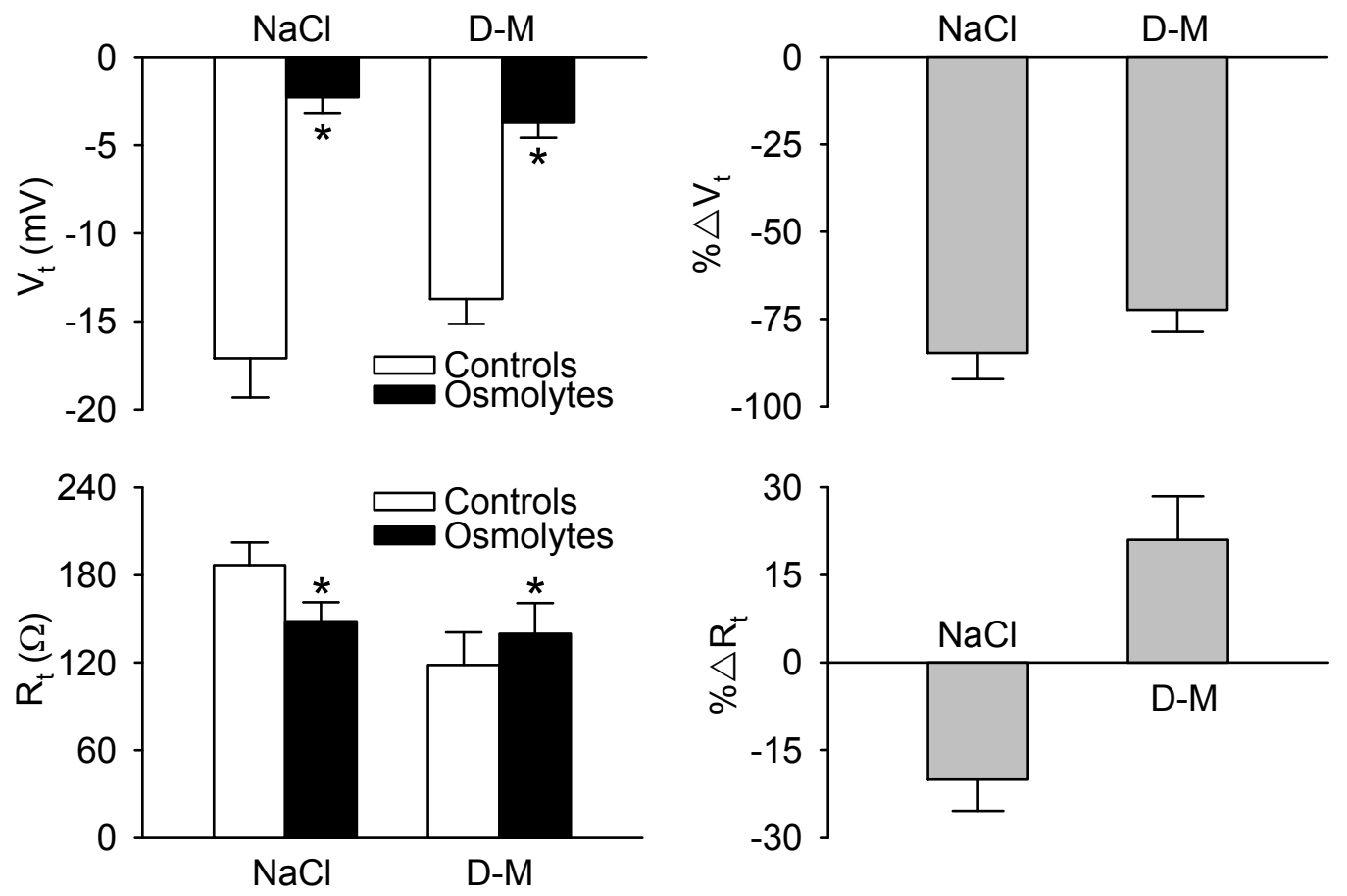

B 
Fig. Cll-4. Effects of hyperosmolar $\mathrm{NaCl}$ and $\mathrm{D}-\mathrm{M}$ (300 mosM each, IL) on $\mathrm{V}_{t}, \mathrm{R}_{t}$ and $\triangle \mathrm{P}$. (A) Representative tracings. $\mathrm{NaCl}$ and $\mathrm{D}-\mathrm{M}$ caused depolarization and relaxation in the presence of MCh. (B) Summary of the effects of $V_{t}$ and $R_{t}$. Though both osmolytes caused depolarization, $\mathrm{NaCl}$ decreased $\mathrm{R}_{\mathrm{t}}$ while $\mathrm{D}-\mathrm{M}$ increased $\mathrm{R}_{\mathrm{t} .} n=4,{ }^{*} p<0.05$. 

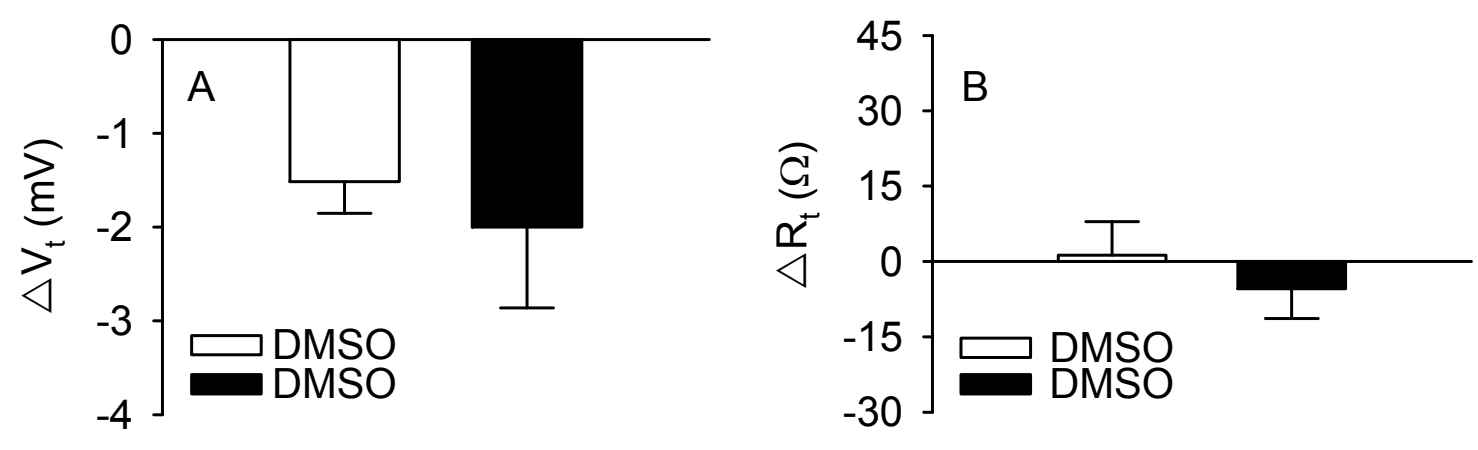

MCh-induced responses
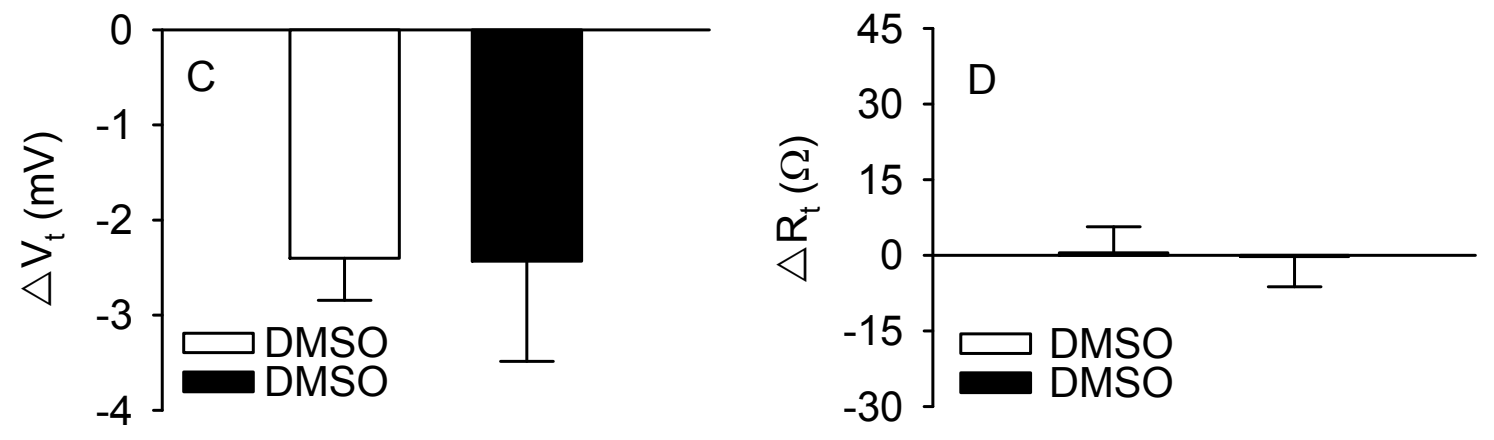

D-M-induced responses

Fig. Cll-5. Effects of DMSO (0.04\%, IL) on MCh- and D-M-induced $V_{t}$ and $R_{t}$ responses. (A and B) DMSO had no significant effect on MCh-induced hyperpolarization. There was also no effect on $R_{t}$. $(C$ and $D)$ DMSO had no effect on D-M-induced hyperpolarization. There was no effect on $\mathrm{R}_{\mathrm{t}} . n=6$. 

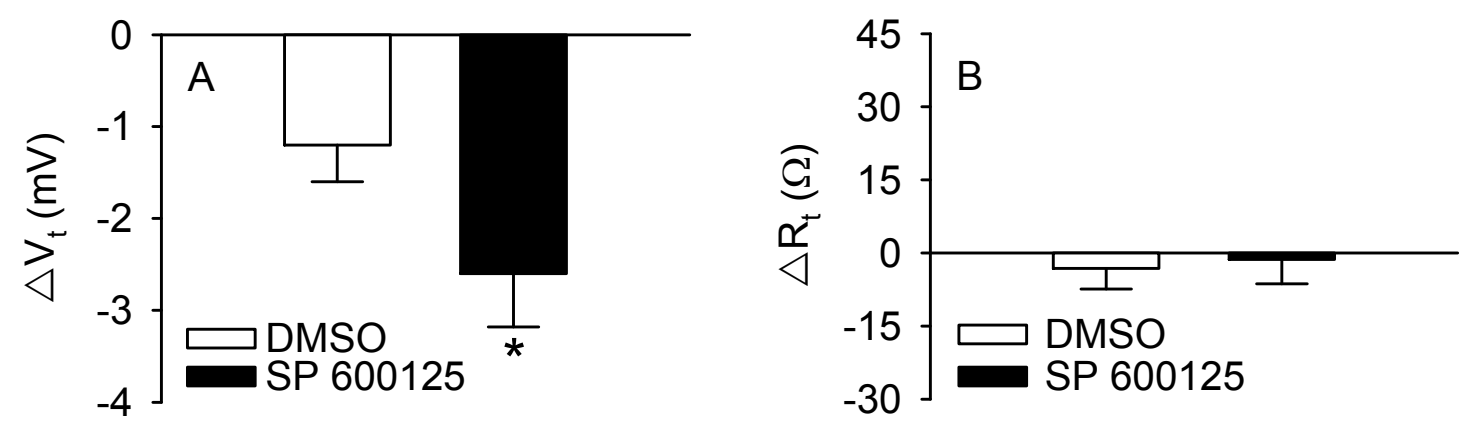

MCh-induced responses
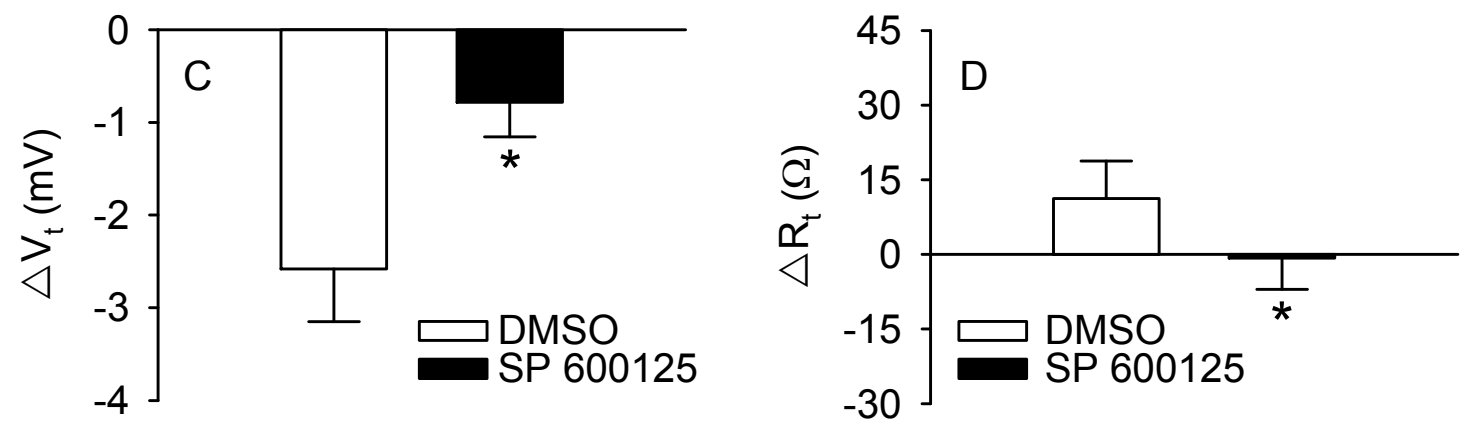

D-M-induced responses

Fig. CII-6. Effects of SP $600125(30 \mu \mathrm{M}, \mathrm{IL})$ on MCh- and D-M-induced $\mathrm{V}_{t}$ and $\mathrm{R}_{\mathrm{t}}$ responses. (A and B) SP 600125 potentiated MCh-induced hyperpolarization. There was no change in $R_{t}$. (C and D) SP 600125 inhibited D-M-induced hyperpolarization. It also caused a small but significant decrease in $\mathrm{R}_{\mathrm{t}} \cdot n=6,{ }^{*} p<$ 0.05 . 

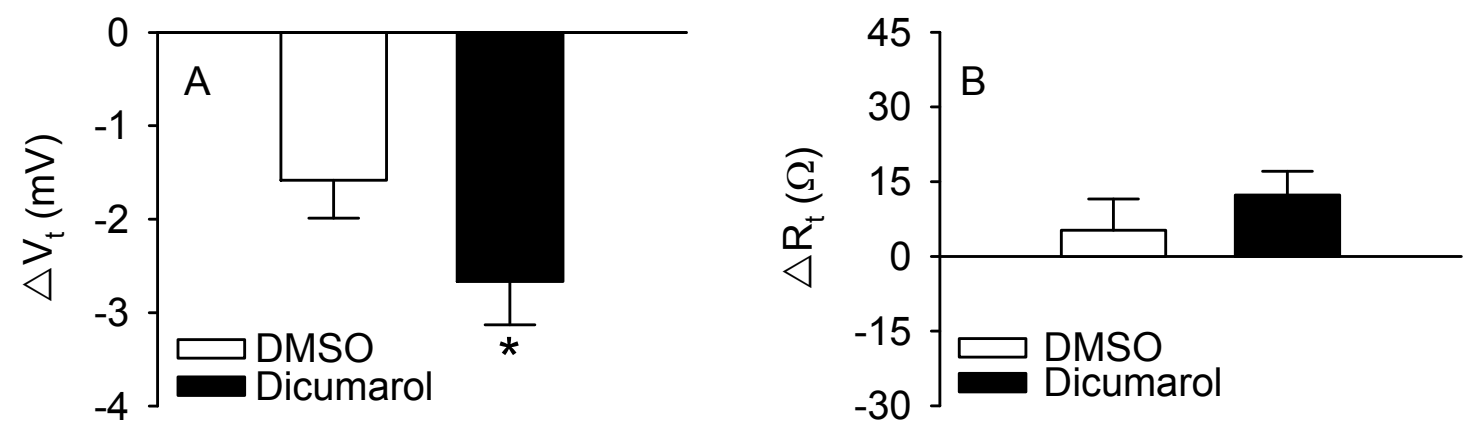

MCh-induced responses
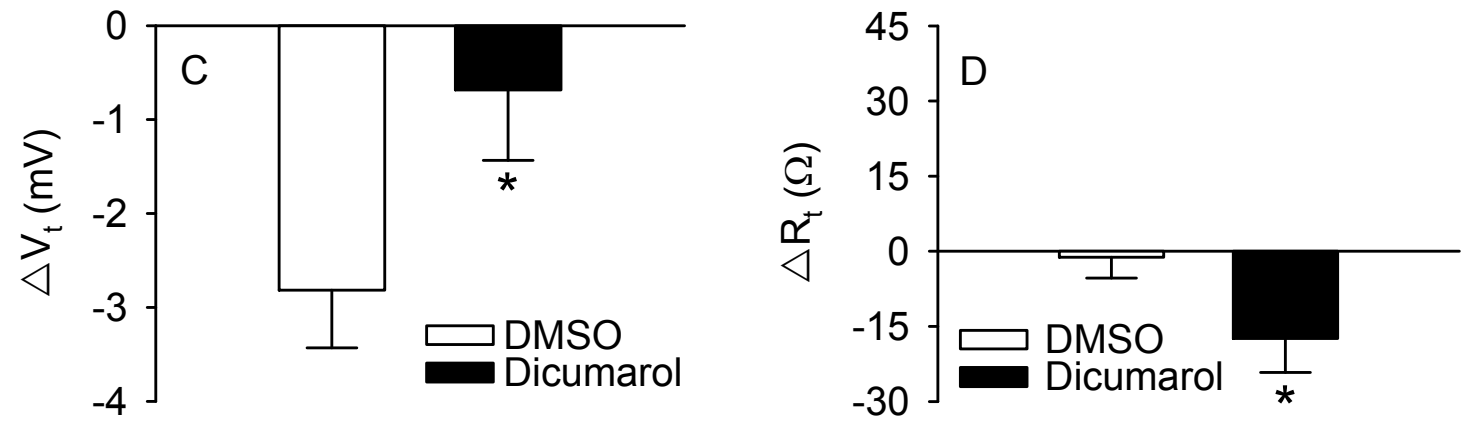

D-M-induced responses

Fig. Cll-7. Effects of dicumarol $(15 \mu \mathrm{M}, \mathrm{IL})$ on MCh- and D-M-induced $\mathrm{V}_{t}$ and $\mathrm{R}_{\mathrm{t}}$ responses. (A and B) Dicumarol potentiated MCh-induced hyperpolarization. There was no significant change in $R_{t}$ ( $C$ and $\left.D\right)$ Dicumarol inhibited D-M-induced hyperpolarization. There was also a decrease in $\mathrm{R}_{\mathrm{t} .} n=6,{ }^{*} p<0.05$. 

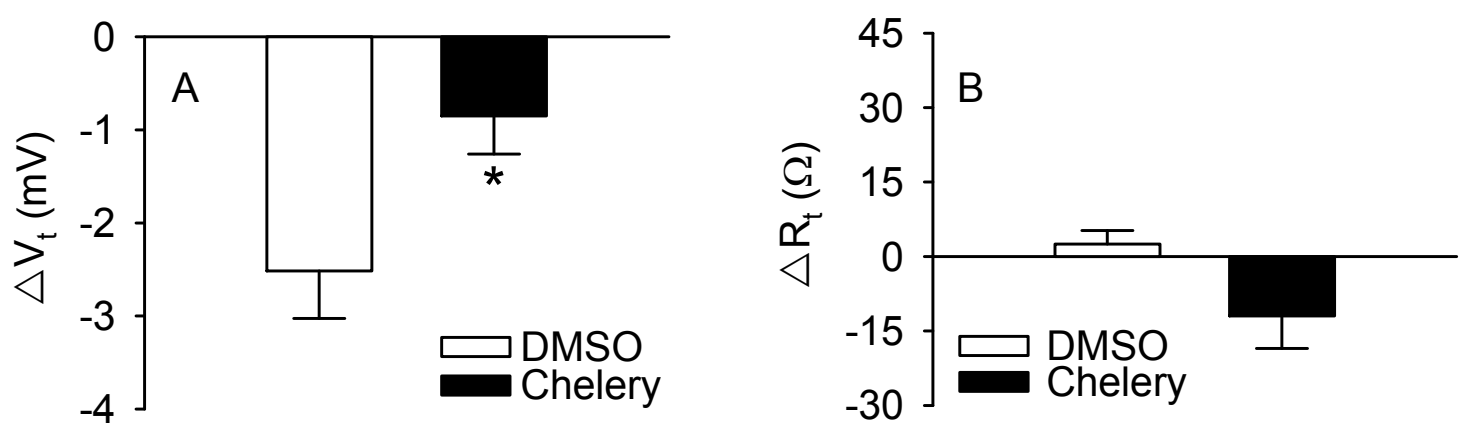

MCh-induced responses
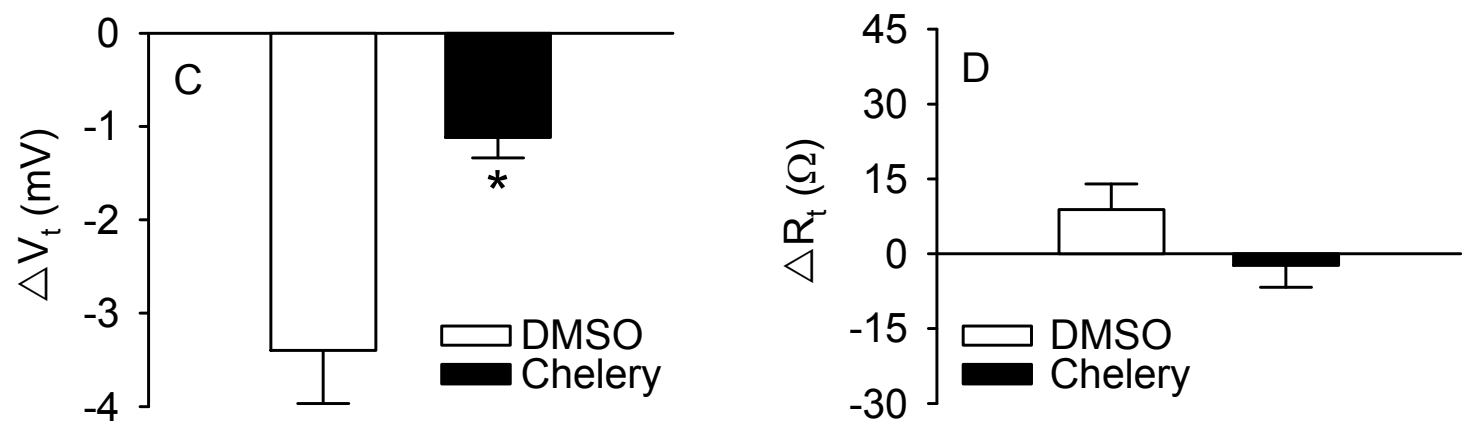

D-M-induced responses

Fig. CII-8. Effects of chelerythrine $(20 \mu \mathrm{M}, \mathrm{IL})$ on MCh- and D-M-induced $\mathrm{V}_{t}$ and $R_{t}$ responses. ( $A$ and $B$ ) Chelerythrine inhibited MCh-induced hyperpolarization. There was no significant change in $R_{t}$. (C and $\left.D\right)$ Chelerythrine inhibited D-M-induced hyperpolarization. $\mathrm{R}_{\mathrm{t}}$ was not affected. $n=6,{ }^{*} p<0.05$. 

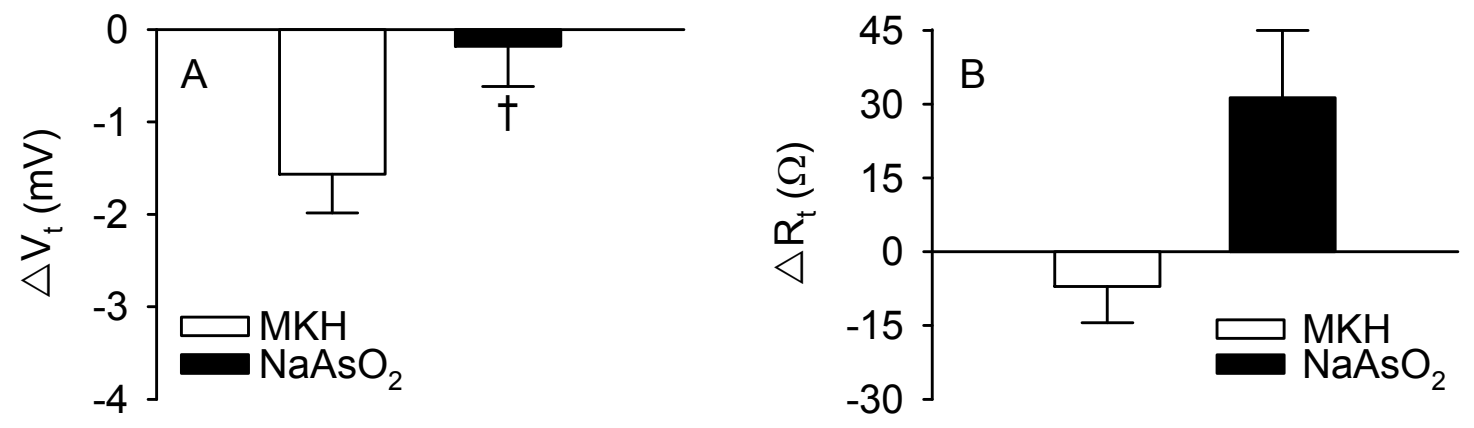

MCh-induced responses
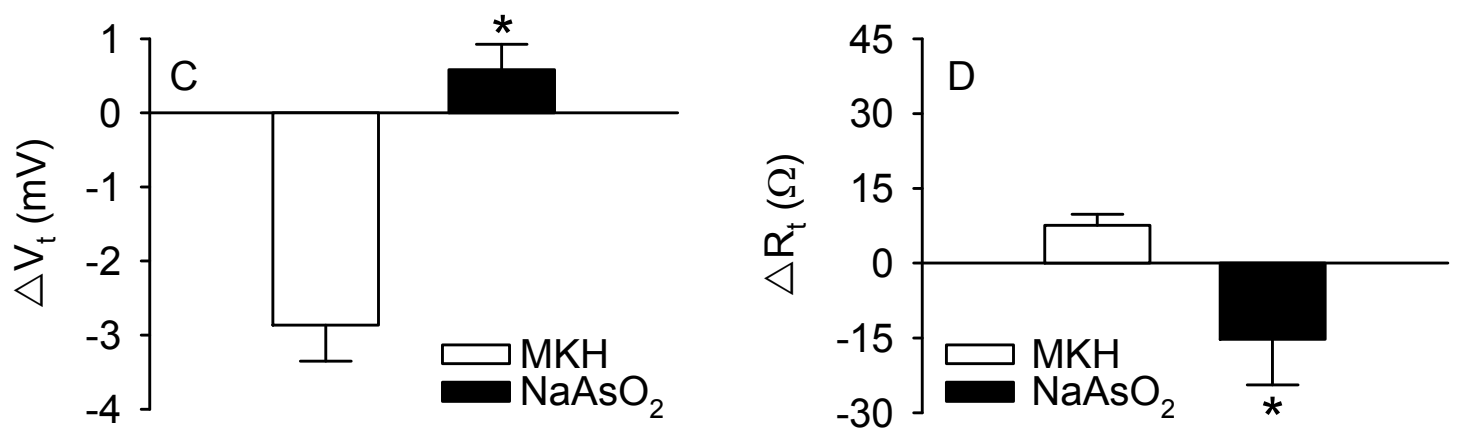

D-M-induced responses

Fig. CII-9. Effects of $\mathrm{NaAsO}_{2}(300 \mu \mathrm{M}, \mathrm{IL})$ on MCh- and D-M-induced $\mathrm{V}_{t}$ and $\mathrm{R}_{t}$ responses. ( $\mathrm{A}$ and $\mathrm{B}$ ) $\mathrm{NaAsO}_{2}$ had no significant effect on $\mathrm{MCh}$-induced hyperpolarization $(p=0.056)$; its effect in $\mathrm{R}_{\mathrm{t}}$ was also not significant $(p=0.082)$. (C and D) $\mathrm{NaAsO}_{2}$ completely inhibited D-M-induced hyperpolarization, which was accompanied by a decrease in $\mathrm{R}_{\mathrm{t} .} n=6,{ }^{*} p<0.05$. 

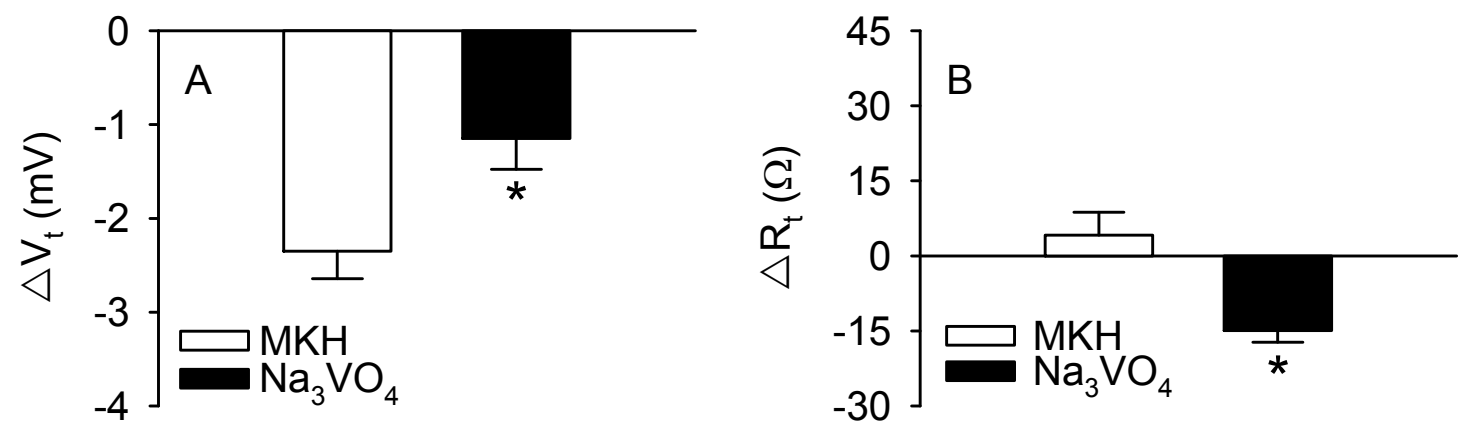

MCh-induced responses
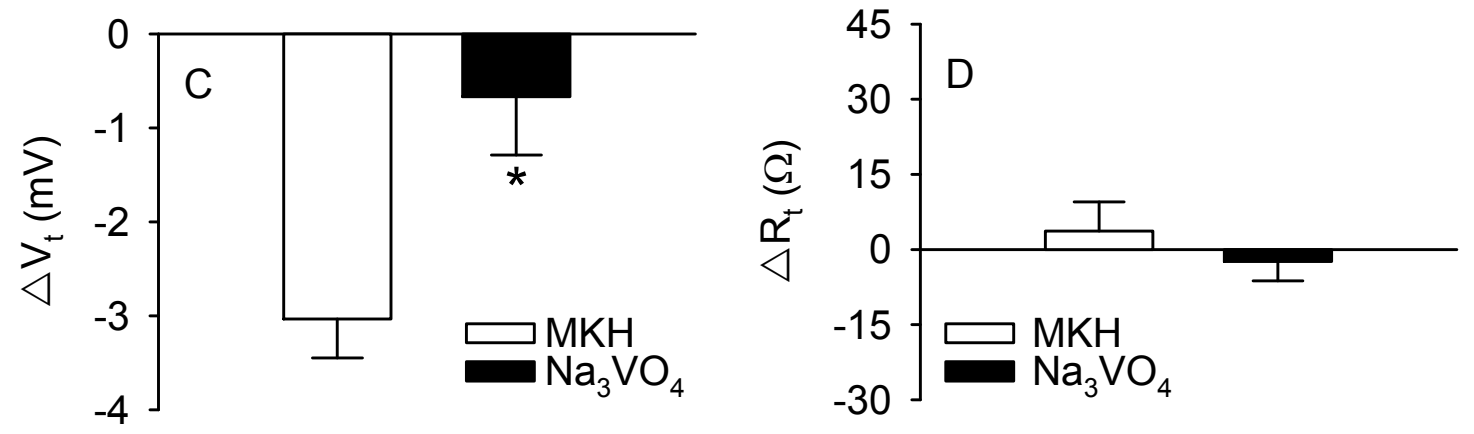

D-M-induced responses

Fig. Cll-10. Effects of $\mathrm{Na}_{3} \mathrm{VO}_{4}(300 \mu \mathrm{M}, \mathrm{IL})$ on MCh- and D-M-induced $\mathrm{V}_{t}$ and $\mathrm{R}_{\mathrm{t}}$ responses. ( $\mathrm{A}$ and $\mathrm{B}$ ) $\mathrm{Na}_{3} \mathrm{VO}_{4}$ inhibited $\mathrm{MCh}$-induced hyperpolarization and decreased $\mathrm{R}_{\mathrm{t}}$ ( $\mathrm{C}$ and $\mathrm{D}$ ) $\mathrm{Na}_{3} \mathrm{VO}_{4}$ inhibited $\mathrm{D}$-M-induced hyperpolarization without affecting $\mathrm{R}_{\mathrm{t} .} n=6,{ }^{*} p<0.05$. 


\section{Chapter III}

\section{Volume Change in Guinea-pig Airway Epithelial Cells Induced by Methacholine and Hyperosmolar Challenge}

Yi Jing, Janet A. Dowdy, Michael R. Van Scott and Jeffrey S. Fedan

Department of Biochemistry and Molecular Pharmacology, Robert C. Byrd Health Sciences Center, West Virginia University, Morgantown, West Virginia (Y.J., J.S.F.); Department of Physiology, The Brody School of Medicine, East Carolina University, Greenville, North Carolina (M.R.V.S.); and Pathology and Physiology Research Branch, Health Effects Laboratory Division, National Institute for Occupational Safety and Health, Morgantown, West Virginia (J.A.D., J.S.F.) 
Running title: Airway Epithelial Cell Shrinkage Induced by Hyperosmolarity

Corresponding author: Jeffrey S. Fedan, Health Effects Laboratory Division, National Institute for Occupational Safety and Health, 1095 Willowdale Road, Morgantown, WV 26505-2888. E-mail: jsf2@cdc.gov

Number of text pages: 16

Number of tables: 0

Number of figures: 5

Number of references: 20

Number of words in Abstract: 146

Number of words in Introduction: 416

Number of words in Discussion: 563

Abbreviations: ASL, airway surface liquid; EpDRF, epithelium-derived relaxing factor; MKH, modified Krebs-Henseleit; MCh, methacholine; D-M, D-mannitol.

Section assignment: Pulmonary 


\begin{abstract}
Airway epithelium modulates underlying smooth muscle tone by releasing epithelium-derived relaxing factor (EpDRF) in response to hyperosmolarity of the airway surface liquid (ASL). The mechanism by which the epithelium senses the increase in osmolarity to release EpDRF is largely unknown. Studies in other cell types have demonstrated that shrinkage occurs in response to hyperosmolar challenge. Our earlier, functional studies have suggested that cell shrinkage does not necessarily evoke EpDRF release. However, these studies were not able to assess changes in cell volume directly. Therefore, we isolated airway epithelial cells from guinea-pig trachea with protease, and examined directly the cell volume response to hyperosmolarity using a cell multisizer. Hyperosmolar challenge with D-mannitol, over a concentration range that elicits EpDRF release and airway relaxation in functional studies using the isolated, perfused trachea, induced rapid, prolonged and concentration-dependent shrinkage, suggesting a potential link between epithelial shrinkage and EpDRF release.
\end{abstract}




\section{Introduction}

We have previously performed functional studies using guinea-pig isolated, perfused trachea apparatus to investigate the epithelial mechanisms involved in the regulation of airway diameter in response to hyperosmolar challenge. Hyperosmolarity of the airway surface liquid (ASL), occurring during exercise (Freed and Davis, 1999; Anderson and Daviskas, 2000), elicits changes in epithelial ion transport and initiates airway smooth muscle relaxation mediated via epithelium-derived relaxing factor (EpDRF); the bioelectric and mechanical responses are thought to be functionally linked (Dortch-Carnes et al., 1999; Fedan et al., 1999). Our previous studies performed with kinase inhibitors demonstrated that transepithelial potential $\left(V_{t}\right)$ changes and EpDRF release in response to hyperosmolar challenge of the epithelium involved common signaling kinases, e.g., JNK, PKC and p38 (Chapters I and II). It is well known that hyperosmolar challenge causes cell shrinkage, and osmosensing mechanisms initiate signaling events which contribute to the regulation of adaptive responses (Schliess and Haussinger, 2006).

The airway epithelium behaves as an osmometer and transducer that sensitively perceives osmolarity changes in the ASL (Willumsen et al., 1994; Matsui et al., 2000; Fedan et al., 2004a). Although the fact that epithelium regulates the underlying smooth muscle tone by releasing EpDRF has been known for years (Munakata et al., 1988; Fedan et al., 1990), the mechanisms by which the epithelium senses increase in osmolarity to release EpDRF are still 
poorly understood. Several hypotheses have been postulated for other cell types, including changes in pathways involving membrane tension response elements, cytoskeletal actin filament architecture, macromolecular crowding and mechanosensitive channels (Burg, 2000; Kinnunen, 2000; Papakonstanti et al., 2000; Zhang and Bourque, 2003; Okada, 2004). Recent studies have presented new evidence that airway epithelium senses the incremental increase in osmolarity rather than the volume changes or absolute osmolarity per se (Fedan et al., 2004a). However, cell volume changes in response to hyperosmolar challenge were not measured directly in that study. Currently none of these mechanisms has been firmly established. The multiple sensing mechanisms could exist selectively in different types of cells or be activated by the magnitude or nature of challenges (Strange, 2004). Thus, it is important to characterize the volume effects of hyperosmolar challenge of airway epithelium using direct measurement.

To understand the relationship between epithelial volume change and EpDRF release, we investigated the effects of hyperosmolar challenge on freshly isolated epithelial cells from guinea-pig trachea. The cell volume changes were measured under osmolar conditions used previously in functional experiments involving the perfused tracheal apparatus, and the results were compared with those obtained in the functional studies. 


\section{Materials and Methods}

Animals. These studies were conducted in facilities accredited fully by the Association for the Assessment and Accreditation of Laboratory Animal Care International and were approved by the institutional Animal Care and Use Committee. Male guinea pigs (550 - 700 g), HsdPoc:DH, from Harlan (Indianapolis, IN), monitored free of endogenous viral pathogens, parasites, and bacteria were used in all experiments. The animals were acclimated before use and were housed in filtered ventilated cages on Alpha-Dri virgin cellulose chips and hardwood Beta-chips as bedding, provided HEPA-filtered air, Teklad 7006 diet and tap water ad libitum, under controlled light cycle (12 h light) and temperature $\left(22-25^{\circ} \mathrm{C}\right)$ conditions. The animals were anesthetized with sodium pentobarbital (65 mg/kg, i.p.) and sacrificed by thoracotomy and bleeding before removing the trachea.

Materials. Modified Krebs-Henseleit (MKH) solution (pH 7.4 at $\left.37{ }^{\circ} \mathrm{C}\right)$ contained $113 \mathrm{mM} \mathrm{NaCl}, 4.8 \mathrm{mM} \mathrm{KCl}, 2.5 \mathrm{mM} \mathrm{CaCl}_{2}, 1.2 \mathrm{mM} \mathrm{KH_{2 }} \mathrm{PO}_{4}, 1.2 \mathrm{mM}$ $\mathrm{MgSO}_{4}, 25 \mathrm{mM} \mathrm{NaHCO}_{3}$, and $5.7 \mathrm{mM}$ glucose, and was saturated with $95 \% \mathrm{O}_{2}$ and $5 \% \mathrm{CO}_{2}$. The osmolarity of MKH was $281 \pm 5$ mosM. EMEM (minimum essential medium eagle) and FBS (fetal bovine serum) were obtained from Cambrex Bioscience (Walkersville, MD) and Invitrogen (Carlsbad, CA), respectively. Protease, DNase I, Acetyl- $\beta$-methylcholine chloride (methacholine, MCh) and D-mannitol (D-M) were purchased from Sigma-Aldrich (St. Louis, MO). Stock solutions of MCh and D-M were prepared in saline. 
Preparation of Cell Suspension. Tracheas were removed and opened longitudinally by cutting through the smooth muscle band. The tracheas were incubated in $2 \mathrm{ml} 0.2 \%$ protease in EMEM at $37^{\circ} \mathrm{C}$ for $1 \mathrm{~h}$. Digestion was stopped with $10 \% \mathrm{FBS} / \mathrm{EMEM}$ solution at $4^{\circ} \mathrm{C}$. The epithelia were gently scraped off with a scalpel blade, rinsed, and triturated in $10 \mathrm{ml}$ of EMEM solution containing $0.1 \%$ DNase I to disaggregate clumps. The suspended cells were screened through a strainer (Falcon $40 \mathrm{~mm}$ nylon filter) and collected by centrifugation at $800 \mathrm{rpm}$ for $5 \mathrm{~min}$. The pellet of cells was suspended in $1 \mathrm{ml} \mathrm{MKH}$ solution saturated with $95 \%$ $\mathrm{O}_{2}$ and $5 \% \mathrm{CO}_{2}$ at $37^{\circ} \mathrm{C}$ for $1 \mathrm{~h}$.

Trypan Blue Assay. $4 \mu \mathrm{l}$ of cell suspension was diluted with $16 \mu \mathrm{MKH}$ and then mixed with $20 \mu \mathrm{l} 0.4 \%$ trypan blue solution (Sigma-Aldrich, St. Louis, MO). After incubating for $2 \mathrm{~min}$, cells were evaluated under a microscope for the active beating of cilia and ability to exclude trypan blue.

\section{Epithelial Volume Changes Induced by MCh and Hyperosmolar D-M}

Solutions. The effects of MCh and D-M on cell volume were examined under similar conditions, e.g., exposure times and concentrations, that were used previously in functional studies on isolated, perfused trachea (Chapters I and II). Because the relaxation response to hyperosmolar D-M was rapid and long-lasting in functional studies, the time-course response to D-M was measured initially beginning at $0 \mathrm{~min}$ and continuing for $5 \mathrm{~h}$. Subsequently, the concentration-dependent responses to $\mathrm{D}-\mathrm{M}(10,30,80$ and 120 mosM) were examined for a period of $30 \mathrm{~min}$. As in the protocol used in functional studies, 
epithelial suspensions were exposed to $\mathrm{MCh}\left(3 \times 10^{-7} \mathrm{M}\right)$ for $15 \mathrm{~min}$ before exposing to D-M (120 mosM) for another $15 \mathrm{~min}$.

Cell Volume Measurement. Epithelial cell diameter was measured using a Coulter Multisizer (Model II; Coulter Scientific Instruments; Hialeah, Florida). Epithelial cells were suspended in MKH solution lacking or containing MCh and/or D-M for this measurement. Volumes expressed in picoliter (pl) were calculated from cell diameters $(\mu \mathrm{m})$.

Data Analysis. Cell volumes measured in the presence of MCh and D-M were compared to their sizes at the starting point $(t=0)$ in the time-course and concentration-dependence experiments. The effects of MCh and D-M on cell volume were analyzed by one way repeated-measures analysis of variance. $p<$ 0.05 was regarded as significant. Each experiment was repeated at least 4 times. 


\section{Results}

Epithelial Cell Morphology and Cilia Movement. Epithelial cells were examined by microscopy. Epithelia were scraped off in small sheets; their cilia were actively beating after the protease digestion (Figs. CIII-1A and CIII-1B). After filtration, most of the cells were separated individually; there were some occasional doublets (Figs. CIII-2A and CIII-2B). The average diameter of the cells (at $\mathrm{t}=0$ ) was $9.5-10 \mu \mathrm{m}$. Active beating of cilia lasted for more than $5 \mathrm{~h}$ (Figs. CIII-2A and CIII-2B). Cell suspensions with more than $85 \%$ of cells excluding trypan blue were used for these experiments.

Time-Dependent Effects of D-M. Epithelial cells suspended in MKH solution gradually reduced their volume during a $5 \mathrm{~h}$ period. However, the volume change over the first 60 min was not significant (Fig. ClII-3). Therefore, the effects of MCh and D-M were examined during the initial 30-min period. D-M (120 mosM) caused a rapid decrease in volume, which reached about $22 \%$ shrinkage at $3 \mathrm{~min}$, compared to their original $(t=0)$ volume. Only a small regulatory volume increase was observed during the following $5 \mathrm{~h}$ (Fig. Clll-3).

Concentration-Dependent Effects of D-M. Hyperosmolar D-M induced a rapid and concentration-dependent decrease in epithelial cell volume. The shrinkage induced by $10,30,80$ and 120 mosM D-M solutions at 3 min were about $7 \%, 9 \% 20 \%$ and $22 \%$, respectively, compared to their original $(t=0)$ volume. No regulatory volume increase was observed (Fig. CIII-4). 
Volume Changes Induced by MCh and Hyperosmolar D-M. The experimental conditions with respect to $M C h$ and $D-M$ were similar to those previously used in the trachea perfusion experiments. MCh $\left(3 \times 10^{-7} \mathrm{M}\right)$ had no effect on the volume of epithelial cells. D-M (120 mosM) caused similar epithelial cell shrinkage in the absence and presence of MCh (Fig. Clll-5). 


\section{Discussion}

Hyperventilation during exercise is thought to result in hyperosmolarity of the ASL due to evaporative water loss (Freed and Davis, 1999; Anderson and Daviskas, 2000). Airway epithelium has been recognized as an osmometer that sensitively perceives osmolarity changes in the ASL and regulates the underlying smooth muscle tone by releasing EpDRF (Matsui et al., 2000; Fedan et al., 2004a). Our functional studies demonstrated that in response to hyperosmolar challenge the epithelial bioelectric responses and EpDRF release are functionally linked (Dortch-Carnes et al., 1999; Fedan et al., 1999); and kinase signaling plays a role in regulating the epithelial ion transport and EpDRF-mediated airway relaxation (Chapters I and II). In order to understand the relationship between epithelial volume change and EpDRF release we developed a novel method with cell suspensions freshly prepared from guinea-pig trachea to investigate the epithelial volume changes under the pharmacological conditions that were previously used in the functional studies.

Under the microscope most freshly prepared epithelial cells exhibited diameters between 9.5 and $10 \mu \mathrm{m}$, which matched the values obtained from the Coulter Multisizer. The lengths of the cilia were a little smaller than the diameters of their cells. In normal airways the length of the epithelial cilia has been reported to be approximately $7 \mu \mathrm{m}$ (Tarran, 2004). Suspended in MKH solution, epithelial cells could live for more than $5 \mathrm{~h}$, during which active cilia beating was observed and trypan blue was excluded by most of the cells. Although the cells gradually 
lost volume after being suspended in MKH solution, the volume changes were not significant over the first $60 \mathrm{~min}$. This window allowed us to examine the volume effects induced by MCh and hyperosmolar D-M. In functional studies, the airway contraction and relaxation responses to $\mathrm{MCh}$ and $\mathrm{D}-\mathrm{M}$, respectively, require about $15-20$ min to reach their plateaus (Chapters I and II).

Hyperosmolar challenge with D-M solutions induced a rapid, prolonged and concentration-dependent decrease in cell volume. The shrinkage reached plateau at about 3 min. Although 120 mosM hypertonic medium caused a $40 \%$ reduction in the volume of rat skeletal muscle cells (Zhao et al., 2004), the maximal cell shrinkage observed in our time-dependent and concentration-dependent studies with the highest exposure, 120 mosM D-M, was about 22\%. 30 mosM D-M induced about a $10 \%$ reduction in epithelial volume, suggesting that it is close to the $\mathrm{EC}_{50}$ concentration for its effect on cell shrinkage. This value is comparable to the $\mathrm{EC}_{50}$ of $\mathrm{D}-\mathrm{M}$ as a relaxant of the guinea-pig perfused trachea.

Like many other types of mammalian cells (O'Neill, 1999), no regulatory volume increase was observed in most of the groups of this study after hypertonic exposure. In guinea-pig colonic epithelial cells, muscarinic stimulation with carbachol induced no cell volume change in the upper region of crypts but shrinkage in the basal region of crypts within $10 \mathrm{~min}$ and the volume was recovered by 20 min (Manabe et al., 2004). In this study, MCh had no effect on the volume of airway epithelia at 15 min, but the cells were shrunk by hyperosmolar D-M 15 min later. 
The results indicate that this novel method is useful for the study of epithelial volume changes in response to anisosmotic conditions. Hyperosmolar challenge, over a concentration range that elicits EpDRF release in the functional studies, induces rapid, long lasting and concentration-dependent shrinkage in airway epithelia, suggesting a possible link between epithelial shrinkage and EpDRF release. 


\section{References}

Anderson SD and Daviskas E (2000) The mechanism of exercise-induced asthma is... J Allergy Clin Immunol 106:453-459.

Burg MB (2000) Macromolecular crowding as a cell volume sensor. Cell Physiol Biochem 10:251-256.

Dortch-Carnes J, Van Scott MR and Fedan JS (1999) Changes in smooth muscle tone during osmotic challenge in relation to epithelial bioelectric events in guinea pig isolated trachea. J Pharmacol Exp Ther 289:911-917.

Fedan JS, Dowdy JA, Johnston RA and Van Scott MR (2004a) Hyperosmolar solution effects in guinea pig airways. I. Mechanical responses to relative changes in osmolarity. J Pharmacol Exp Ther 308:10-18.

Fedan JS, Nutt ME and Frazer DG (1990) Reactivity of guinea-pig isolated trachea to methacholine, histamine and isoproterenol applied serosally versus mucosally. Eur J Pharmacol 190:337-345.

Fedan JS, Yuan LX, Chang VC, Viola JO, Cutler D and Pettit LL (1999) Osmotic regulation of airway reactivity by epithelium. J Pharmacol Exp Ther 289:901-910.

Freed AN and Davis MS (1999) Hyperventilation with dry air increases airway surface fluid osmolality in canine peripheral airways. Am J Respir Crit Care Med 159:1101-1107.

Kinnunen PK (2000) Lipid bilayers as osmotic response elements. Cell Physiol Biochem 10:243-250. 
Manabe K, Shimizu T, Morishima S and Okada Y (2004) Regulatory volume increase after secretory volume decrease in colonic epithelial cells under muscarinic stimulation. Pflugers Arch 448:596-604.

Matsui H, Davis CW, Tarran R and Boucher RC (2000) Osmotic water permeabilities of cultured, well-differentiated normal and cystic fibrosis airway epithelia. J Clin Invest 105:1419-1427.

Munakata M, Mitzner W and Menkes H (1988) Osmotic stimuli induce epithelial-dependent relaxation in the guinea pig trachea. J Appl Physiol 64:466-471.

O'Neill WC (1999) Physiological significance of volume-regulatory transporters. Am J Physiol 276:C995-C1011.

Okada Y (2004) lon channels and transporters involved in cell volume regulation and sensor mechanisms. Cell Biochem Biophys 41:233-258.

Papakonstanti EA, Vardaki EA and Stournaras C (2000) Actin cytoskeleton: a signaling sensor in cell volume regulation. Cell Physiol Biochem 10:257-264.

Schliess F and Haussinger D (2006) Osmosensing and signaling in the regulation of liver function. Contrib Nephrol 152:198-209.

Strange K (2004) Cellular volume homeostasis. Adv Physiol Educ 28:155-159.

Tarran R (2004) Regulation of airway surface liquid volume and mucus transport by active ion transport. Proc Am Thorac Soc 1:42-46.

Willumsen NJ, Davis CW and Boucher RC (1994) Selective response of human 
airway epithelia to luminal but not serosal solution hypertonicity. Possible role for proximal airway epithelia as an osmolality transducer. $J$ Clin Invest 94:779-787.

Zhang Z and Bourque CW (2003) Osmometry in osmosensory neurons. Nat Neurosci 6:1021-1022.

Zhao H, Hyde R and Hundal HS (2004) Signalling mechanisms underlying the rapid and additive stimulation of NKCC activity by insulin and hypertonicity in rat L6 skeletal muscle cells. J Physiol 560:123-136. 


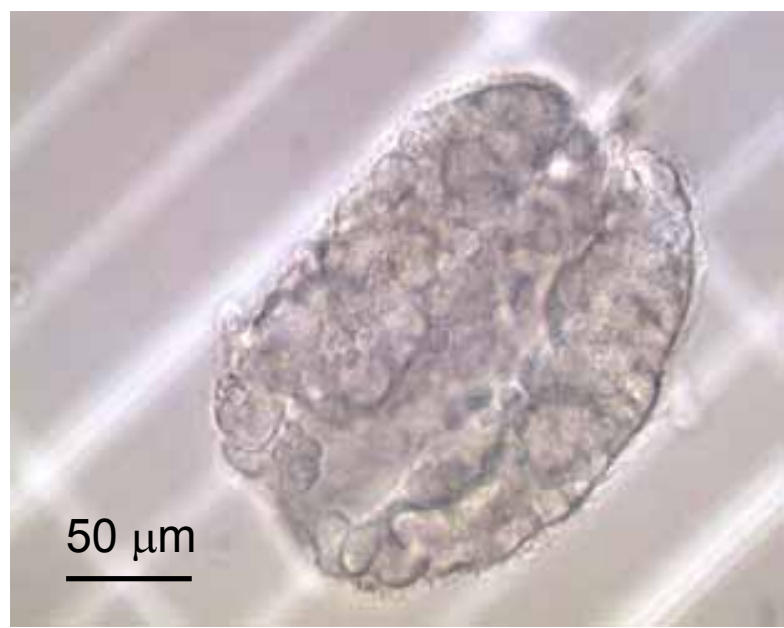

A

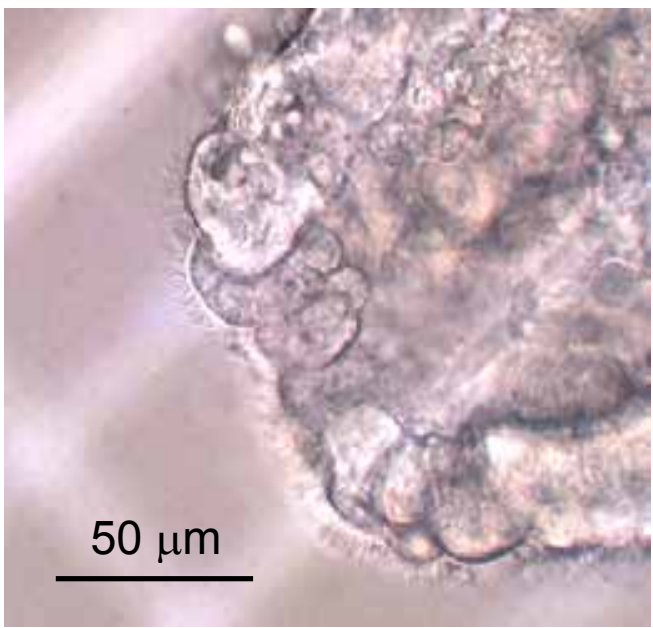

B

Fig. CIII-1. Clump of the airway epithelial cells after protease digestion. (A) 40x objective, (B) 60x objective. Epithelia were scraped off in small sheets. Cilia were actively beating after enzyme treatment. 


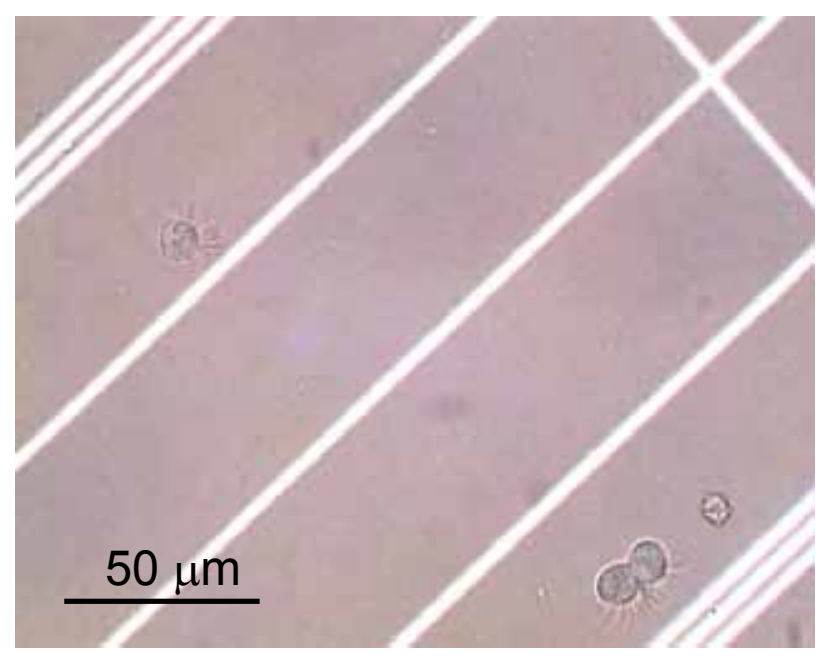

A

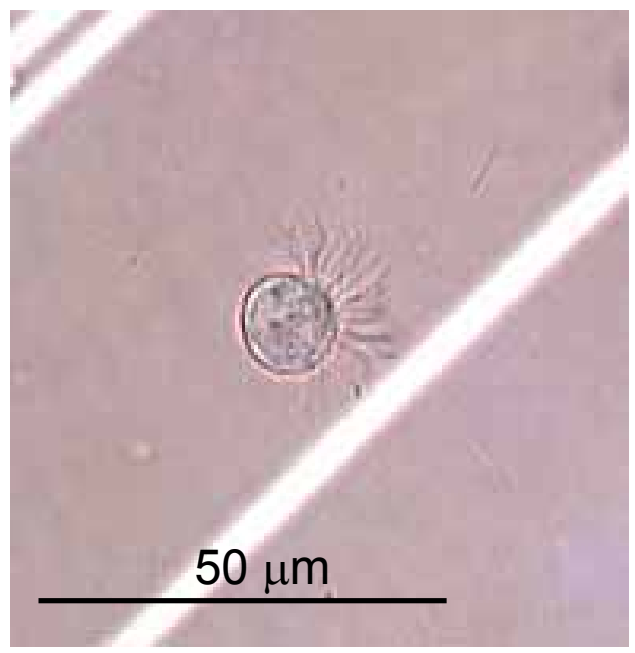

B

Fig. CIII-2. Isolated airway epithelial cells in MKH solution. (A) 60x objective, (B) 100x objective. Epithelial clumps were gently separated by trituration into single cell suspensions. More than $85 \%$ of the cells excluded trypan blue for up to $5 \mathrm{~h}$, during which active cilia beating were observed. 


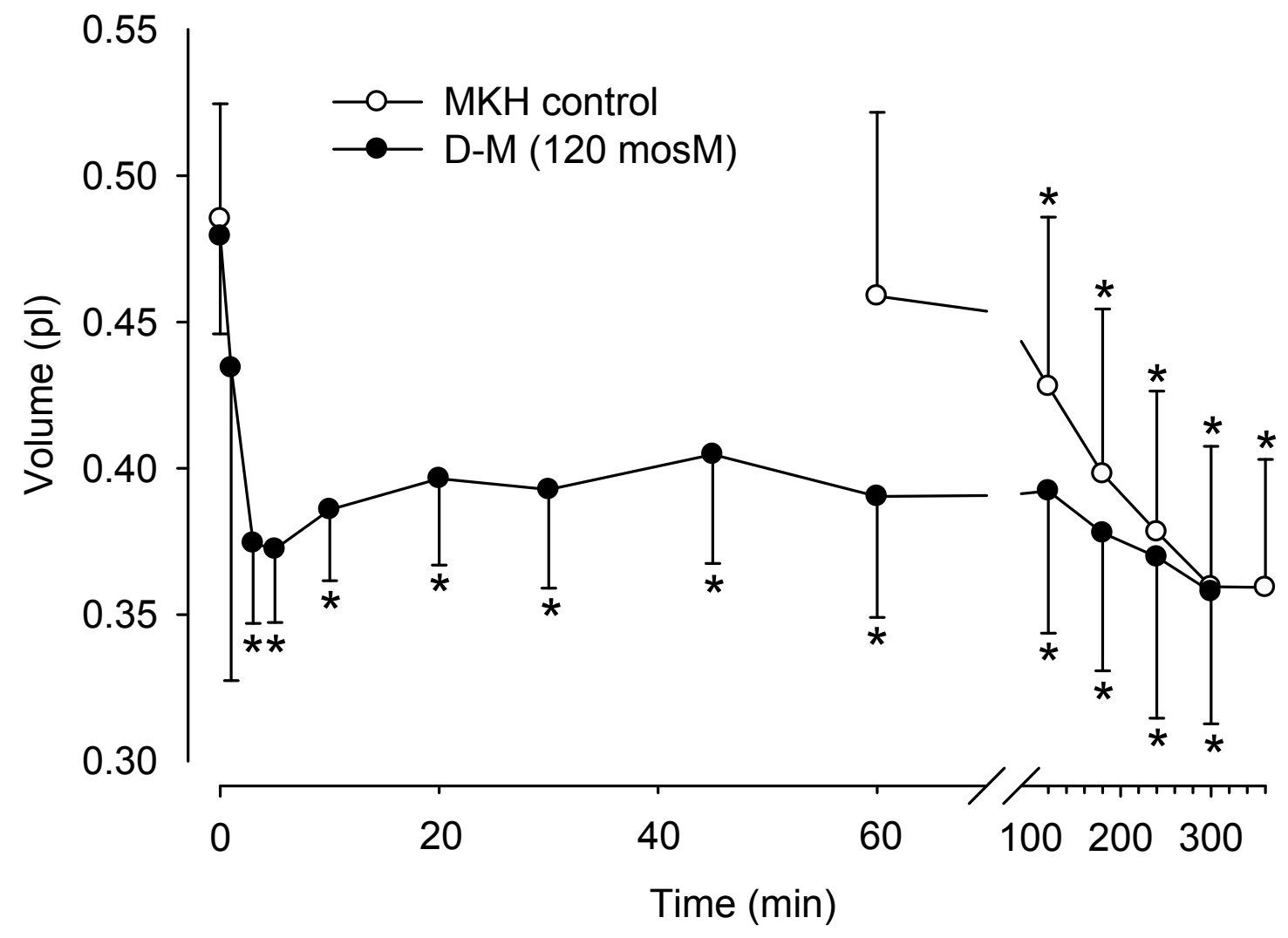

Fig. CIII-3. Time-dependent effects of D-M (120 mosM) on the volume of isolated airway epithelial cells. The volume of un-challenged epithelial cells suspended in MKH solution was measured every $60 \min$ for $6 \mathrm{~h}$, beginning with $\mathrm{t}=0$. To monitor the shrinkage of epithelial cells exposed to D-M, cell volume was measured at 0,1 , $3,5,10,20,30,45,60,120,180,240$ and 300 min. Suspended in MKH solution, epithelia gradually reduced their volumes and reached plateau at $5 \mathrm{~h}$. Their volume change was not significant over the first $60 \mathrm{~min}$. D-M induced a rapid decrease in volume, which reached about 22\% shrinkage, between 3 to 5 minutes. Only a small regulatory volume increase was observed during the following $5 \mathrm{~h}$. $n$ $=4,{ }^{*} p<0.05$ compared to $t=0$. 


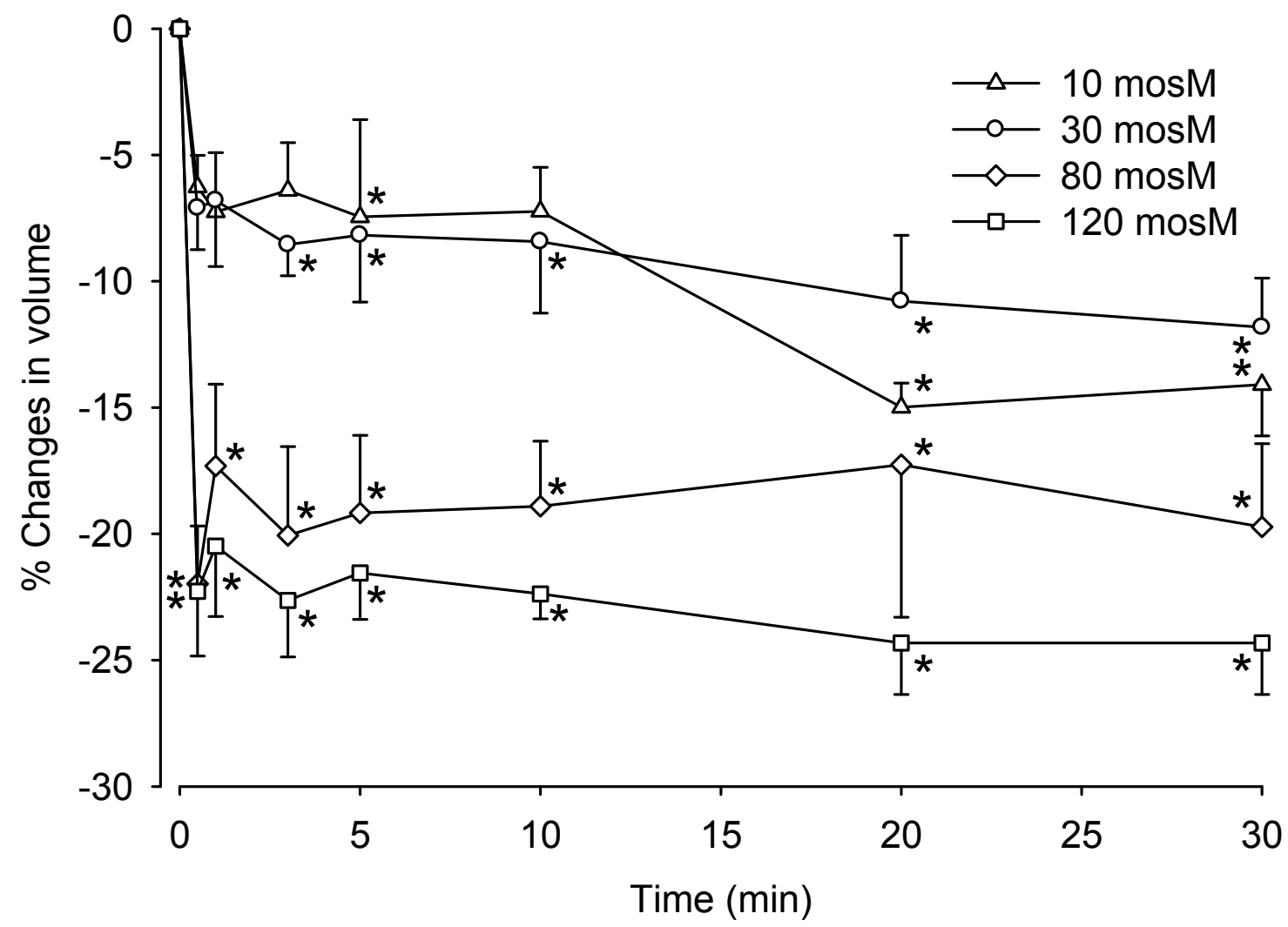

Fig. CIII-4. Concentration-dependent effects of D-M on the volume of isolated airway epithelial cells. The time points of volume measurement were $0.5,1,3,5$, 10, 20 and 30 min. D-M induced a rapid decrease in cell volume at all concentrations. The percentage of the cell shrinkage induced by 10, 30, 80 and 120 mosM D-M solutions at 3 min was around $7 \%, 9 \%, 20 \%$ and $22 \%$, respectively, compared to their original $(t=0)$ volumes. $n \geq 4,{ }^{*} p<0.05$. No regulatory volume increase was observed. 


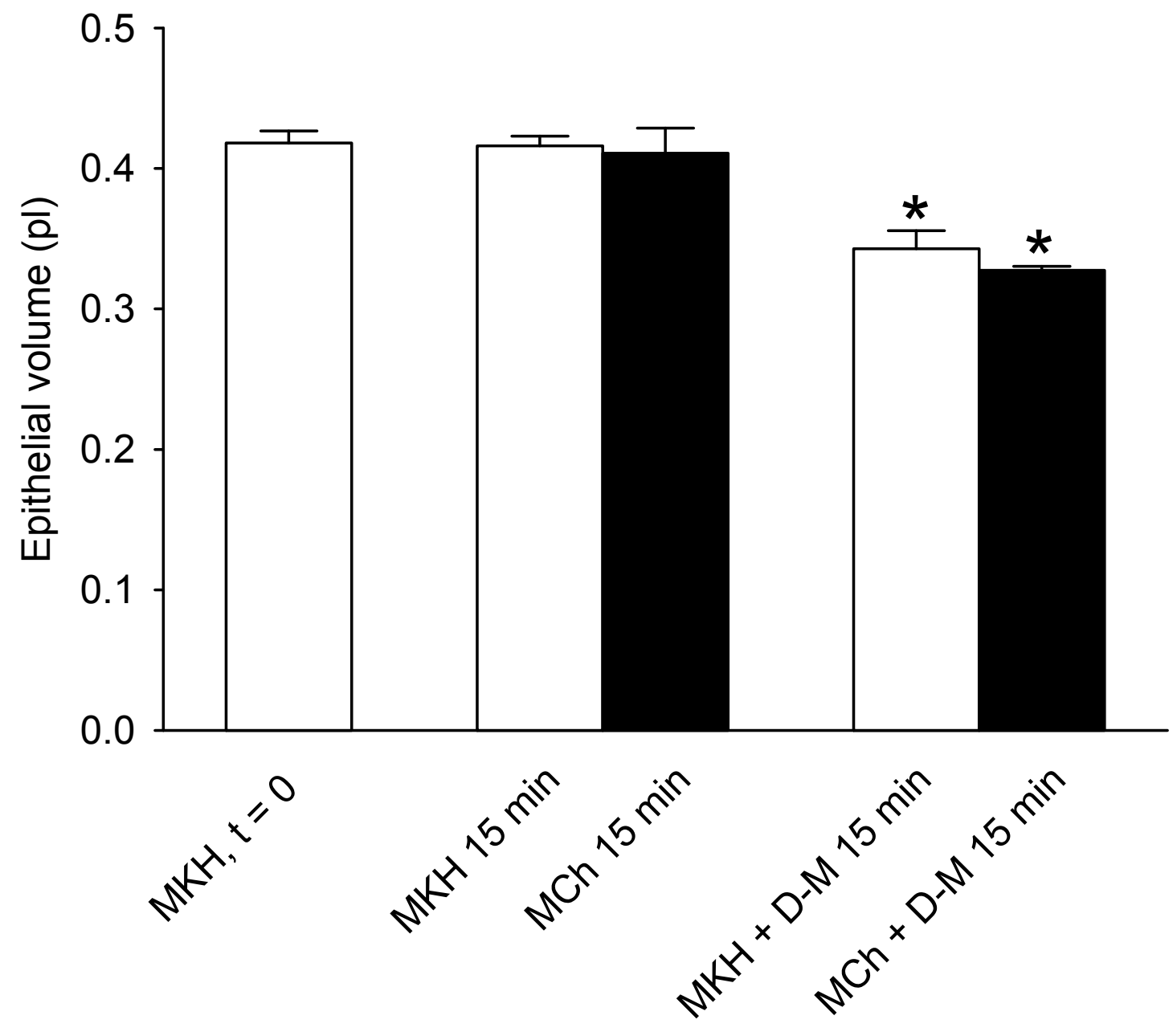

Fig. CIII-5. Airway epithelial volume changes induced by $\mathrm{MCh}\left(3 \times 10^{-7} \mathrm{M}\right)$ and D-M (120 mosM). Exposure of suspended epithelia to MCh for $15 \mathrm{~min}$ (the time required for $\mathrm{MCh}$-induced contraction to reach plateau in functional studies) had no effect on cell volume. Exposure of suspensions to D-M for another $15 \mathrm{~min}$ (the time needed for D-M-induced relaxation to reach plateau in functional studies) caused epithelial shrinkage in the absence and presence of MCh. $n=4,{ }^{*} p<0.05$. 


\section{General Conclusions}

A physiologically-relevant osmolarity increase in the ASL caused by exercise induces airway epithelial hyperpolarization and smooth muscle relaxation; the two responses share the same osmolarity concentration-dependence. The concentrations which induce the maximal relaxation and the transition of bioelectric responses from hyperpolarization to depolarization are coincidently around 80 mosM. The depolarization elicited by more than 80 mosM hyperosmolarity is primarily caused by an inhibition of epithelial ion transport but not by a decrease of transepithelial resistance (Fig. GC-1).

The guinea-pig trachea perfusion apparatus which allows $\triangle P, V_{t}$ and $R_{t}$ to be monitored simultaneously is useful for the study of airway physiology and pharmacology. PKC is intimately involved in the regulation of epithelial ion transport. JNK and protein phosphatase play a role in the epithelial bioelectric responses induced by MCh and D-M, respectively. The permeability of epithelial tight junctions could be regulated by common protein kinases, such as JNK.

Although some signaling kinases, e.g., PKC, are involved in the regulation of basal $V_{t}$ and $\triangle P$, as well as $V_{t}$ responses induced by MCh and $D-M$, only the inhibition of p38 potentiated the airway relaxation elicited by hyperosmolar challenge, suggesting that p38 inhibitors could potentially have the therapeutic effect of reducing the bronchoconstriction induced by exercise. A common signaling pathway regulating both the bioelectric and mechanical responses to hyperosmolarity was not identified; therefore, in terms of kinase signaling, there 
may not be a cause-effect relationship between the two responses.

Hyperosmolar challenge elevates the phosphorylation of p38 and JNK in airway epithelia and many other types of cells. The inhibitors of p38 are being developed as anti-asthma medicines because p38 signaling contributes to the pathogenesis of airway inflammation and hyperresponsiveness. The results of this study provided additional support for the notion that p38 inhibitors also have the potential for the treatment of bronchoconstriction induced by exercise possibly through the potentiation of EpDRF release (Fig. GC-2).

Hyperosmolar challenge over a concentration range that elicits epithelial bioelectric events and EpDRF release in the functional studies also induces concentration-dependent decreases in epithelial cell volume. The rapid and prolonged shrinkage is similar to the quick and long-lasting bioelectric and mechanical responses, suggesting a possible link between epithelial shrinkage and EpDRF release. 
Hyperosmolarity above

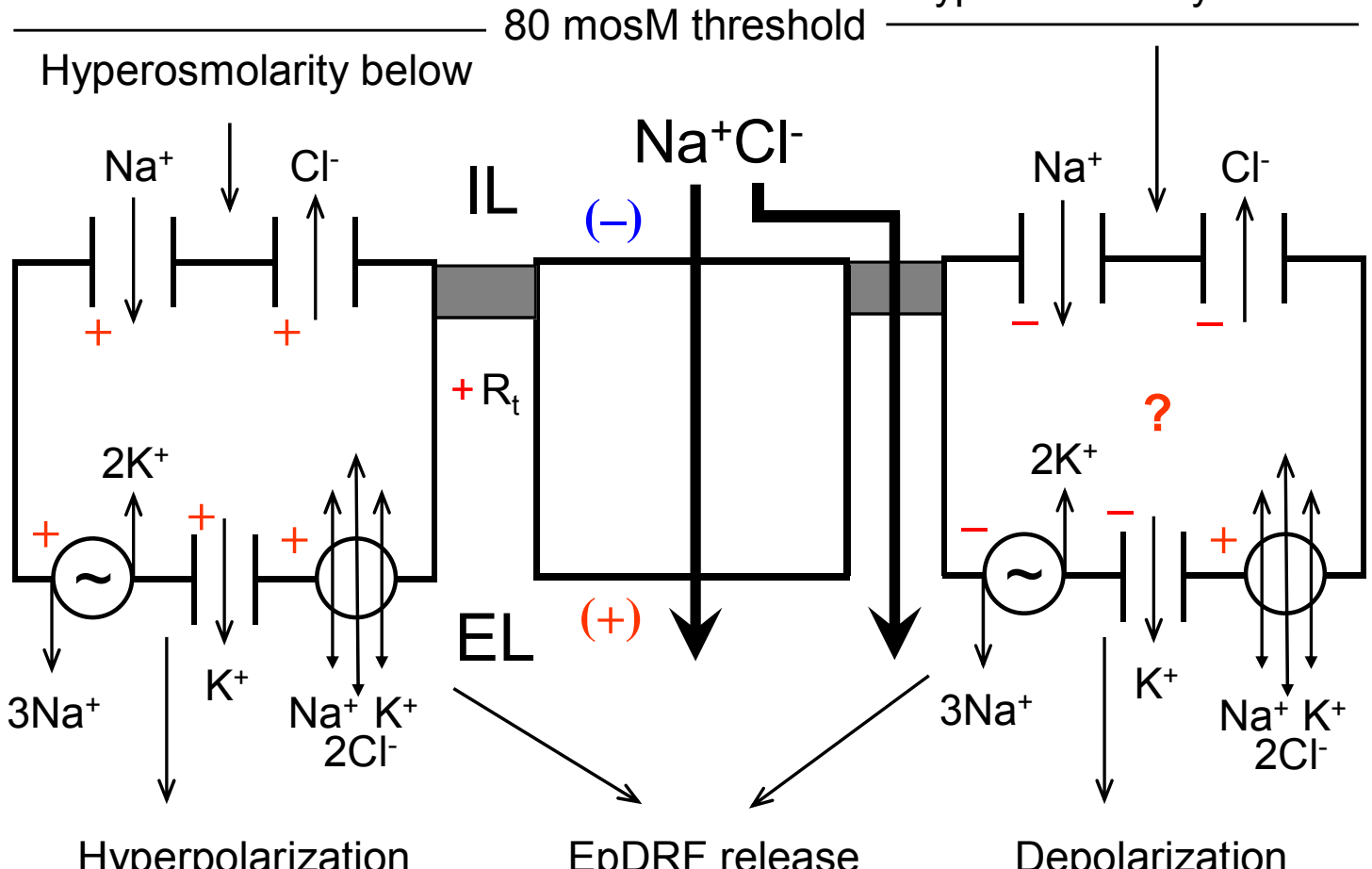

Fig. GC-1. Proposed model of epithelial ion transport and EpDRF release induced by hyperosmolarity. Hyperosmolar challenge lower than 80 mosM threshold induces secretion of $\mathrm{Cl}^{-}$and $\mathrm{K}^{+}$and activation of the $\mathrm{Na}^{+}-\mathrm{K}^{+}-2 \mathrm{Cl}^{-}$cotransporter, and possibly, secondary activation of the $\mathrm{Na}^{+}-\mathrm{K}^{+}$-pump, causing hyperpolarization. Although the activity of electroneutral $\mathrm{Na}^{+}-\mathrm{K}^{+}-2 \mathrm{Cl}^{-}$cotransporter may remain unchanged, more than 80 mosM hyperosmolar challenge could inhibit the activity of $\mathrm{Na}^{+}-\mathrm{K}^{+}$-pump and secretion of $\mathrm{Cl}^{-}$and $\mathrm{K}^{+}$, which was evidenced by the significant decrease of transepithelial short-circuit current (Wu et al., 2004), causing depolarization. This conclusion was also supported by the finding that the decreased $V_{t}$ did not result from the decrease of $R_{t}$. Hyperosmolarity always induces airway smooth muscle relaxation via EpDRF release. The maximal response was elicited by an 80 mosM increase in osmolarity. 


\section{Hyperosmolarity}

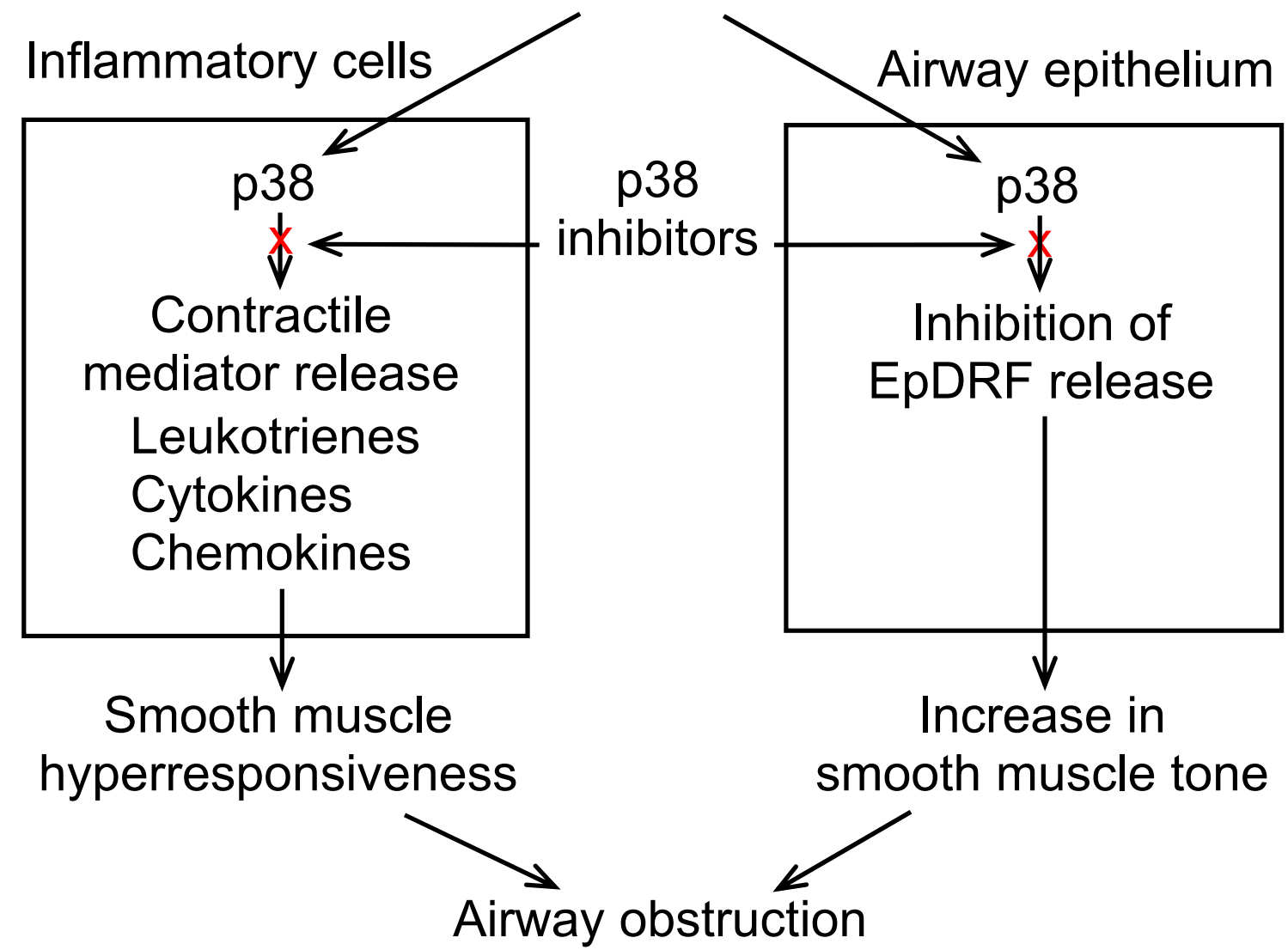

Fig. GC-2. Effects of p38 inhibitors on hyperosmolarity-induced airway smooth muscle response. Hyperosmolar challenge activates p38 in both inflammatory and airway epithelial cells, causing contractile mediator release and inhibition of EpDRF release, respectively. Inhibitors of p38 block the activities of p38 signaling and decrease the airway smooth muscle tone, which could be useful for the treatment of exercise-induced airway obstruction. 


\section{References of General Introduction}

Anderson S (1997b) Pathophysology of Exercise-induced asthma, in Allergic and respiratory disease in sports medicine. (Weiler $\mathrm{J}$ ed) pp 87-114, Marcel Dekker, New York.

Anderson SD (1984) Is there a unifying hypothesis for exercise-induced asthma? J Allergy Clin Immunol 73:660-665.

Anderson SD (2006) How does exercise cause asthma attacks? Curr Opin Allergy Clin Immunol 6:37-42.

Anderson SD, Brannan J, Spring J, Spalding N, Rodwell LT, Chan K, Gonda I, Walsh A and Clark AR (1997a) A new method for bronchial-provocation testing in asthmatic subjects using a dry powder of mannitol. Am J Respir Crit Care Med 156:758-765.

Anderson SD and Daviskas E (1992) The airway microvasculature and exercise induced asthma. Thorax 47:748-752.

Anderson SD and Daviskas E (2000) The mechanism of exercise-induced asthma is... J Allergy Clin Immunol 106:453-459.

Anderson SD, Daviskas E and Smith CM (1989) Exercise-induced asthma: a difference in opinion regarding the stimulus. Allergy Proc 10:215-226.

Barnes PJ, Cuss FM and Palmer JB (1985) The effect of airway epithelium on smooth muscle contractility in bovine trachea. Br J Pharmacol 86:685-691. Boucher RC (1994a) Human airway ion transport. Part one. Am J Respir Crit Care Med 150:271-281. 
Boucher RC (1994b) Human airway ion transport. Part two. Am J Respir Crit Care Med 150:581-593.

Boucher RC (1999) Molecular insights into the physiology of the "thin film" of airway surface liquid. J Physiol 516:631-638.

Brannan JD, Gulliksson M, Anderson SD, Chew N and Kumlin M (2003) Evidence of mast cell activation and leukotriene release after mannitol inhalation. Eur Respir J 22:491-496.

Brannan JD, Koskela H, Anderson SD and Chew N (1998) Responsiveness to mannitol in asthmatic subjects with exercise- and hyperventilation-induced asthma. Am J Respir Crit Care Med 158:1120-1126.

Clarke LL and Boucher RC (1993) Ion and water transport across airway epithelia, in Pharmacology of the Respiratory Tract. (Chung KF, Barnes PJ eds) pp 505-550, Marcel Dekker, Inc., New York.

Cross JV, Deak JC, Rich EA, Qian Y, Lewis M, Parrott LA, Mochida K, Gustafson D, Vande Pol S and Templeton DJ (1999) Quinone reductase inhibitors block SAPK/JNK and NFkB pathways and potentiate apoptosis. J Biol Chem 274:31150-31154.

Davis MJ, Wu X, Nurkiewicz TR, Kawasaki J, Gui P, Hill MA and Wilson E (2001) Regulation of ion channels by protein tyrosine phosphorylation. Am J Physiol Heart Circ Physiol 281:H1835-1862.

Daviskas E, Gonda I and Anderson SD (1990) Mathematical modeling of heat and water transport in human respiratory tract. J Appl Physiol 69:362-372. 
Daviskas E, Gonda I and Anderson SD (1991) Local airway heat and water vapour losses. Respir Physiol 84:115-132.

Deal EC, Jr., McFadden ER, Ingram RH, Jr., Strauss RH and Jaeger JJ (1979) Role of respiratory heat exchange in production of exercise-induced asthma. J Appl Physiol 46:467-475.

Dortch-Carnes J, Van Scott MR and Fedan JS (1999) Changes in smooth muscle tone during osmotic challenge in relation to epithelial bioelectric events in guinea pig isolated trachea. J Pharmacol Exp Ther 289:911-917.

Duzgun SA, Rasque H, Kito H, Azuma N, Li W, Basson MD, Gahtan V, Dudrick SJ and Sumpio BE (2000) Mitogen-activated protein phosphorylation in endothelial cells exposed to hyperosmolar conditions. J Cell Biochem 76:567-571

Elias JA, Lee CG, Zheng T, Ma B, Homer RJ and Zhu Z (2003) New insights into the pathogenesis of asthma. J Clin Invest 111:291-297.

English JM and Cobb MH (2002) Pharmacological inhibitors of MAPK pathways. Trends Pharmacol Sci 23:40-45.

Farmer SG, Fedan JS, Hay DW and Raeburn D (1986) The effects of epithelium removal on the sensitivity of guinea-pig isolated trachealis to bronchodilator drugs. Br J Pharmacol 89:407-414.

Fedan JS, Dowdy JA, Johnston RA and Van Scott MR (2004a) Hyperosmolar solution effects in guinea pig airways. I. Mechanical responses to relative changes in osmolarity. J Pharmacol Exp Ther 308:10-18. 
Fedan JS, Dowdy JA, Van Scott MR, Wu DX and Johnston RA (2004b) Hyperosmolar solution effects in guinea pig airways. III. Studies on the identity of epithelium-derived relaxing factor in isolated perfused trachea using pharmacological agents. J Pharmacol Exp Ther 308:30-36.

Fedan JS and Frazer DG (1992) Influence of epithelium on the reactivity of guinea pig isolated, perfused trachea to bronchoactive drugs. J Pharmacol Exp Ther 262:741-750.

Fedan JS, Nutt ME and Frazer DG (1990) Reactivity of guinea-pig isolated trachea to methacholine, histamine and isoproterenol applied serosally versus mucosally. Eur J Pharmacol 190:337-345.

Fedan JS, Yuan LX, Chang VC, Viola JO, Cutler D and Pettit LL (1999) Osmotic regulation of airway reactivity by epithelium. J Pharmacol Exp Ther 289:901-910.

Fernandes LB and Goldie RG (1990b) Pharmacological evaluation of a guinea-pig tracheal epithelium-derived inhibitory factor (EpDIF). $\mathrm{Br} \mathrm{J}$ Pharmacol 100:614-618.

Fernandes LB, Preuss JM, Paterson JW and Goldie RG (1990a) Epithelium-derived inhibitory factor in human bronchus. Eur J Pharmacol 187:331-336.

Flatman PW and Creanor $\mathrm{J}$ (1999) Stimulation of $\mathrm{Na}^{+}-\mathrm{K}^{+}-2 \mathrm{Cl}^{-}$cotransport by arsenite in ferret erythrocytes. J Physiol 519:143-152.

Flavahan NA, Aarhus LL, Rimele TJ and Vanhoutte PM (1985) Respiratory 
epithelium inhibits bronchial smooth muscle tone. J Appl Physiol 58:834-838.

Folkerts G and Nijkamp FP (1998) Airway epithelium: more than just a barrier! Trends Pharmacol Sci 19:334-341.

Freed AN and Davis MS (1999) Hyperventilation with dry air increases airway surface fluid osmolality in canine peripheral airways. Am J Respir Crit Care Med 159:1101-1107.

Furuichi S, Hashimoto S, Gon Y, Matsumoto K and Horie T (2002) p38 mitogen-activated protein kinase and C-Jun- $\mathrm{NH} 2$-terminal kinase regulate interleukin-8 and RANTES production in hyperosmolarity stimulated human bronchial epithelial cells. Respirology 7:193-200.

Godfrey RW (1997b) Human airway epithelial tight junctions. Microsc Res Tech 38:488-499.

Goggel R and Uhlig S (2005) The inositol trisphosphate pathway mediates platelet-activating-factor-induced pulmonary oedema. Eur Respir J 25:849-857.

Goldie RG, Fernandes LB, Farmer SG and Hay DW (1990) Airway epithelium-derived inhibitory factor. Trends Pharmacol Sci 11:67-70.

Goldie RG and Hay DWP (1997) Epithelium-dependent responsiveness of airway smooth muscle: The role of epithelium-derived relaxant factors, in Asthma (Barnes PG, Leff AR, Grunstein MM, Woolcock AJ eds) pp 901-915, Lippincott-Raven, Philadelphia. 
Gordon JA (1991) Use of vanadate as protein-phosphotyrosine phosphatase inhibitor. Methods Enzymol 201:477-482.

Güc MO, Ilhan M and Kayaalp SO (1988a) Epithelium-dependent relaxation of guinea-pig tracheal smooth muscle by carbachol. Arch Int Pharmacodyn Ther 294:241-247.

Güc MO, Ilhan M and Kayaalp SO (1988b) The rat anococcygeus muscle is a convenient bioassay organ for the airway epithelium-derived relaxant factor. Eur J Pharmacol 148:405-409.

Gumbiner B (1987) Structure, biochemistry, and assembly of epithelial tight junctions. Am J Physiol 253:C749-758.

Hallstrand TS, Moody MW, Wurfel MM, Schwartz LB, Henderson WR, Jr. and Aitken ML (2005a) Inflammatory basis of exercise-induced bronchoconstriction. Am J Respir Crit Care Med 172:679-686.

Hamilton LM, Davies DE, Wilson SJ, Kimber I, Dearman RJ and Holgate ST (2001) The bronchial epithelium in asthma-much more than a passive barrier. Monaldi Arch Chest Dis 56:48-54.

Hashimoto S, Matsumoto K, Gon Y, Nakayama T, Takeshita I and Horie T (1999) Hyperosmolarity-induced interleukin-8 expression in human bronchial epithelial cells through p38 mitogen-activated protein kinase. Am J Respir Crit Care Med 159:634-640.

Hay DW, Farmer SG, Raeburn D, Muccitelli RM, Wilson KA and Fedan JS (1987b) Differential effects of epithelium removal on the responsiveness of 
guinea-pig tracheal smooth muscle to bronchoconstrictors. Br J Pharmacol 92:381-388.

Hay DW, Farmer SG, Raeburn D, Robinson VA, Fleming WW and Fedan JS (1986) Airway epithelium modulates the reactivity of guinea-pig respiratory smooth muscle. Eur J Pharmacol 129:11-18.

Hay DW, Muccitelli RM, Horstemeyer DL, Wilson KA and Raeburn D (1987a) Demonstration of the release of an epithelium-derived inhibitory factor from a novel preparation of guinea-pig trachea. Eur J Pharmacol 136:247-250.

Heinzinger $\mathrm{H}$, van den Boom F, Tinel $\mathrm{H}$ and Wehner $\mathrm{F}$ (2001) In rat hepatocytes, the hypertonic activation of $\mathrm{Na}^{+}$conductance and $\mathrm{Na}^{+}-\mathrm{K}^{+}-2 \mathrm{Cl}^{-}$symport-but not $\mathrm{Na}^{+}-\mathrm{H}^{+}$antiport-is mediated by protein kinase C. J Physiol 536:703-715.

Herbert JM, Augereau JM, Gleye J and Maffrand JP (1990) Chelerythrine is a potent and specific inhibitor of protein kinase C. Biochem Biophys Res Commun 172:993-999.

Hirst SJ, Hallsworth MP, Peng Q and Lee TH (2002) Selective induction of eotaxin release by interleukin-13 or interleukin-4 in human airway smooth muscle cells is synergistic with interleukin- $1 \beta$ and is mediated by the interleukin-4 receptor $\alpha$-chain. Am J Respir Crit Care Med 165:1161-1171.

Ilhan M and Sahin I (1986) Tracheal epithelium releases a vascular smooth muscle relaxant factor: demonstration by bioassay. Eur J Pharmacol 131:293-296. 
Klein JD, Lamitina ST and O'Neill WC (1999) JNK is a volume-sensitive kinase that phosphorylates the $\mathrm{Na}-\mathrm{K}-2 \mathrm{Cl}$ cotransporter in vitro. Am J Physiol 277:C425-431.

Klein JD, Perry PB and O'Neill WC (1993) Regulation by cell volume of $\mathrm{Na}^{+}-\mathrm{K}^{+}-2 \mathrm{Cl}^{-}$cotransport in vascular endothelial cells: role of protein phosphorylation. J Membr Biol 132:243-252.

Kuhn C, III (1976) The cells of the lung and their organelles, in Lung biology in health and disease Vol 2, The biochemical basis of pulmonary function (Crystal RG ed) pp 3-48, Dekker, New York.

Lang F, Busch GL, Ritter M, Volkl H, Waldegger S, Gulbins E and Haussinger D (1998) Functional significance of cell volume regulatory mechanisms. Physiol Rev 78:247-306.

Levitzky M (2003) Pulmonary Physiology, Sixth Edition. McGraw-Hill, Crawfordsville, Indiana.

Liedtke CM and Cole TS (2002a) Activation of NKCC1 by hyperosmotic stress in human tracheal epithelial cells involves PKC- $\delta$ and ERK. Biochim Biophys Acta 1589:77-88.

Ludwig S, Hoffmeyer A, Goebeler M, Kilian K, Hafner H, Neufeld B, Han J and Rapp UR (1998) The stress inducer arsenite activates mitogen-activated protein kinases extracellular signal-regulated kinases 1 and 2 via a MAPK kinase 6/p38-dependent pathway. J Biol Chem 273:1917-1922.

Masse T and Kelly PT (1997) Overexpression of Ca2+/calmodulin-dependent 
protein kinase II in PC12 cells alters cell growth, morphology, and nerve growth factor-induced differentiation. J Neurosci 17:924-931.

Matsui H, Davis CW, Tarran R and Boucher RC (2000) Osmotic water permeabilities of cultured, well-differentiated normal and cystic fibrosis airway epithelia. J Clin Invest 105:1419-1427.

McFadden ER (1999) Exercise-Induced Asthma. Marcel Dekker, Inc., New York. McFadden ER, (1990) Hypothesis: Exercise-induced asthma as a vascular phenomenon. Lancet 335:880-883.

McFadden ER, Lenner KA and Strohl KP (1986) Postexertional airway rewarming and thermally induced asthma. New insights into pathophysiology and possible pathogenesis. J Clin Invest 78:18-25.

Munakata M, Huang I, Mitzner W and Menkes H (1989) Protective role of epithelium in the guinea pig airway. J Appl Physiol 66:1547-1552.

Munakata M, Masaki Y, Sakuma I, Ukita H, Otsuka Y, Homma Y and Kawakami Y (1990) Pharmacological differentiation of epithelium-derived relaxing factor from nitric oxide. J Appl Physiol 69:665-670.

Munakata M, Mitzner W and Menkes H (1988) Osmotic stimuli induce epithelial-dependent relaxation in the guinea pig trachea. J Appl Physiol 64:466-471.

Murlas C (1986) Effects of mucosal removal on guinea-pig airway smooth muscle responsiveness. Clin Sci (Lond) 70:571-575.

Nadel JA (1980) Physiology and pharmacology of the airways. Dekker, New York. 
Pelaia G, Cuda G, Vatrella A, Gallelli L, Caraglia M, Marra M, Abbruzzese A, Caputi M, Maselli R, Costanzo FS and Marsico SA (2005) Mitogen-activated protein kinases and asthma. J Cell Physiol 202:642-653. Prabhakar U, Lipshutz D and Truneh A (1993) Inhibition of CD44, CD45 and LFA-3 mediated cytokine release from human monocytes by SK\&F 86002 and pentoxifylline. Int J Immunopharmacol 15:205-209.

Prazma J, Coleman CC, Shockley WW and Boucher RC (1994) Tracheal vascular response to hypertonic and hypotonic solutions. J Appl Physiol 76:2275-2280.

Pugazhenthi S, Tanha F, Dahl B and Khandelwal RL (1996) Inhibition of a Src homology 2 domain containing protein tyrosine phosphatase by vanadate in the primary culture of hepatocytes. Arch Biochem Biophys 335:273-282.

Raeburn D, Hay DW, Farmer SG and Fedan JS (1986a) Epithelium removal increases the reactivity of human isolated tracheal muscle to methacholine and reduces the effect of verapamil. Eur J Pharmacol 123:451-453.

Raeburn D, Hay DW, Robinson VA, Farmer SG, Fleming WW and Fedan JS (1986b) The effect of verapamil is reduced in isolated airway smooth muscle preparations lacking the epithelium. Life Sci 38:809-816.

Roger F, Martin PY, Rousselot M, Favre H and Feraille E (1999) Cell shrinkage triggers the activation of mitogen-activated protein kinases by hypertonicity in the rat kidney medullary thick ascending limb of the Henle's loop. Requirement of p38 kinase for the regulatory volume increase response. $J$ 
Biol Chem 274:34103-34110.

Schneeberger EE and Lynch RD (1992) Structure, function, and regulation of cellular tight junctions. Am J Physiol 262:L647-661.

Sheikh-Hamad D and Gustin MC (2004) MAP kinases and the adaptive response to hypertonicity: Functional preservation from yeast to mammals. Am J Physiol Renal Physiol 287:F1102-1110.

Shen MR, Furla P, Chou CY and Ellory JC (2002) Myosin light chain kinase modulates hypotonicity-induced $\mathrm{Ca}^{2+}$ entry and $\mathrm{Cl}^{-}$channel activity in human cervical cancer cells. Pflugers Arch 444:276-285.

Shrode LD, Krump E and Grinstein S (1998) Activation of protein kinases upon volume changes: role in cellular homeostasis. Contrib Nephrol 123:79-93.

Slavin R and Reisman R (2002) Asthma. American College of Physicians, Philadelphia.

Smith TL, Prazma J, Coleman CC, Drake AF and Boucher RC (1993) Control of the mucosal microcirculation in the upper respiratory tract. Otolaryngol Head Neck Surg 109:646-652.

Tarran R (2004) Regulation of airway surface liquid volume and mucus transport by active ion transport. Proc Am Thorac Soc 1:42-46.

Taube C, Holz O, Mucke M, Jorres RA and Magnussen H (2001) Airway response to inhaled hypertonic saline in patients with moderate to severe chronic obstructive pulmonary disease. Am J Respir Crit Care Med 164:1810-1815. 
Tokumitsu H, Chijiwa T, Hagiwara M, Mizutani A, Terasawa M and Hidaka H (1990) KN-62, 1-[N, O-bis(5-isoquinolinesulfonyl)-N-methyl-L-tyrosyl]-4phenylpiperazine, a specific inhibitor of $\mathrm{Ca}^{2+} /$ calmodulin-dependent protein kinase II. J Biol Chem 265:4315-4320.

Vlahos CJ, Matter WF, Hui KY and Brown RF (1994) A specific inhibitor of phosphatidylinositol 3-kinase, 2-(4-morpholinyl)-8-phenyl-4H-1benzopyran-4-one (LY294002). J Biol Chem 269:5241-5248.

Weibel ER (1963) Morphometry of the Human Lung. Springer, Heidelberg.

Weibel ER and Burri PH (1973) Funktionelle Aspekte der Lungenmorphologie, in Aktuelle probleme der roentgendiagnostik, vol 2 (Fuchs WA, Voegeli E eds) pp 1-17, Huber, Bern.

Weibel ER (1980) Design and structure of the human lung, in Pulmonary Diseases and Disorders (Fishman AP ed) pp 224-271, McGraw-Hill, Inc., New York.

Weiss KB, Sullivan SD and Lyttle CS (2000) Trends in the cost of illness for asthma in the United States, 1985-1994. J Allergy Clin Immunol 106:493-499.

Widdicombe JH (2002) Regulation of the depth and composition of airway surface liquid. J Anat 201:313-318.

Widdicombe JH, Bastacky SJ, Wu DX and Lee CY (1997) Regulation of depth and composition of airway surface liquid. Eur Respir J 10:2892-2897.

Widdicombe JH and Widdicombe JG (1995) Regulation of human airway surface 
liquid. Respir Physiol 99:3-12.

Willumsen NJ, Davis CW and Boucher RC (1989) Intracellular $\mathrm{Cl}^{-}$activity and cellular $\mathrm{Cl}^{-}$pathways in cultured human airway epithelium. Am J Physiol 256:C1033-1044.

Willumsen NJ, Davis CW and Boucher RC (1994) Selective response of human airway epithelia to luminal but not serosal solution hypertonicity. Possible role for proximal airway epithelia as an osmolality transducer. J Clin Invest 94:779-787.

Woo $\mathrm{CH}$, Lim JH and Kim JH (2005) VCAM-1 upregulation via PKC $\delta$-p38 kinase-linked cascade mediates the TNF- $\alpha$-induced leukocyte adhesion and emigration in the lung airway epithelium. Am J Physiol Lung Cell Mol Physiol 288:L307-316.

Zhang Z and Bourque CW (2003) Osmometry in osmosensory neurons. Nat Neurosci 6:1021-1022. 


\title{
Curriculum Vitae
}

\author{
Yi Jing \\ Department of Biochemistry and Molecular Pharmacology \\ School of Medicine, West Virginia University \\ Morgantown, WV 26506 \\ Tele: (304) 293-5068 \\ E-mail: yjing@mix.wvu.edu or ybj1@cdc.gov
}

\section{EDUCATION}

$2000-2007$ Ph.D., Pharmacology. Department of Biochemistry and Molecular Pharmacology, West Virginia University, Morgantown, West Virginia.

$1989-1992 \quad$ M.S., Pharmacology and Toxicology. Institute of Pharmacology and Toxicology, Beijing, China.

1981 - 1986 M.D., Medicine. Tianjin Medical College, Tianjin, China.

\section{EXPERIENCE}

2000-2007 Graduate Student. Department of Biochemistry and Molecular Pharmacology, West Virginia University. Under the guidance of Dr. Jeffrey Fedan, working on a project investigating the airway epithelial mechanisms in exercise-induced asthma. Elucidate the relationship between airway transepithelial bioelectric and smooth muscle mechanical responses evoked by luminal hyperosmolarity. Investigate epithelial signaling mechanisms in regulating airway diameter using protein kinase inhibitors and ion transport blockers. Confirm the involvement of MAP kinases in epithelial signaling using western blots. Characterize volume change of isolated epithelial cells during hyperosmolar challenge.

1999 - $2000 \quad$ Research Fellow in Dr. Yao-tseng Chen's laboratory. Ludwig Institute for Cancer Research, Memorial Sloan-Kettering Cancer Center. Involved in the immunoscreening of expressing tumor cDNA libraries and characterizing the isolated clones. Prepared cDNA libraries from tumor specimens or cell lines and screened them with autologous or allogeneic serums from cancer patients. Analyzed the selected cDNA clones by DNA sequencing and mRNA expressing in normal and tumor tissues. Expressed cDNA clones showing differential mRNA tissue expression to make specific antibodies. Identified tumor antigens with restricted tissue expression and used as targets for immunotherapy and/or immunodiagnosis.

1997 - 1999 Research Associate in Dr. Neena Singh's laboratory. Department of Pathology, Case Western Reserve University. Worked on the cell and molecular biology of prion disease, especially on the analysis of an inherited form of CJD that co-segregated with a mutation in the prion 
protein gene. Investigated synthesis and processing of mutant prion protein in order to elucidate the pathogenic mechanisms of prion disease with in vitro models.

$1994-1997 \quad$ Research Assistant. Institute of Medical and Pharmaceutical Sciences. Tianjin, China. In charge of evaluating the toxicity of synthetic medical materials, and establishing the cell cultural methods on microcarrier and microencapsulation.

1993-1994 Research Assistant. Institute of Biotechnology, Beijing, China. Participated in the research of pro-urokinase (pro-UK) gene. Removed the signal peptide sequence from the human pro-UK gene; inserted non-signal peptide sequence of human pro-UK cDNA into pBV220 just under the control of temperature-induced promoter PR PL. Successfully expressed mature pro-UK in E. coli at $42^{\circ} \mathrm{C}$.

1989 - 1992 Graduate Student. Institute of Pharmacology and Toxicology, Beijing, China. Investigated the carcinogenicity of tris(2-methyl-1-aziridinyl)phosphine oxide (MAPO) and unsymmetrical dimethyl hydrazine (UDMH). Completed the thesis "SHE cell malignant transformation induced by MAPO and UDMH in vitro," and the project "Unscheduled DNA synthesis induced by MAPO and UDMH."

1986 - 1989 Research Intern. Institute of Hygiene and Environmental Medicine. Tianjin, China. For the approval of a second class new medicine, sustained-effect riboflavin injection, completed all the required evaluations for its toxicity.

\section{PUBLICATIONS}

\section{Papers}

1. Gu Y., Jing Y., Kumar A., Sharma Y., Fujioka H. and Singh N. Isolation of human neuronal cells resistant to toxicity by the prion protein peptide 106-126. J Alzheimers Dis. 3(2): 169-180; 2001.

2. Zanusso G., Petersen B. R., Jin T., Jing Y., Kanoush R., Ferrari S., Gambetti P. and Singh N. Proteasomal degradation and N-terminal protease resistance of the codon 145 mutant prion protein. J Biol Chem. 274(33): 23396-23404; 1999.

3. Guo Z. and Jing Y. Acute and subacute toxicity studies of sustained-effect riboflavin injection. Inform Chin Pharmacol Soc (Chinese). 12(2): 15-18; 1995.

4. Guo Z. and Jing Y. Teratogenicity study of sustained-effect riboflavin injection. J Chin Prev Med (Chinese). 13(1): 69-72; 1995.

5. Shi J., Zhang Z. and Jing Y. Comparison of unscheduled DNA synthesis induced by MAPO and UDMH in mice. J Health Toxicol (Chinese). 9(3): 183-185; 1995.

6. Jing $Y$., Wang Z. and Guan G. Effect of UDMH in inducing cell malignant transformation. Bull Acad Milit Med Sci (Chinese). 18(2): 113-117; 1994.

7. Jing $Y$., Guan $G$. and Wang $Z$. Cell malignant transformation in vitro induced by tris(2-methyl-1-aziridinyl)phosphine oxide. Carcinogenesis, Teratogenesis and Mutagenesis (Chinese). 6(2): 9-15; 1994. 
8. Guo Z. and Jing Y. Study on mutagenicity of sustained effect riboflavin injection. J Chin Prev Med (Chinese). 10(1): 32-36; 1992.

\section{Abstracts}

1. Fedan J. S., Jing Y., Dowdy J. A., Ismailoglu U. B. Tracheal cell shrinkage induced by hyperosmolar solution. The 15th World Congress of Pharmacology (IUPHAR); 2006.

2. Jing Y., Dowdy J. A., Van Scott M. R. and Fedan J. S. Guinea-pig tracheal epithelial cell shrinkage induced by hyperosmolar challenge. FASEB J. 20: A835; 2006.

3. Fedan J. S., Dowdy J. A., Jing Y., Van Scott M. R., Ismailoglu U. B. Shrinkage of guinea-pig tracheal epithelial cells in response to hyperosmolar challenge. Proc Am Thoracic So, 3:A425; 2006.

4. Ismailoglu U. B., Dowdy J. A., Jing Y., Van Scott M. R. and Fedan J. S. Effects of $\mathrm{Na}^{+}$ and $\mathrm{Cl}^{-}$channel blockers on guinea-pig isolated tracheal epithelial cell shrinkage in response to hyperosmolar challenge. FASEB J. 20:A835; 2006.

5. Jing Y., Van Scott M. R. and Fedan J. S. Effects of protein kinase and phosphatase inhibitors on bioelectric responses of guinea-pig tracheal epithelium to hyperosmolarity and methacholine. FASEB J. 19:A539; 2005.

6. Jing Y., Van Scott M. R. and Fedan J. S. Epithelial bioelectric and muscle mechanical effects of pharmacological agents in a newly-developed guinea-pig isolated trachea perfusion apparatus. FASEB J. 19:A1549; 2005.

7. Jing $Y .$, Van Scott M. R. and Fedan J. S. Effects of protein kinase inhibitors on bioelectric and mechanical responses of guinea-pig isolated, perfused trachea to hyperosmolar D-mannitol. FASEB J. 18:A235; 2004.

8. Jing Y., Fedan J. S. and Van Scott M. R. Hyperosmolar solution-induced Bioelectric and mechanical responses of guinea-pig isolated, perfused trachea: effects of MAPK inhibitors. FASEB J. 17:A1046; 2003.

9. Jin T., Zanusso G., Jing Y., Petersen B. R., Gambetti P., and Singh N. Atypical fragments of the mutant prion protein in GSS Q217R, Y145 stop and P102L are degraded by the proteasomal pathway and accumulate in distinct intracellular compartments. Soc Neuro. 25:1305; 1999.

10. Jin T., Zanusso G., Jing $Y$., Gambetti P. and Singh N. An abnormal isoform of the mutant prion protein in GSS Q217R is bound to the endoplasmic reticulum chaperone Bip. Soc Neuro. 24:256; 1998.

\section{Manuscripts}

1. Jing Y., Dowdy J., Van Scott M. R. and Fedan J. S. Epithelial kinase signaling in airway bioelectric and mechanical responses induced by hyperosmolarity (submitting to J Pharmacol Exp Ther).

2. Jing Y., Dowdy J., Van Scott M. R. and Fedan J. S. Epithelial mechanisms in airway bioelectric and mechanical responses induced by hyperosmolarity: Studies on a novel tracheal perfusion apparatus (submitting to J Pharmacol Exp Ther).

3. Jing Y., Dowdy J., Van Scott M. R. and Fedan J. S. Volume changes in guinea-pig airway epithelial cells induced by methacholine and hyperosmolar challenge (in preparation).

\section{PATENT}

Co-inventor of the pending patent "Device to measure muscle contractile/relaxant and epithelial bioelectric responses of perfused, intact airways in vitro." 


\section{AWARDS}

2005 Travel award to Experimental Biology meeting, American Society for Pharmacology and Experimental Therapeutics.

2004 Oral presentation award, Van Liere research convocation, Office of Research and Graduate Studies, West Virginia University.

2003 - 2005 Predoctoral Fellowship "Epithelial mechanism involved in exercise induced asthma." American Heart Association. 